\title{
Behind a Door that Doesn't Exist: A Journey Into the Horrific Spaces Beneath Us \\ Ryan M D Fleming
}

\author{
A thesis submitted to \\ the Faculty of Graduate and \\ Postdoctoral Affairs \\ in partial fulfillment of \\ the requirements for the degree of \\ Master of Architecture \\ M.Arch (Professional)
}
Azrieli School of Architecture and Urbanism
Carleton University
ottawa, Ontario, Canada

(C) 2019

Ryan M D Fleming 
Beinind a Door that Doesn't Exist:

A Jarney Fnto the Horrific Spaces Beneati Us

\author{
Kyan $D$ Fleming \\ ik. Connain \\ Y. Cazabon
}


Rumaurs

In the dead of the winter of 2014 while looking for shelter from the weather, I heard a rumour that there existed a secret place in Carleton's tunnel system, a place away from the eyes and ears of security, a place that everyone had forgotten about. 
Contents

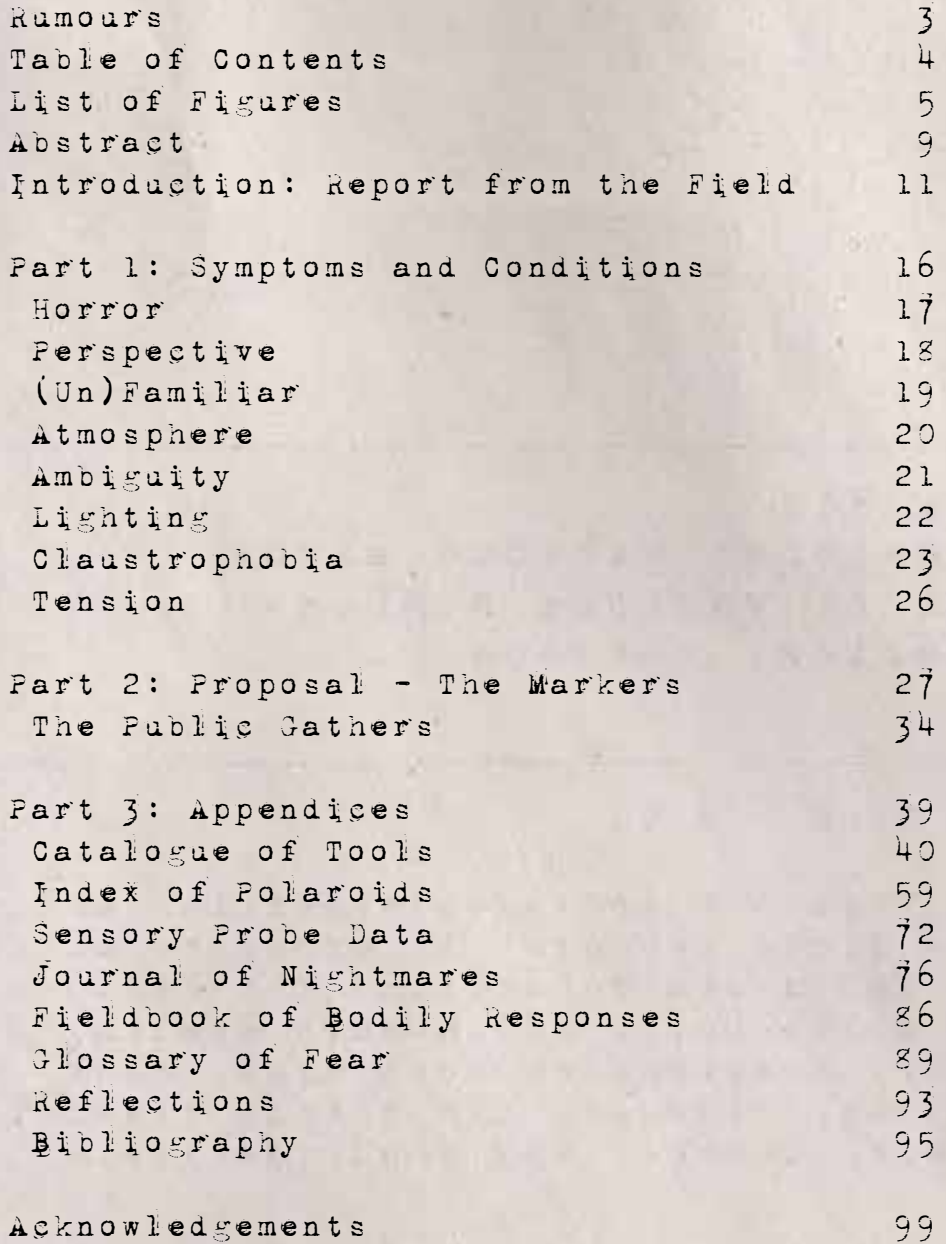

Tension

Fart 2: Froposal - The Markers 27 The Fublic Gathers 34

Fart 3: appendices 39

Catalosue of Toals 40

Fndex of Folaroids 59

Sensory Frobe Data 72

Journal of $N i$ shtmares 76

Fieldbook of Bodily responses 86

Glossary of Fear 89

reflections 93

Bibliography 95

Hcknowledsements 99 
Beilind a Doar that Doesn't Exist:

A Jaunery Into the Harrific Spaces Beneatin Us

- Iist af Fignures -

All illustrations in the following list and in the appendices were created by the author unless otherwise noted. 


\section{Iist of Fignures}

page 10 - Figure 01. Timelapse of tunnel photograph documentation

page 12 - Figure 02. Disused section of the Carleton University tunnel system.

page 12 - Figure 03. Aerial View of Carleton University River Campus during construction, 1957.

Carleton.ca

page 13 - Figure 04. Carleton site plan, 1958 overlayed with current site plan in red.

page 13 - Figure 05. Subterranean infrastructure away from serviceable buildings.

page 14 - Figure 06. Evidence of construction - transition from poured in place concrete to cinderblocks indicate an opening has been closed.

page 15 - Figure 07. Access to subterranean area below grate.

page 15 - Figure 08. Shaft to lost tunnels covered by steel door.

page 15 - Figure 09. Pathway to lost tunnels beyond HVAC.

page 17 - Figure 10. Ferrin Knob tunnel, stage 8: Horror. Edited

page 18 - Figure 11. Ferrin Knob tunnel, stage 1: Perspective. Unedited, https://www.nps.gov/blri/planyourvisit/tunnel-heights.htm

page 18 - Figure 12. Wikileaks HQ. Stockholm, Sweden. Repurposed military bunker. Constructed: 1943. Https://gizmodo.Com/5626381/this-is-the-nuclear-bunker-where-wikileaks-will-be-located

page 19 - Figure 13. Ferrin Knob tunnel, stage 2: (Un) Familiar. edited

page 19 - Figure 14. Carleton university tunnel system. Ottawa, Canada. Circulation and maintenance tunnels. Constructed: 1958 - Present.

Carleton.ca

page 20 - Figure 15. Ferrin Knob tunnel, stage 3: Atmosphere. edited

page 20 - Figure 16. Diefenbunker. Ottawa, Canada. Cold war era nuclear bunker. Constructed: 1962. Https://hautevitrine.Com/tag/nuclear-shelter/

page 21 - Figure 17. Ferrin Knob tunnel, stage 4: Ambiguity. edited

page 21 - Figure 18. A frame from the film "It Follows" Directed: David Mitchell, 2014

page 22 - Figure 19. Ferrin Knob tunnel, stage 5: Lighting. edited

page 22 - Figure 20. A frame from the film "Psycho", Directed: Alfred Hitchcock, 1960

page 23 - Figure 21. Ferrin Knob tunnel, stage 6: Claustrophobia. edited 


\section{List af Figncues - Continued}

page 23 - Figure 22. A frame from the film "10 Cloverfield Lane". Directed: Dan Trachtenberg, 2016

$=$

page 24 - Figure 23. Sonar device equipped to sensory probe.

page 24 - Figure 24. Final photograph from physical boundary. Sensory probe was deployed at this location to continue Sonic and tactile documentation.

page 25 - Figure 25. Spatial Boundary Data recovered from Sensory Probe. See Appendix: Sensory Probe Data for more images (Page 72).

page 26 - Figure 26. Ferrin Knob tunnel, stage 7: Tension. edited

page 26 - Figure 27. "Grey Tube Shelter", Henry Moore. 1940

page 28 - Figure 28. Marker at Maintenance Building.

page 29 - Figure 29. Marker array on campus.

page 30 - Figure 30. Field sketch: section displaying proximity of lost tunnel to public concourse. Speculative Marker location.

page 31 - Figure 31. Markers located at: River building, Robertson Building Courtyard, and Campus Childcare Centre

page 32 - Figure 32. Markers located at: Nesbitt Building, The Quad, and Robertson Hall

page 33 - Figure 33. Markers located at: Maintenance Building, University Centre, and 0-Train Tracks

page 35 - Figure 34. The Public Gathers exhibit. Focussed around a constructed cinder block wall, meant to emulate the materiality of the lost tunnels. The wall contains within it multiple occuli through which an observer may interact and experience the symptoms and conditions experienced in the abandoned tunnels.

page 36 - Figure 35. The lightswitch immerses the audience within the context of the site, as well as activates many of the stimuli within the wall.

page 36 - Figure 36. The wall, constructed from CMUs, designed to disorient the viewer by turning the familiar layout of the school of architecture into something foreign and (un) familiar.

page 36 - Figure 37. Sonic occuli, through which sound from the abandoned tunnels is transferred.

page 36 - Figure 38. An opening in the wall through the which the movement of cool air from beyond can be felt.

page 37 - Figure 39. An image of the visualization of sonic and tactile data collected from the sensory probe is depicted through a peep hole in the wall.

page 37 - Figure 40. The face of a missing child is $3 d$ printed printed from data recovered via a photograph. 


\section{Iist of Figncures - Continued}

page 38 - Figure 41. An endless corridor seen beyond the wall suggest the unknown nature of the sprawling expanse of tunnels beneath the campus.

page 38 - Figure 42. Brief moments of sunlight cast shadows through grates and pipes as this still from a video that played within the wall suggests. 


\title{
Benind a Door that Doesn't Exist: \\ H Journey Into the Horrific spaces Beneati Us
}

\author{
Abstract
}

Architectural experiences are perceived, felt, and inspired by numerous physical and psychological factors. Generally, a person's fundamental understanding of an architectural work comes from the way they perceive, engage, and move through its spaces. A journey through and exploration of Carleton University's second, forgotten tunnel system is an experience that provoked intense reactions through multisensory perceptions - reactions comparable to the cinematic and literary genre, horror. By turning our attention to this medium, the thesis takes a narrative approach. By drawing parallels with this narrative medium, this thesis follows a structured path with choreographed movements through space; a journeying into the tunnels. Understanding what makes some spaces horrific, and therefore the occupant, horrified and uncomfortable becomes an essential exercise that offers insight into how a person perceives experiences and space. Indeed, discomfort is not typically part of the architect's repertoire, but Behind a Door that Doesn't Exist sets out as an exploration into the psychological effects of architecture on the mind's perception and the limits of the body's movements. We enter a project of architecture considered too dangerous, even horrific, for the occupants it was built for. 


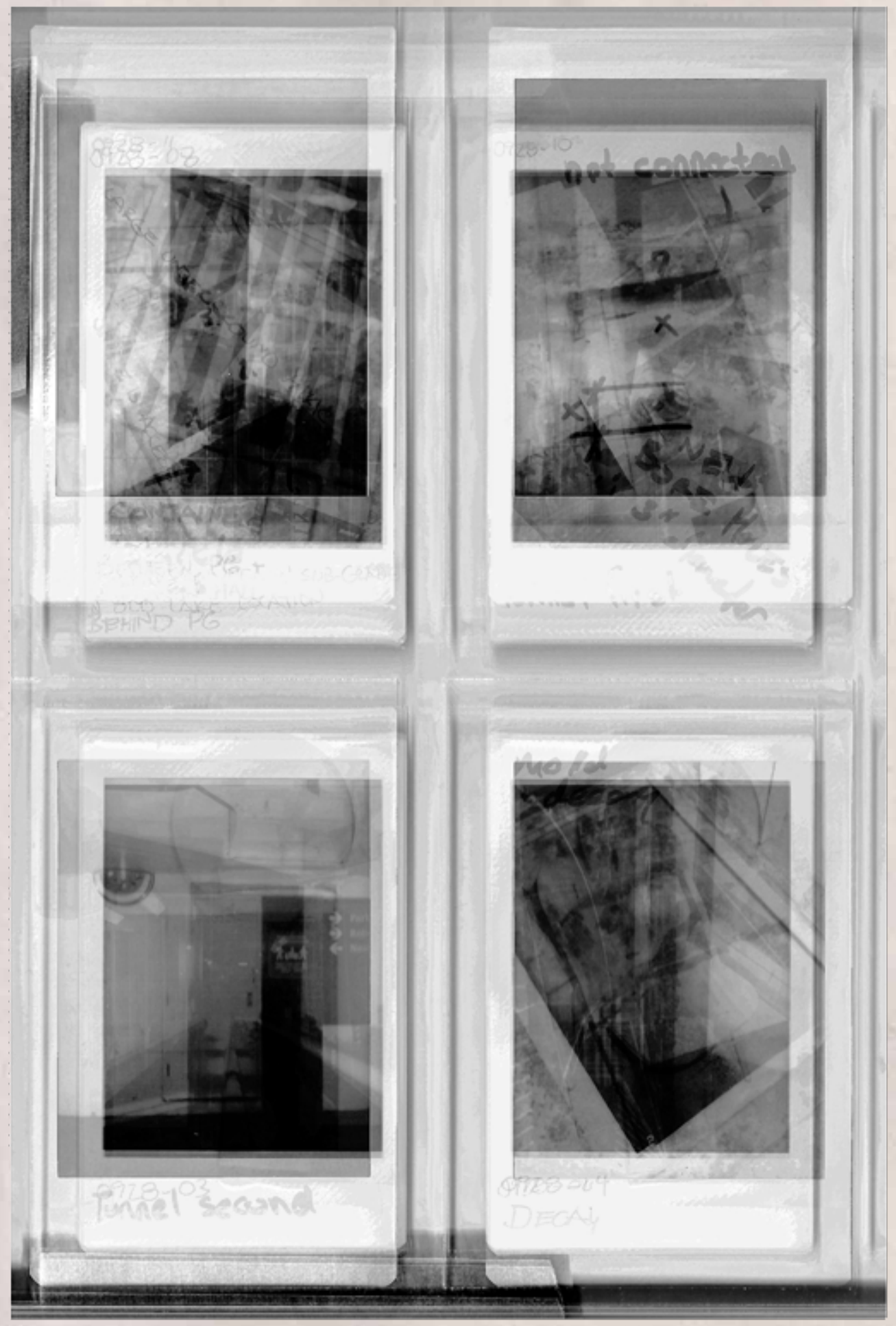

Figure 01. Timelapse of tunnel photograph documentation 
Beinind a Door that Doesn't Exist:

A Journery Into the Horrific spaces Beneati Us

- kepart from the Field - 
report from the Field

In the dead of the winter of 2014 I heard a rumour - that there existed a secret place in Carleton's tunnel system, a place away from the eyes and ears of security, a place that everyone had forgotten about. A friend of a friend and I were in the tunnels, looking for a secluded spot to skateboard during the harsh winter months. He said that somewhere in the tunnels there was a way to access the old tunnel network. We searched for a while, but never found the entrance, eventually settling for a distant corridor to practice our hobby, free from snow. Satisfied with our location, I let the rumour slip from my mind. For a time.

I began my first degree at Carleton University in the fall of 2013. From then until now I've been in the cramped and leaking tunnels under Carleton countless times. Going to and from classes, retrieving things from a distantly parked car, avoiding the harsh Ottawa weather, and taking walks to procrastinate from my work during early morning hours. For countless reasons and on countless occasions, I have been lost, herded, dripped on, overheated, harassed by student governments, crowded, and followed. I have experienced the cramped tunnels as many others before me: convenient, but uncomfortable. There is one aspect of the tunnels however that I had yet to experience. Their vastness always surprised me. With over 5 kilometres of connecting passages, it's no wonder people get lost down there, but now, the rumour I heard years earlier still quietly ate away at my curiosity.

Carleton University first broke ground for their river campus in 1958, after being given land by the government under Prime Minister John Diefenbaker. With 60 years of history on this campus, there are bound to be secrets. Things forgotten, and stories erased.

I had to find them.

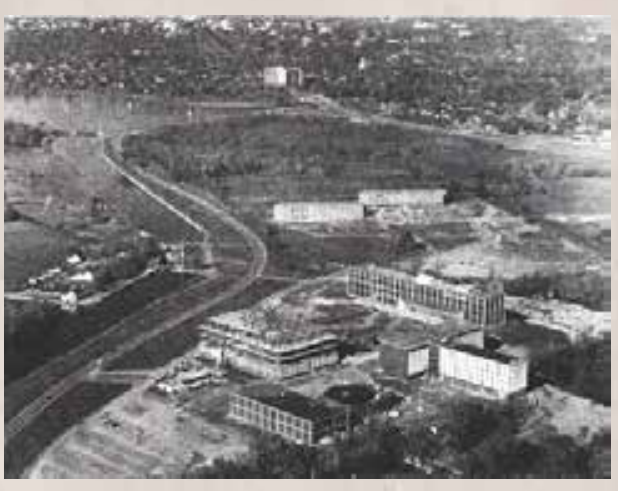


In 1958, during the height of the cold war, the Diefenbaker government gave a parcel of land to carleton university for free to construct a campus along the river, outside of the city. John Diefenbaker, known for his paranoia, going as far as reportedly entombing himself in concrete upon his death, famously commissioned numerous bunkers across Canada to serve as doomsday shelters in the event of looming nuclear war. This contextual political relation coinciding with the construction of Carleton was enough to spur my explorations.

With my Polaroid camera in hand, I took to the campus, searching for any sign of lost, abandoned, secret, or forgotten architecture. I began my search by overlaying a map of Carleton in 1958 on top of a map of the campus today. Tracing pathways to connect campus via subterranean architecture provided me with insight as to where these lost tunnels might be located. Immediately I was presented with a void on campus - a place where high occupancy buildings once stood or were intentioned to be constructed, but where nothing exists today. The area is located centrally on campus, in between the current university centre and administration building, bisected by the o-train tracks. Upon visiting the area, on the west side of the tracks I located an abundance of ventilation covers and manholes in the middle of an empty grassy area. The existence of these services does not align with current campus water and sewage maps, nor does it coincide with the typical manner in which these infrastructure elements appear. Thanks to a recent excavation outside the architecture building, it can be observed that infrastructural services, such as sewage and water, are typically run along the same pathway as the existing tunnels. Evidence of these services appear along the same route as the underground infrastructure before small branches service adjacent buildings. With the knowledge that this infrastructure runs parallel to existing subterranean architecture, it can be supposed that there exists substantial subterranean structures for the abundance of services in the vicinity to run adjacent to and serve. 
Additionally, on the east side of the o-train tracks, the area in question abuts the current maintenance building. The maintenance building must be located centrally as it is connected to all existing infrastructure on campus. Originally, the tunnels under campus - the ones we're aware of - were used exclusively for services such as sewage and HVAC and for the circulation of employees. However, the connectivity of the school in such a cold climate became an immediate draw for the students who desired shelter during the harsh winter weather. The tunnels, under construction as the school expanded, were closed for renovations in 1961 . These renovations created new corridors adjacent to the service ones, free of hot pipes and obstructions, existing solely to provide circulation for the students and faculty. However, the renovations to the these tunnels required severe intervention and many sections and routes were altered, leading to some areas being rerouted and others becoming closed off entirely.

The renovation of the original tunnels meant that access was forever changed, and in some cases, lost. This access, should any remain, would branch out from a central location seeing as all tunnels lead back to the maintenance building. It is therefore clear that the building must be looked at with a very fine lense, observing for any faults and discrepancies in construction, in order to determine if and where these lost tunnels may connect.

With a promising location to investigate, I assembled a kit. This kit would assist me in accessing areas of interest that would otherwise be off limits - be it during daytime working hours or during a clandestine midnight operation. Reaching these out-of-reach areas is crucial for locating the lost tunnels as the "off-limits" areas are where the services are held, the original campus tunnels. These same tunnels were renovated in 1961 to hide access to sensitive areas from the common populace. 
Once I gained access to the parallel services corridors, evidence of construction and old passageways became immediately clear. Grates and metal coverings, broken glass and machinery - all provided glimpses past their boundary and into areas long forgotten. Dust and debris littered what precious space I could see, and in the few areas I was able to access, there was evidence of deviant human activity. In the areas that I could access, I found a great host of objects. The objects, all damaged and dejected beyond use, ranged from cutlery and tools, sleeping areas and drug paraphernalia, and, most shockingly, biological remains and children's toys. These discoveries made accessing or documenting the inaccessible spaces that much more crucial. Without my physical presence, and therefore my most capable observational sense, sight, I would have to find a way to record these spaces that didn't rely on what had been my most crucial forensic tool thus far.

Using equipment available to me, I devised a sensory probe that would, using heightened auxiliary senses, act in my place as an explorer of the unknown. One key element of the probe consisted of a roomba, affectionately called Rosie, who would create a map of spatial confinements through touch as she traversed the floors of these lost locations. The second key element of the probe is a homemade sonar device. The device operates using a beeper and an ultrasonic sensor, mounted on top of Rosie, facing upwards. The system is controlled by an arduino with code that translates the time between sound pulses into distance. The sonar device then creates of map of ceiling height along the path of the roomba. Combining these sensory maps, touch and sound, creates and a tactile and sonic landscape that captures the dimensions of a space beyond my reach.

The sensory probe deployments and my own personal investigations have yielded mountains of data, but key elements of this exploration remain intangible. During this process, the quality of space has taken such a drastic downward curve that it has affected my physical and psychological self. The uncomfortable nature of this environment required documentation and qualification. To complete such a task I turned my focus towards the only other place I knew that so regularly created these same sensations in me. That place is the literary and cinematic genre, Horror.

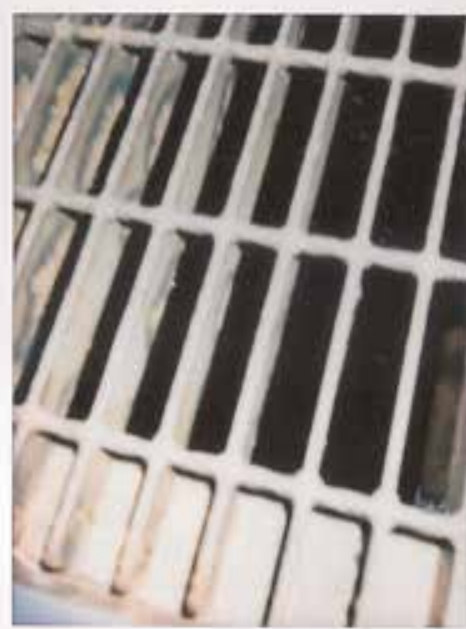

Figure 07. Access to

subterranean area below

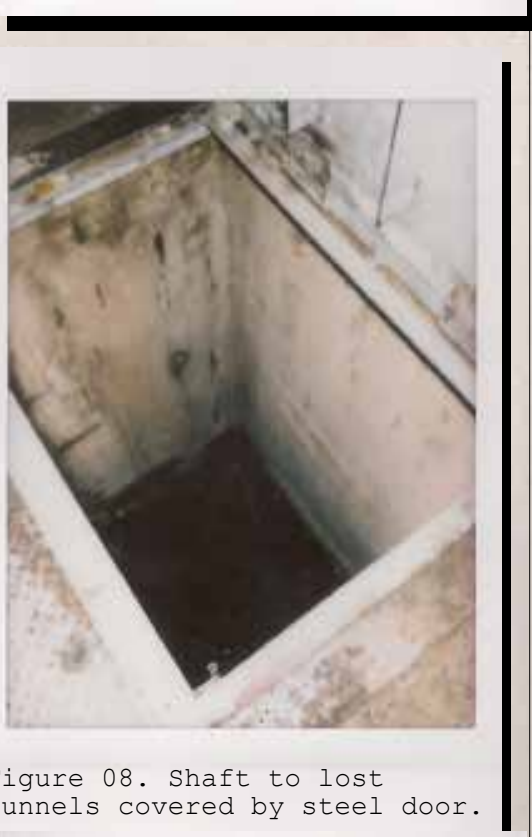

tunnels covered by steel door.

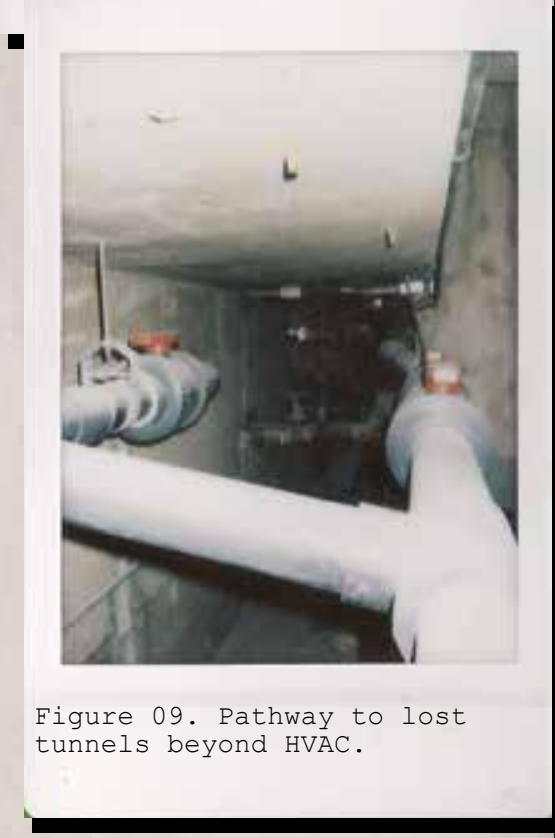




\section{Symptoms and Conditions}

In my research into the horror genre, I have identified qualities of space and spatial experience that are comparable with my experiences in the tunnels. Architecturally, I have identified a series of spatial symptoms and conditions that culminate in the creation of a horrific environment. By comparing and contrasting these symptoms and conditions to real life case studies of other subterranean architecture, I am able to better understand the effects these spaces have had upon myself.

What follows is a list of these symptoms and conditions, each with supporting resources from the horror genre and an accompanying case study of a location or film. In addition, at the top of each page is an image. The image, starting with "perspective", begins as a tunnel that was selected for its subjectively positive qualities and inviting aesthetic characteristics. By making one simple visual change that corresponds to each of the symptoms and conditions, the once positive image changes from some thing that was once pleasing, to an environment that manifests fear in its occupants. This exercise serves to illustrate the potent simplicity of the small list of factors that negatively affect space. While one change may be in and of itself non-aggressive or off putting, perhaps even pleasant, it is the combination of all of these elements that create the architecture of horror. 


\section{Harrar}

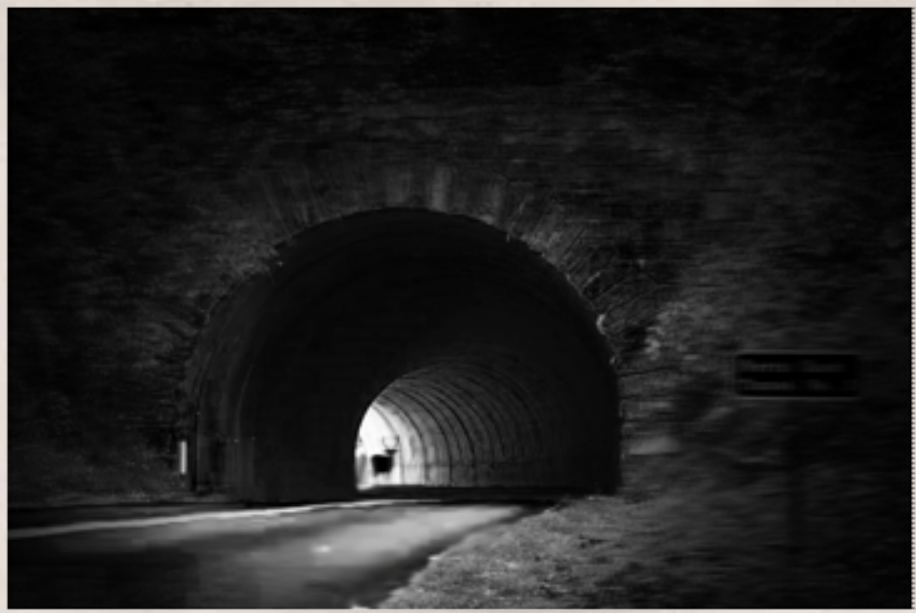

Figure 10. Ferrin Knob tunnel, stage 8: Horror. Edited

\section{CONDITIONS}

Horror, the genre, is brought about by creating conditions that horror, the emotion, uses to fester and breed. These circumstances which affect the way a viewer or occupant lives or works are the basis upon which our emotional responses are founded. It is through these that an environment of fear is constructed. Elements such as lighting, perspective, and the familiar are all conditions which can be used to create environment.

\section{SYMFTOMS}

In response to conditions, just as a person would, the environment also experiences the effects of the imposed circumstances. The space, unable to experience emotions itself, results in the manifestation of the previous conditions. While a person may feel dread, or panic, or dismay, a space instead experiences that which can create these responses. Tension, ambiguity, claustrophobia, and atmosphere are all the result of various conditions that are not inherently terrifying, yet create their own symptoms in the minds and experiences of the viewer.

\section{HOKNOR}

Horror, both as a genre of cinematic and literary fiction and as a feeling of intense fear, is a term that is vague yet instantly recognizable. As humans, it is a natural response to a large range and manner of stimuli; disgust, shock, revulsion. As such, it is the perfect title for a genre that seeks to create and elicit these responses. While the word itself may not provide ample depth in terms of specificity, the expectations are clear, and it is something, whether we seek it out or not, that we can all experience. 


\section{Ferspective}

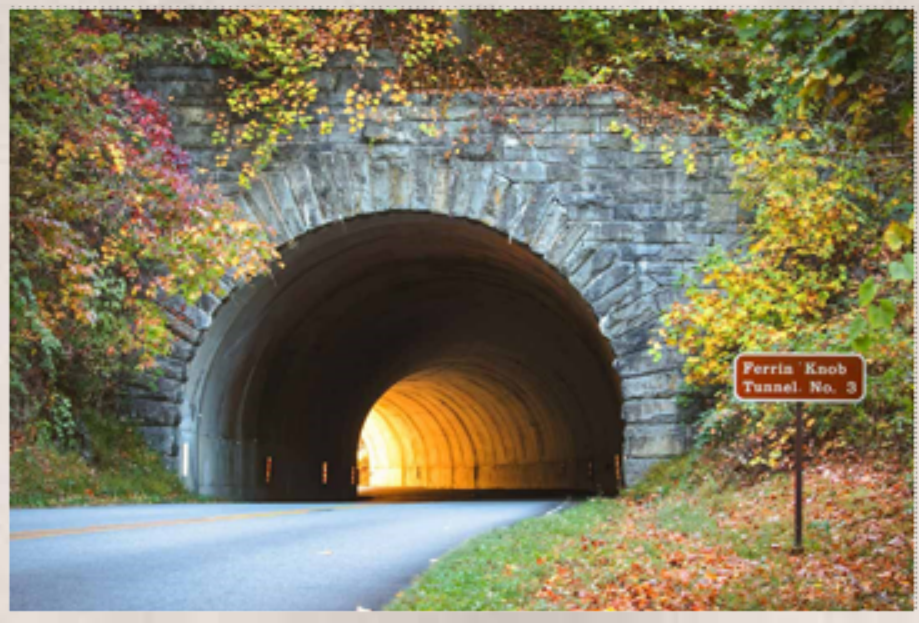

Figure 11. Ferrin Knob tunnel, stage 1: Perspective. Unedited, https://www.nps.gov/blri/planyourvisit/tunnelheights.htm

\section{FEKSFECTIVE (Condition)}

The point of view of the occupants, or the lens through which a work is viewed, plays a key and pivotal role in the immersion of an audience within a story. Whether it be through first-person point of view, an artificial shared experience, or through multiple layers of removal, a mystery unraveling before your eyes, it is a condition that allows entry for the audience and acts as a gateway to the symptoms.

"Stalker", Andrei Tarkovsky

"Cloverfield", Matt Reeves

"Tlön, Uqbar, Orbis Tertius", Jorge Luis Borges

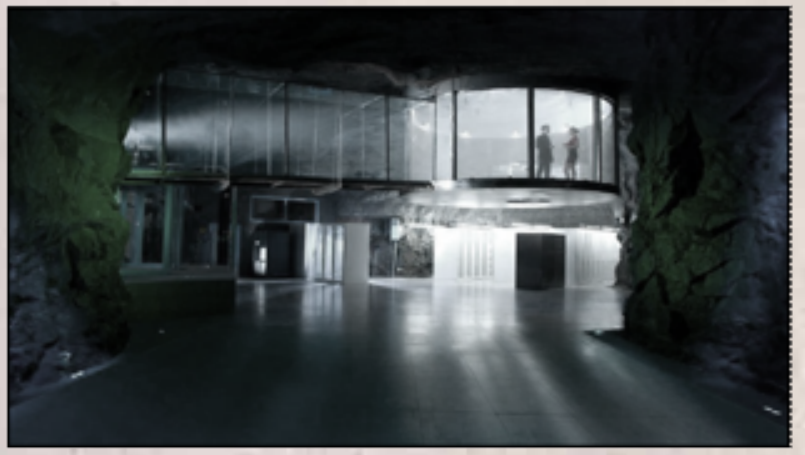

Figure 12. Wikileaks HQ. Stockholm, Sweden. Repurposed military bunker. Constructed: 1943. Https://gizmodo. Com/5626381/this-is-the-nuclear-bunkerwhere-wikileaks-will-be-located

Wikileaks, founded by Julian Assange it's headquarters in a decomissioned bunker under a mountain in Stockholm, Sweden. Beautifully constructed, the server room houses all of the information available on Wikileaks - that being, the top secret files of foreign powers leaked anonymously. The servers present catastrophic risk to those outside of the bunker for what those secrets might lead to, while simultaneously making the bunker a requirement for those within. Your perspective might shift, but the threat of danger is very real. 


\section{2. (Un)Familitiar}

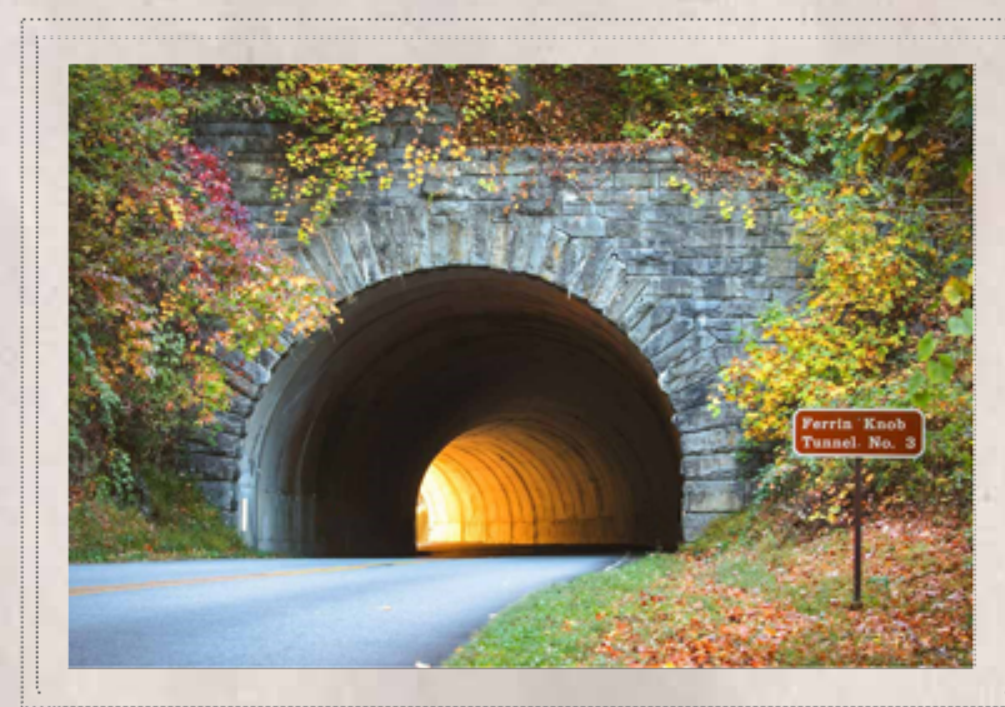

Figure 13. Ferrin Knob tunnel, stage 2: (Un)Familiar. edited

\section{(Un) FaMfintion (Condition)}

The (un)familiar relies on taking a concept that carries with it feelings of familiarity or nostalgia within the viewer, something that exists as expected and has shown itself to be reliable in the experiences of the occupant, and twisting it. Subtle changes to what would otherwise be routine alerts the viewer, albeit potentially subconsciously, that something is amiss even if it is not immediately recognized.

"The birds", Alfred Hitchcock

"Rear Window". Alfred Hitchcock

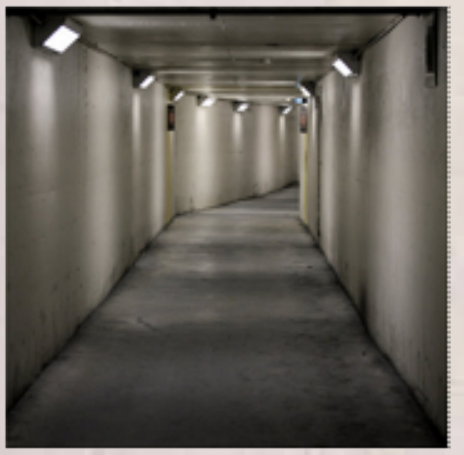

Figure 14. Carleton university tunnel

system. Ottawa, Canada. Circulation and maintenance tunnels. Constructed: 1958 Present. Carleton.ca

The tunnel system at Carleton University is a mainstay for students and faculty alike, essential for navigating campus during the cold winter months. However, the tunnels are old. They were constructed in 1958 during the Cold War after Prime Minister Diefenbaker gave Carleton a parcel of land for free. The tunnels we know today don't tell the whole story. That story begins in the lost tunnels. 


\section{Atmaspiere}

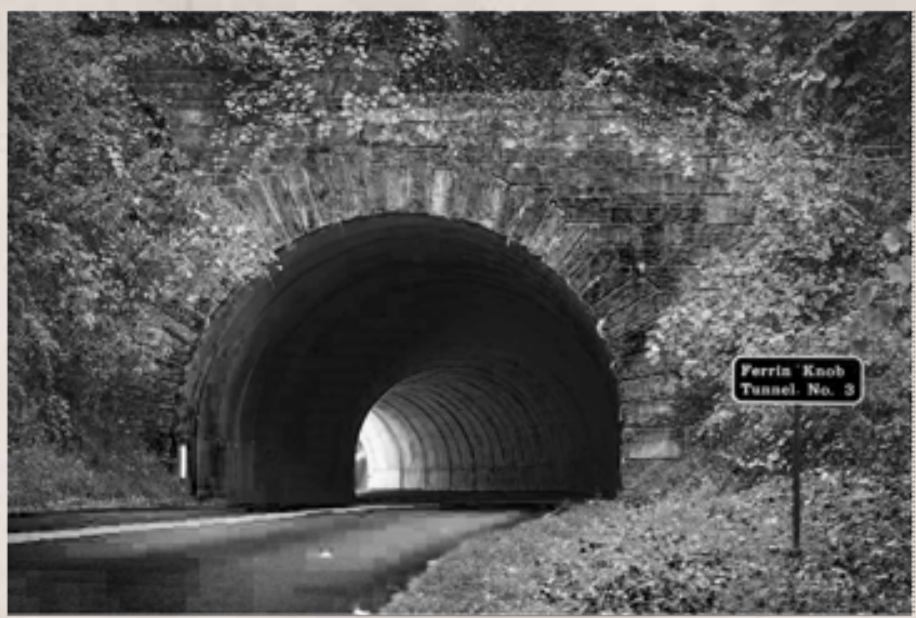

Figure 15. Ferrin Knob tunnel, stage 3: Atmosphere. edited

\section{ATMOSFHER (COndition)}

The pervading tone of a place, often used as a guiding principle to engineer the conditions when the desired outcome is known (the symptoms). Especially effective when used in a cinematic sense but exists in all facets of life as an ambiance that unites all symptoms and conditions together for a cohesive assembly.

"Cat People", Jacques Tourneur

"Get Out", Jordan Peele

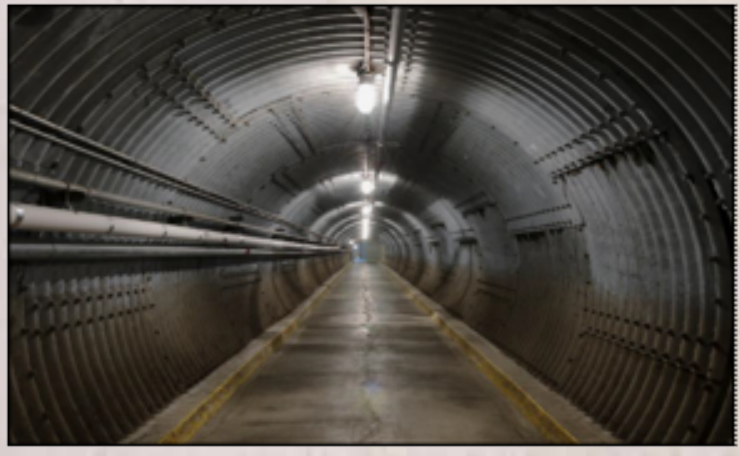

Figure 16. Diefenbunker. Ottawa,

Canada. Cold war era nuclear

bunker. Constructed: 1962. Https://

hautevitrine.Com/tag/nuclear-

shelter/

The Deifenbunker - a Canadian military instalation, constrcuted near Arnprior in 1959 after being comissioned by Prime Minister Diefenbaker, was designed to house the top officials from Parliament and their immediate family - 500 persons - in the event of nuclear attack. The Bunker, now a museum oozes with the social energies of the cold war with its paint, furniture, and "duck and cover" attitude. A false sense of security wafts throughout the structure as calm, upbeat era-appropriate show tunes ring out from the tinny loudspeakers scattered in the doomsday complex. 


\section{Ambiguity}

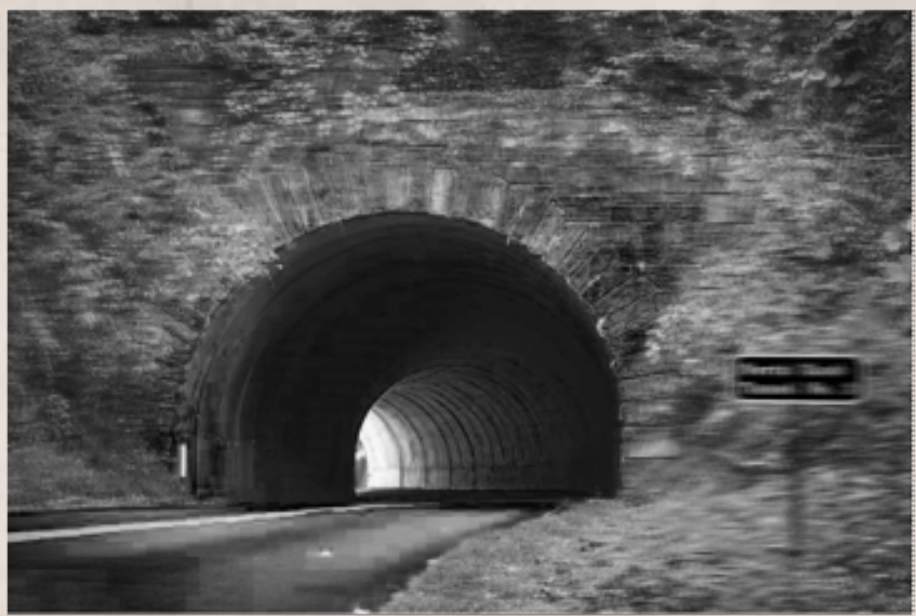

Figure 17. Ferrin Knob tunnel, stage 4: Ambiguity. edited

\section{AMBSUTTY (symptam)}

The audience holds its breath along with the protagonist as she/he (more often she) approaches that door. The protagonist throws it open, and there is a ten-foottall bug. The audience screams, but this particular scream has an oddly relieved sound to it. 'A bug ten feet tall is pretty horrible,' the audience thinks, 'but I can deal with a ten-foot-tall bug. I was afraid it might be a HUNDRED feet tall.'" (Danse Macabre, Stephen King)

"The true importance of Ambiguity is all about leading the audience up to that door, building suspense and tension with every step towards it they take, and once they arrive at that old creaking thing, the writer's job is to cause a gust of wind to blow it open, and in that instance, as you stare out into the gloom you think you see something big and hulking, full of tendrils and fangs moving in the shadows. The trees rustle and all of a sudden that thing is gone. Your heart is beating fast in your throat, a cold sweat runs down your back, and you are compelled by your own god-forsaken curiosity, to follow that shadowy creature outside towards another door in the distance, beyond which something even more hideous hides."

"Babadook", Jennifer Kent

"It Follows", David Robert Mitchell

Figure 18. A frame from the film "It Follows" Directed: David

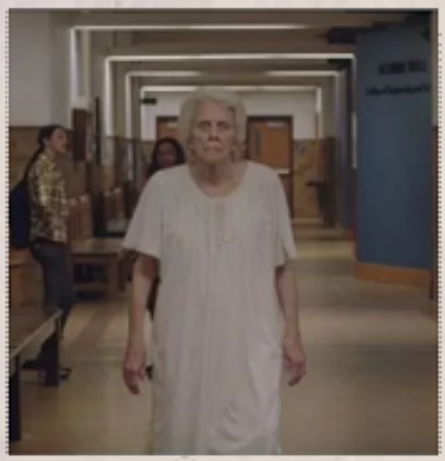




\section{I i is}

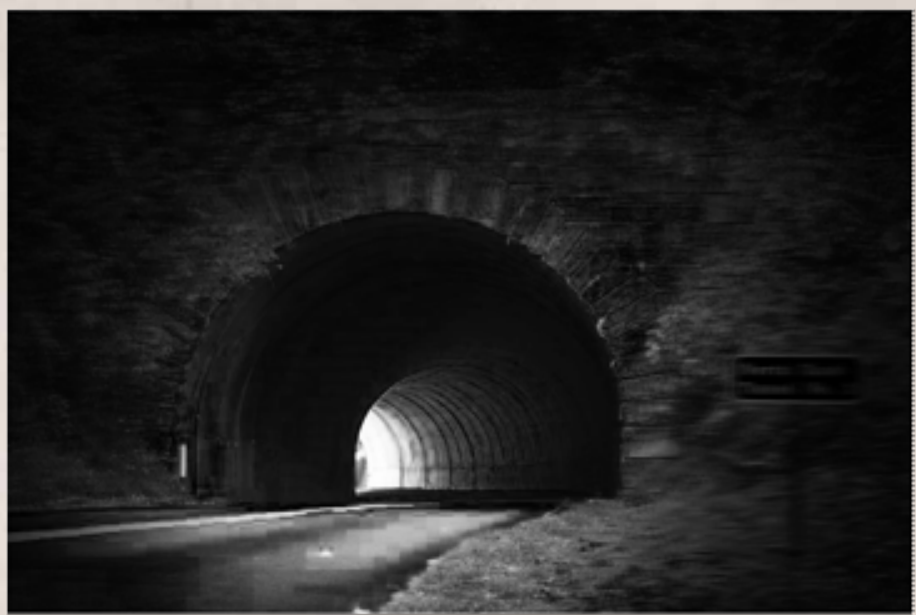

Figure 19. Ferrin Knob tunnel, stage 5: Lighting. edited

\section{IFGHTNG (Condition)}

An incredibly powerful tool that can turn a child's bedroom into a palace of nightmares. The condition is used heavily in the horror genre to use the audience's imagination against them. Ambiguous corners, flickering shadows, dark figures - "Lowkey" lighting is a technique often used in horror films, the dim hue and shadows created by this lighting are suited to the conventions of such a film; it creates tension due to its mysterious and dark atmosphere, controlling how much of the surroundings and characters are revealed. It sets the tone, mood and creates a dangerous association with enigma through the shadows and dull shades.

"Cube", Vincenzo Natali

"The Shining", Stanley Kubrick

Figure 20. A frame from the film "Psycho", Directed: Alfred Hitchcock, 1960

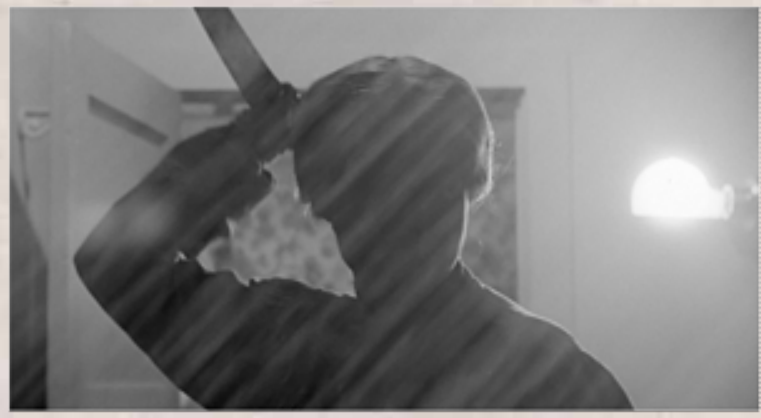

In Alfred Hitchcock's "Psycho", Lighting is used to terrifying effect. The film strayed from the norm of direct lighting and instead used realistic spot lighting on set. The light cast from real objects in frame gave the film a never-before-seen realness. The scene from the bathroom was so haunting because this terrifying figure brandishing a knife is illuminated with what you would have in your own home, thus turning domestic lighting into a chilling tool of fear. 


\section{Claustrophobia}

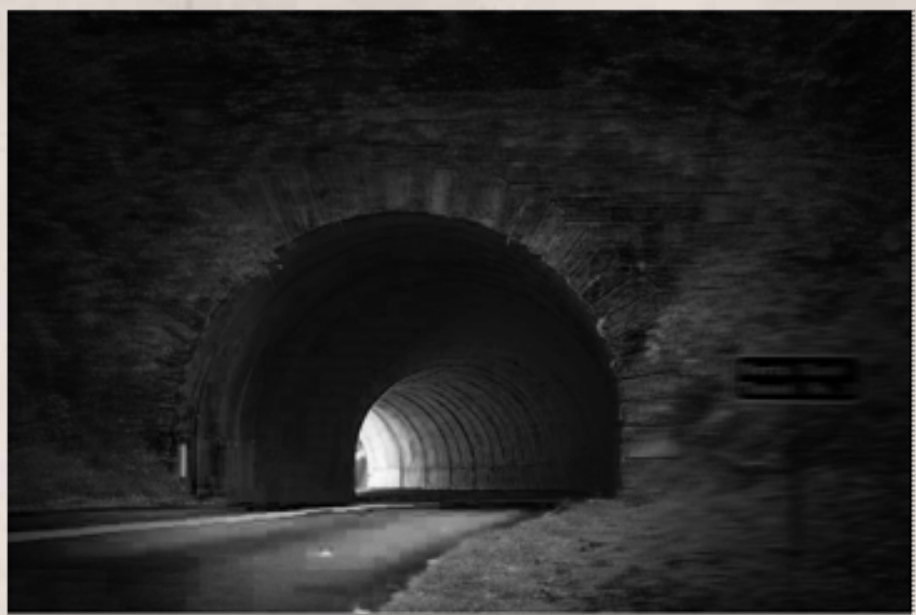

Figure 21. Ferrin Knob tunnel, stage 6: Claustrophobia. edited

\section{CLAUSTROFHOBIA (Symptom)}

While claustrophobia is the intense, yet not always irrational, fear of close or confined spaces, it also carries with it the pretense of other lesser-known phobias, such as that of agoraphobia, the fear of crowded spaces, or autophobia, the fear of isolation. These fears play upon our instincts by making the audience feel unsafe in its inability to make choices or escape from a dangerous situation, whether the danger exists or not. While often classified as an "irrational" fear, claustrophobia is particularily relevant when considering horror in terms of space and to the architect in the construction of occupiable space.

"Tunnel 2011", The tunnel project

"Misery", Stephen King

Figure 22. A frame from the film "10 Cloverfield Lane". Directed: Dan Trachtenberg, 2016

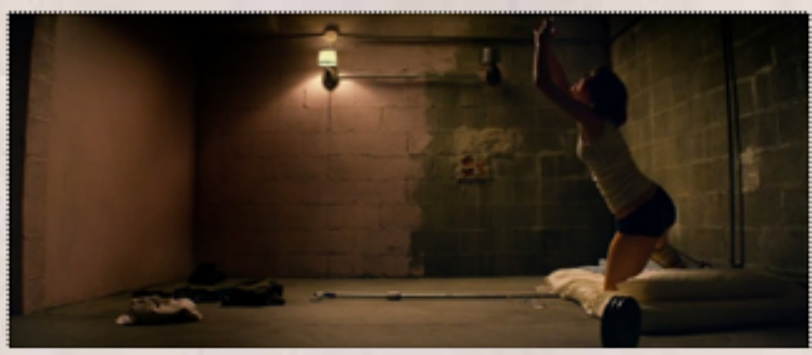

During the 2016 film "10 Cloverfield Lane", Michelle finds herself in a bunker recovering from an apparent car accident. She deals with the confined space, the inability to leave the bunker, the watchful eye of her "protector", the crowded atmosphere of the shelter, the restrictive maze of duct work, and even being chained to the floor and locked in a small room. 10 Cloverfield Lane deals with every aspect of what "Claustrophobia means, socially and architecturally. 


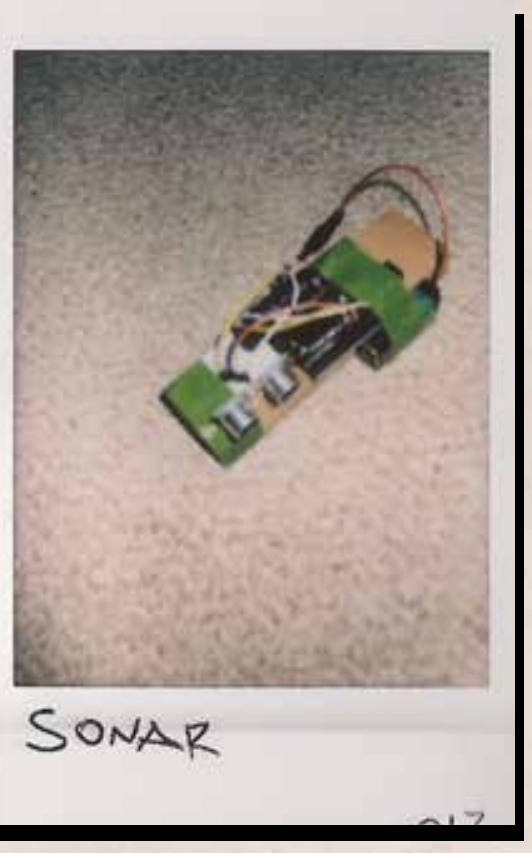

Figure 23. Sonar device equipped to sensory probe

- Abnormality detected

-Battery Warning: Low

-Movement sequencing log pause until abnormality script: Run

- Standby

- Abnormality detected

- Significant ceiling height reduction detected

-Rotation 10. advance

-Contact: Cliff detection alert. Unable to Advance

-Rotation 10. Advance

- Unable to advance. Cancelled

- Advance

- Unable to advance. Cancelled

- Significant ceiling height reduction detected

-Advance

- Unable to advance. Cancelled

-Immobile: initiate sonic distress alert sequence

- No response

-Immobile: initiate sonic distress alert sequence

-No response

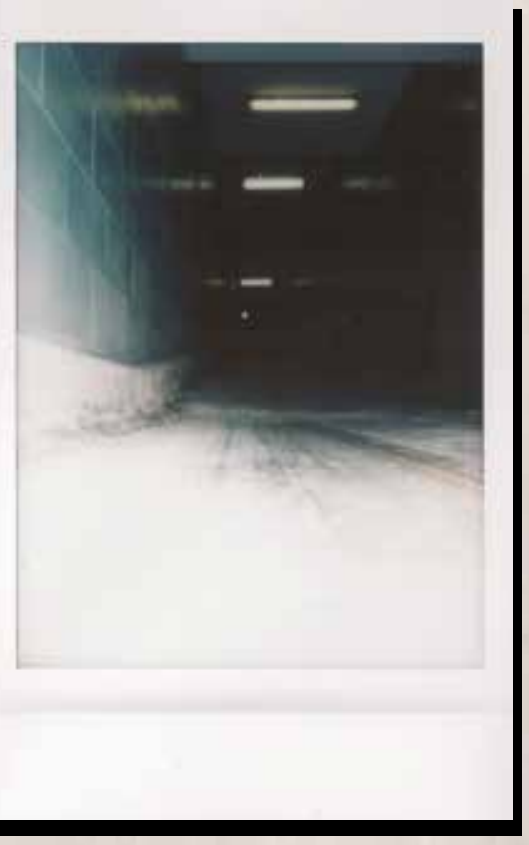

Figure 24. Final photograph from physical boundary. Sensory probe was deployed at this location to continue sonic and tactile documentation

-Battery warning: Critical

-Pówersave mode: Active

-Standby 


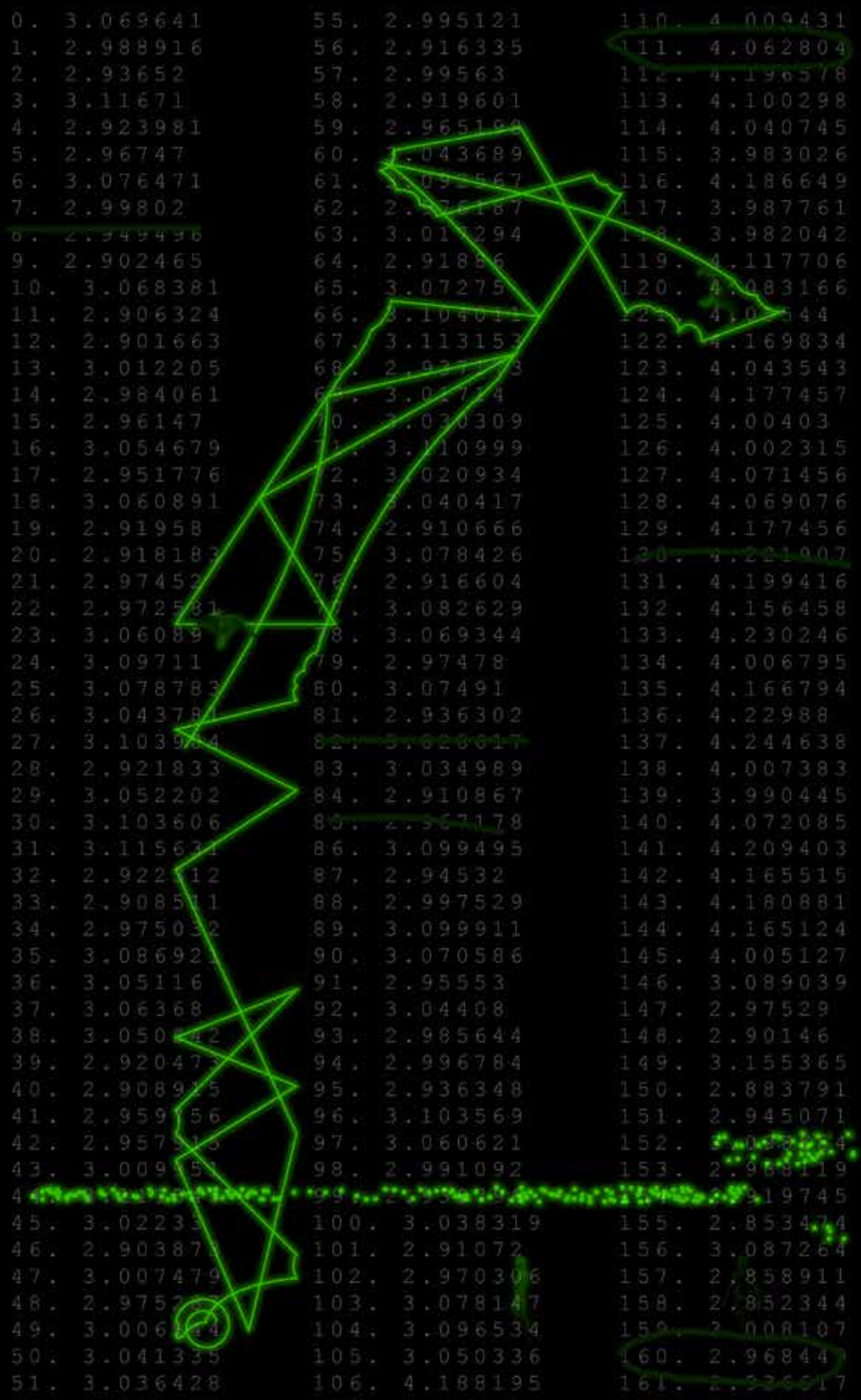




\section{Tension}

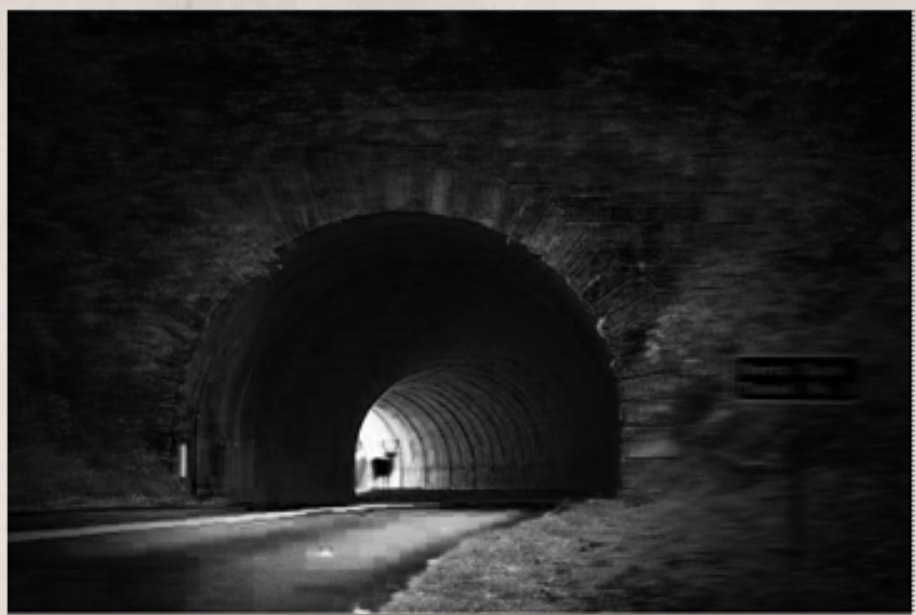

Figure 26. Ferrin knob tunnel, stage 7: Tension. edited

\section{TENSFON (Symptom)}

Tension, a mental and emotional strain or intense suppressed suspense, occurs primarily when an audience is given information that is seemingly enough to form a conclusion from, but lacks key crucial information about outcomes and circumstances that leaves room for the imagination of the viewer to wildly search for answers in the dark.

(On the difference between suspense and surprise) "... Now, let us take a suspense situation. The bomb is underneath the table and the public knows it, probably because they have seen the anarchist place it there. The public is aware the bomb is going to explode at one o'clock and there is a clock in the decor. The public can see that it is a quarter to one. In these conditions, the same innocuous conversation becomes fascinating because the public is participating in the scene. The audience is longing to warn the characters on the screen: "You shouldn't be talking about such trivial matters. There is a bomb beneath you and it is about to explode!" In the first case we have given the public fifteen seconds of surprise at the moment of the explosion. In the second we have provided them with fifteen minutes of suspense. The conclusion is that whenever possible the public must be informed. Except when the surprise is a twist, that is, when the unexpected ending is, in itself, the highlight of the story." -Alfred Hitchcock

"A Quiet Place", John Krasinski

"Amnesia", Frictional Games

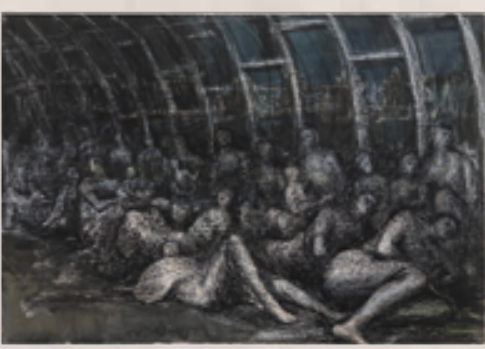




\section{Beinind a Door that Doesn't Exist:}

A Journery fnto the Harrific spaces Beneatin Us

- The Markers - 


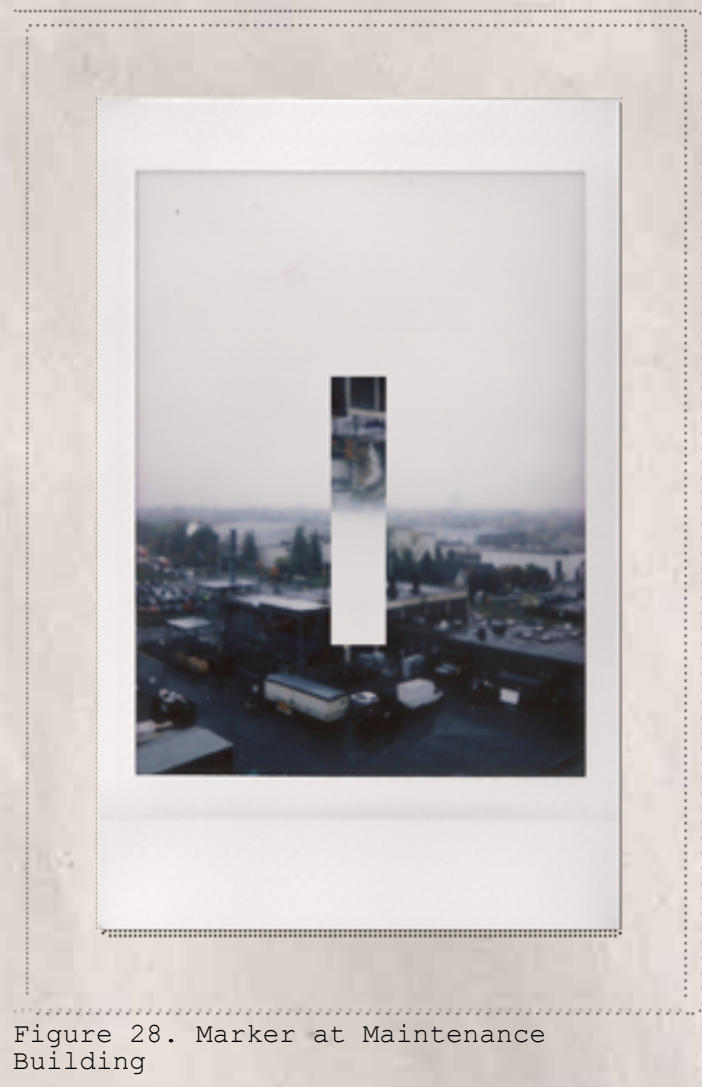

Pìctured above: A parti diagram depicting one of a

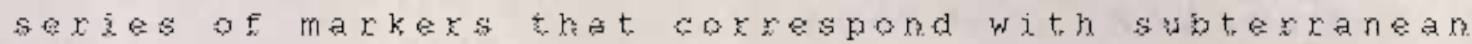
locations ir carleton Uriversity's abandoned second tunnej system. The makkex system exists as a simple intervertior meant to create a refjected experierce for the surface - bringing the conditions and symptons of the lost and Eesticted spaces to the public reas.m.

The markexs exist as ambiguous monoliths a jong a pathway

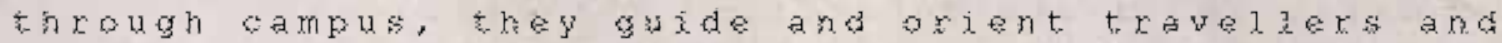
provide ar experience for those who venture close enough.

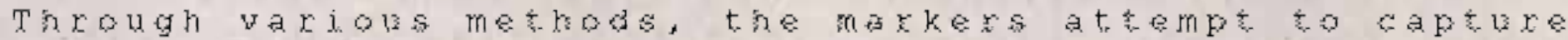

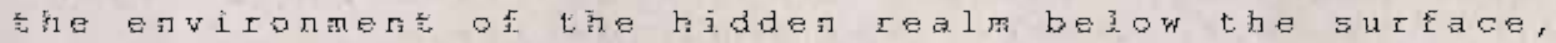
offexing a glimpse into whot lies bejow. 


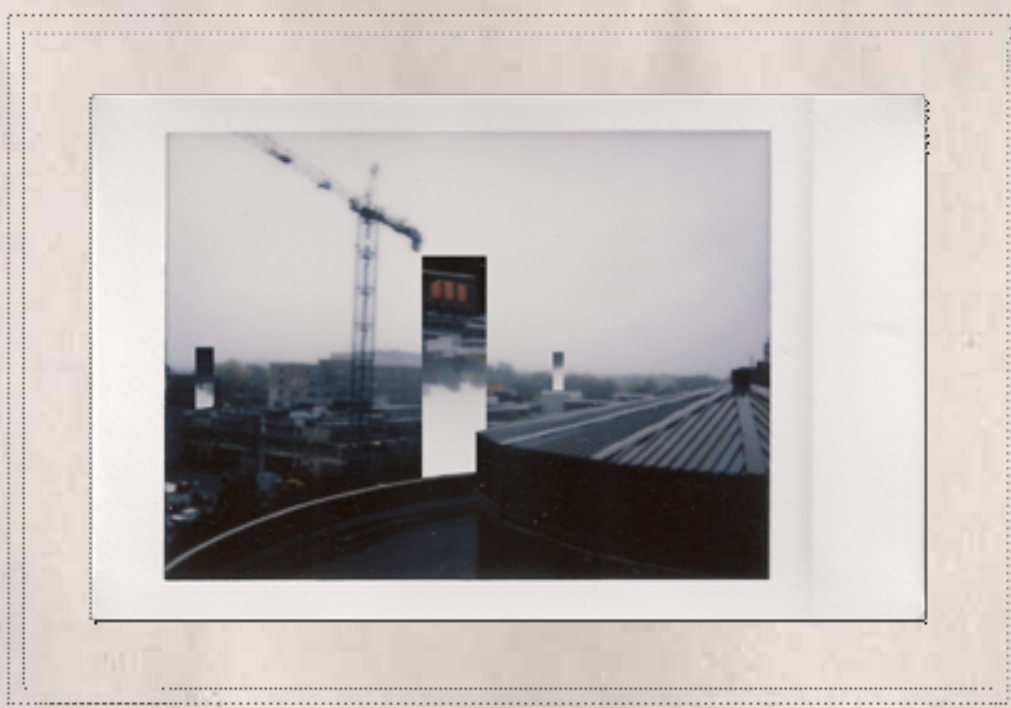

Figure 29. Marker array on campus

These methods attempt to transxit or exulate the sensations of touch, solnd, tempexature, and sight khat

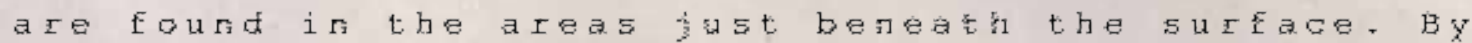
bxingng at tertion to the conditions of the tunnels below, the markers highlight the cIiticaj jmportance of the poychological effects of architecture on the mind's perception and the lisits of the body's movemerts.

During these contemplative noments of spatiajexperience, the obsexver entexs a pxoject of axchitectse that captures what is contidered too dangerous, everigrifich, for the ocenpants it was bijt for. 


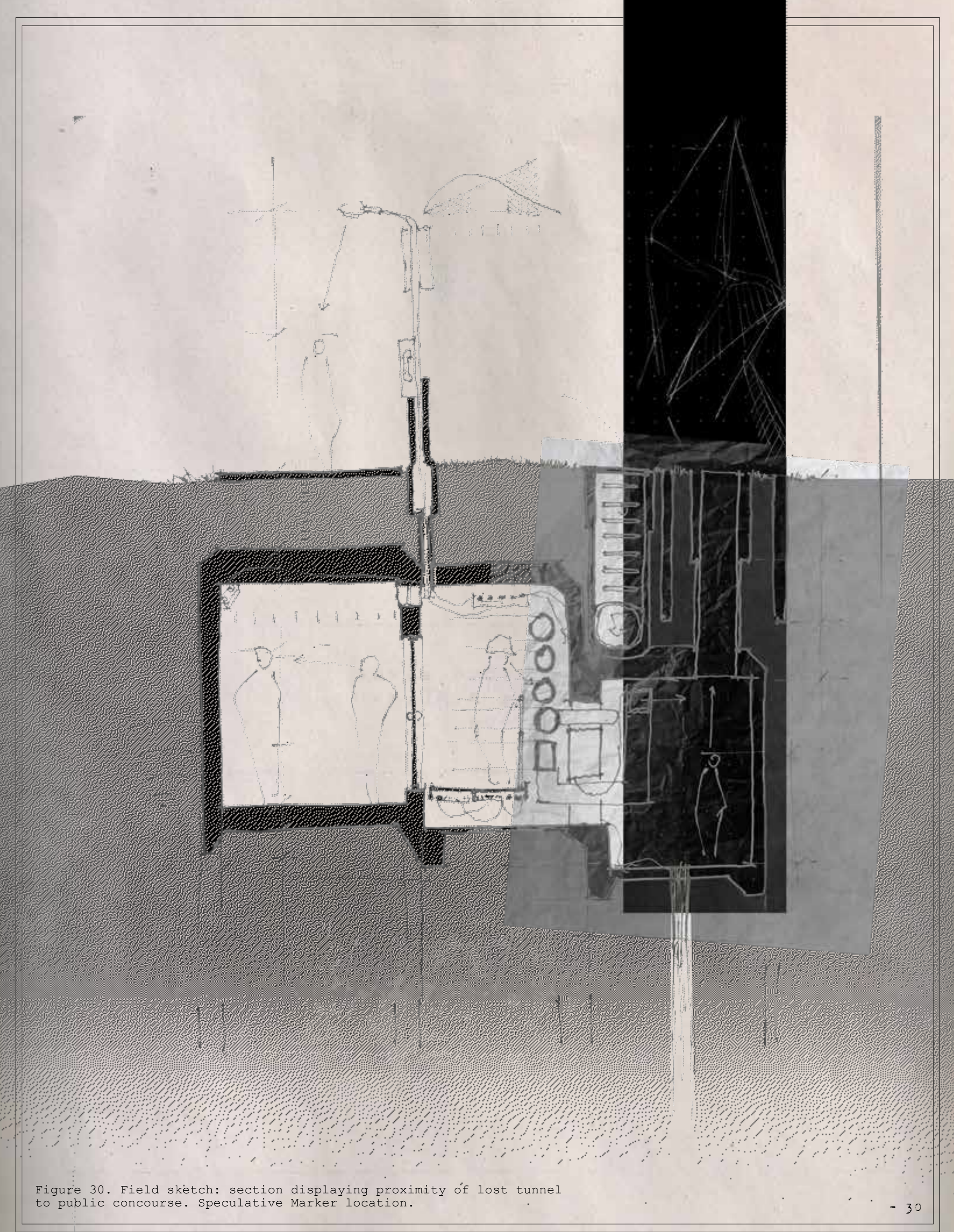




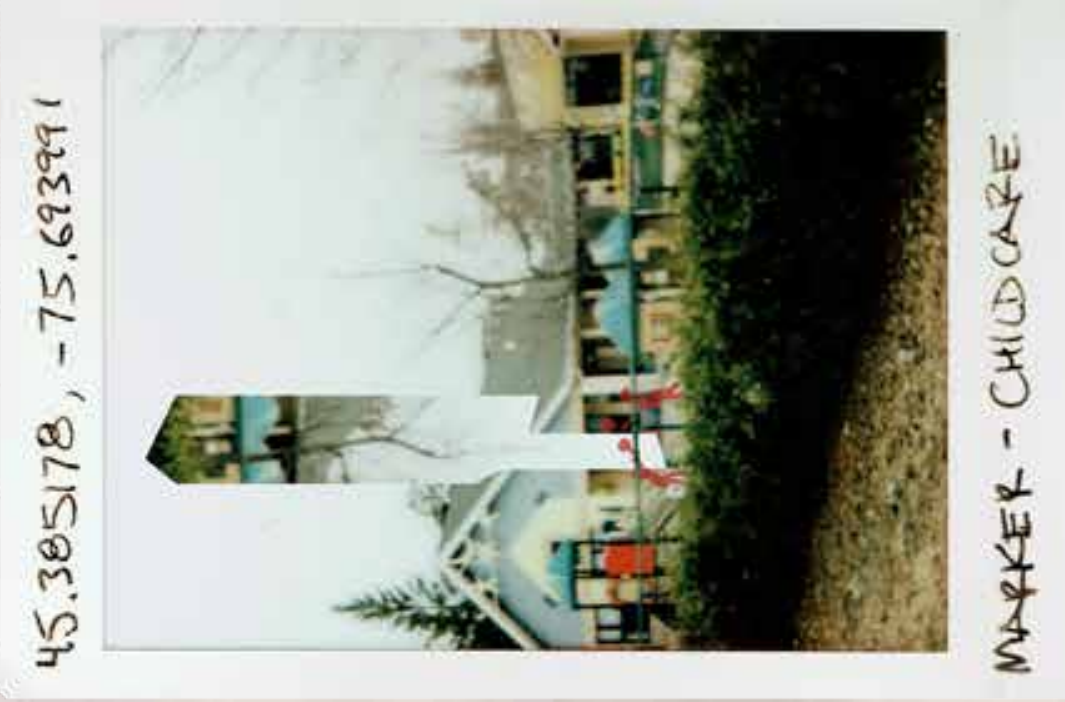

$\stackrel{0}{+}$

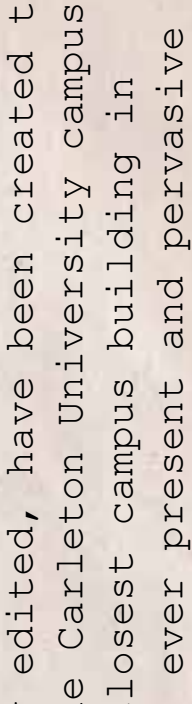

걷워

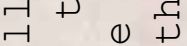

元

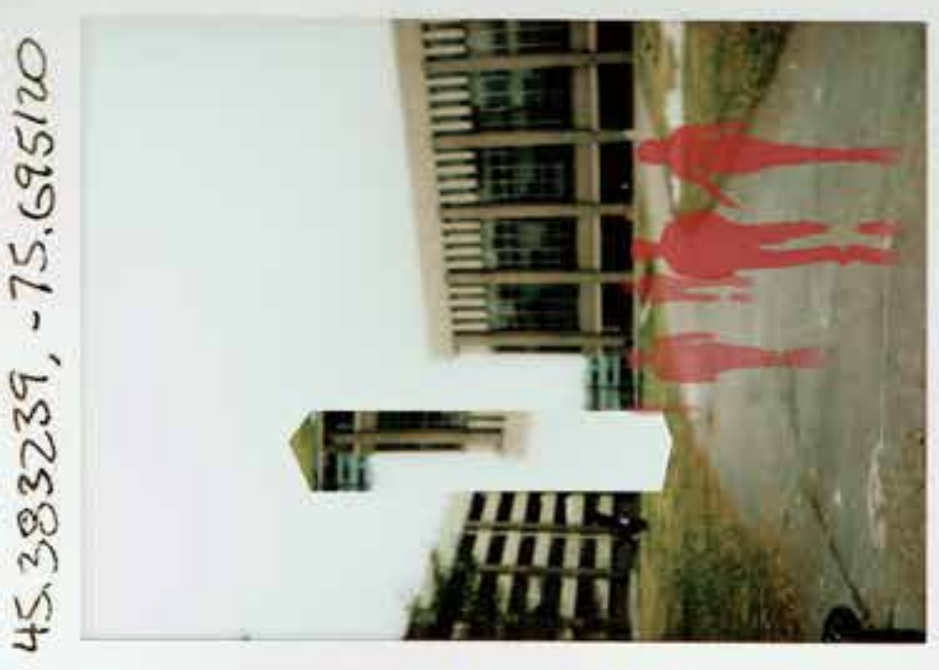

$\frac{5}{3}$
$\frac{2}{8}$
$\frac{5}{4}$
$\frac{1}{4}$
$\frac{1}{4}$
$\frac{7}{2}$

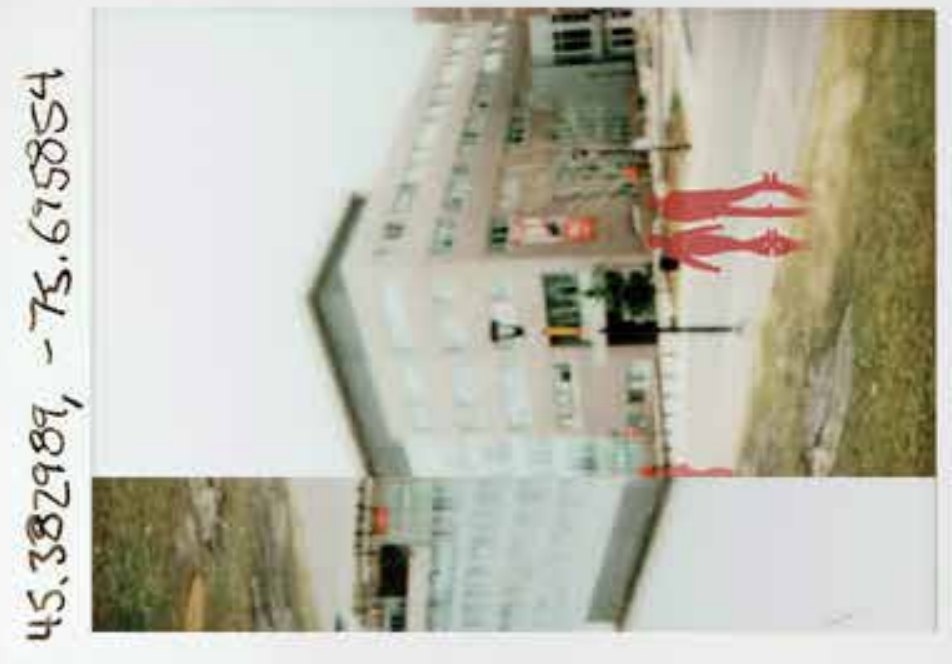

$\frac{1}{\frac{11}{2}}$ 

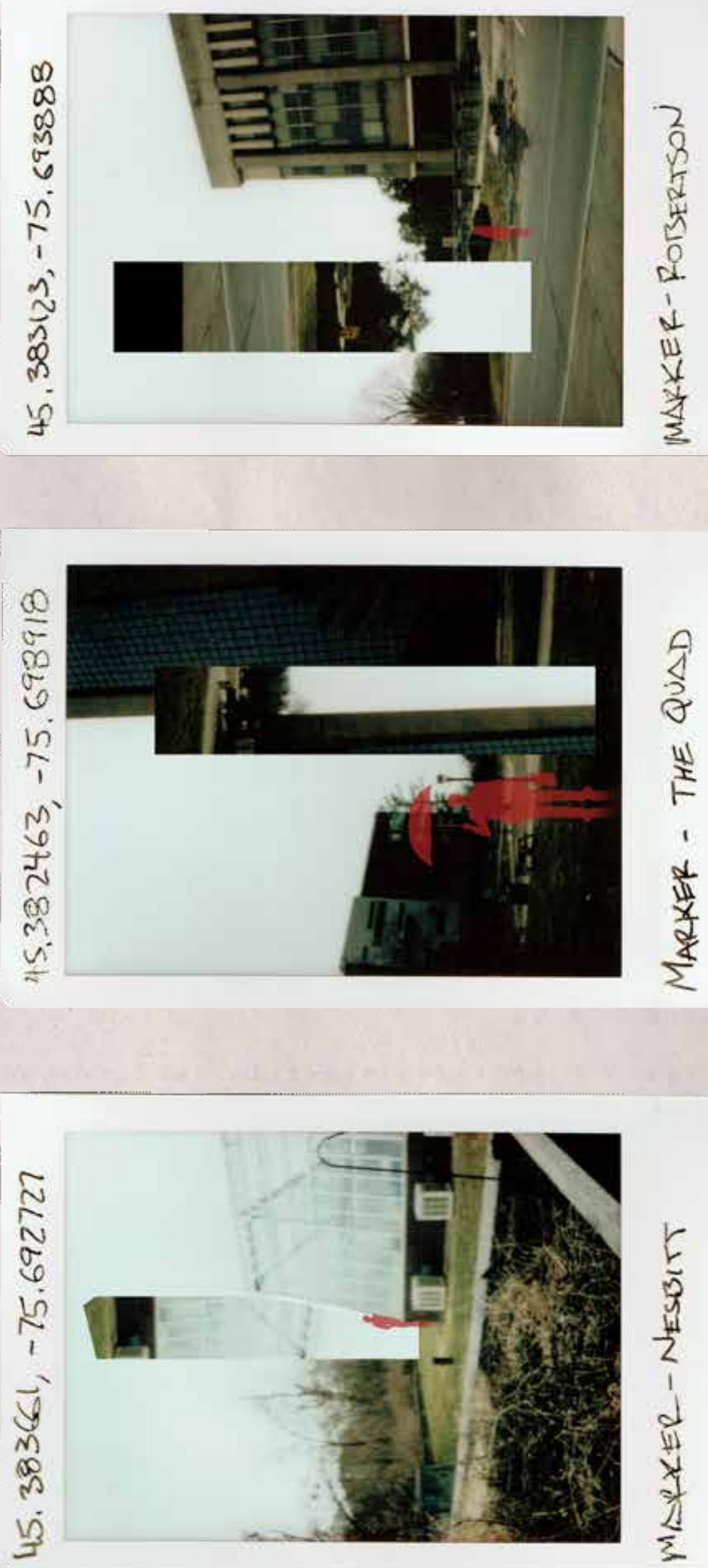

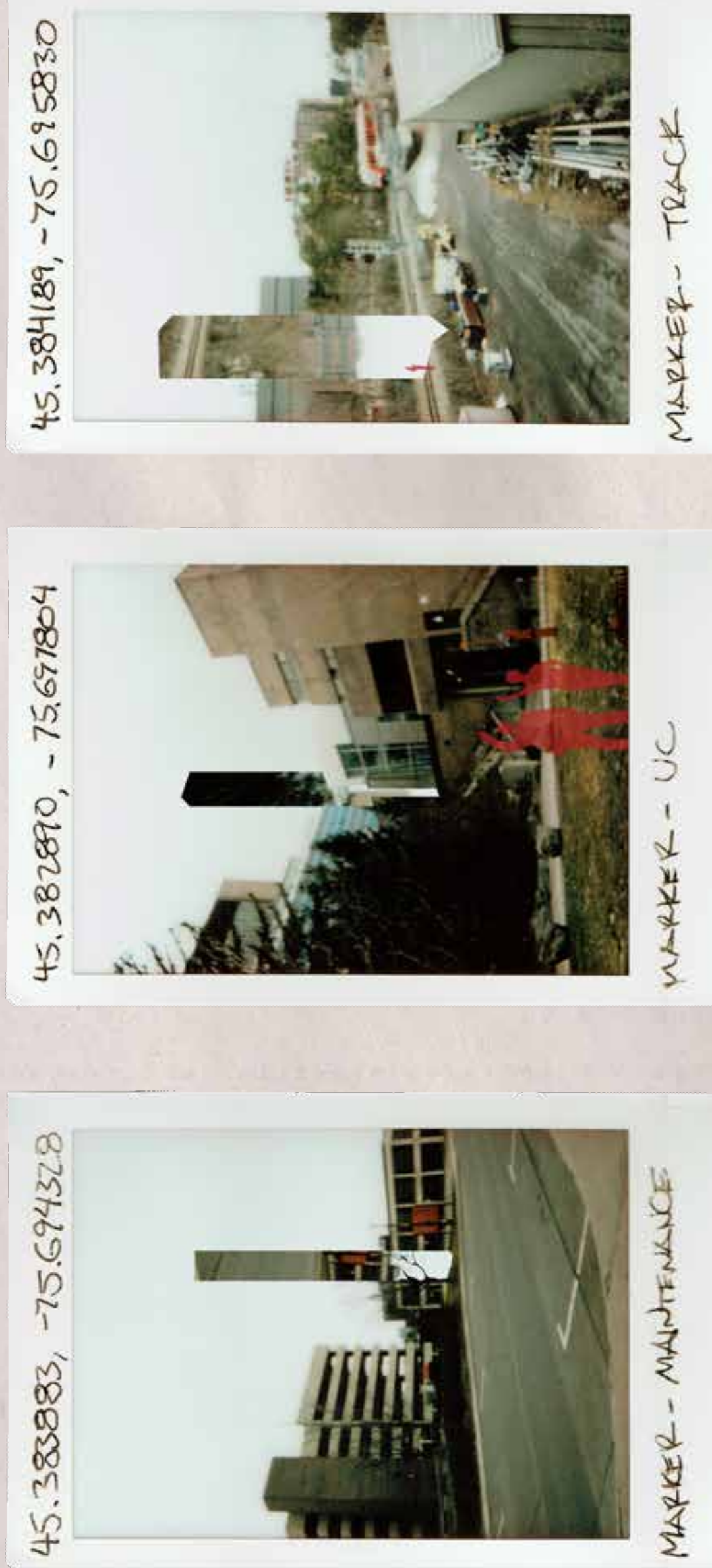


\section{Benind a Door that Doesn't Exist:}

\section{A Jaunery fnto the Horrific spaces Beneati Us}

\section{- The Fublic Gathers -}

The following chapter exists as a demonstration of the possibilities for a translation of the symptoms and conditions of the tunnels from their site to another location. It can be supposed that the effectiveness of these strategies during their exhibit, in conjunction with their interactive nature - that of stepping up to and very closely viewing an object or phenomena can be applied in principle to the construction of the markers. 


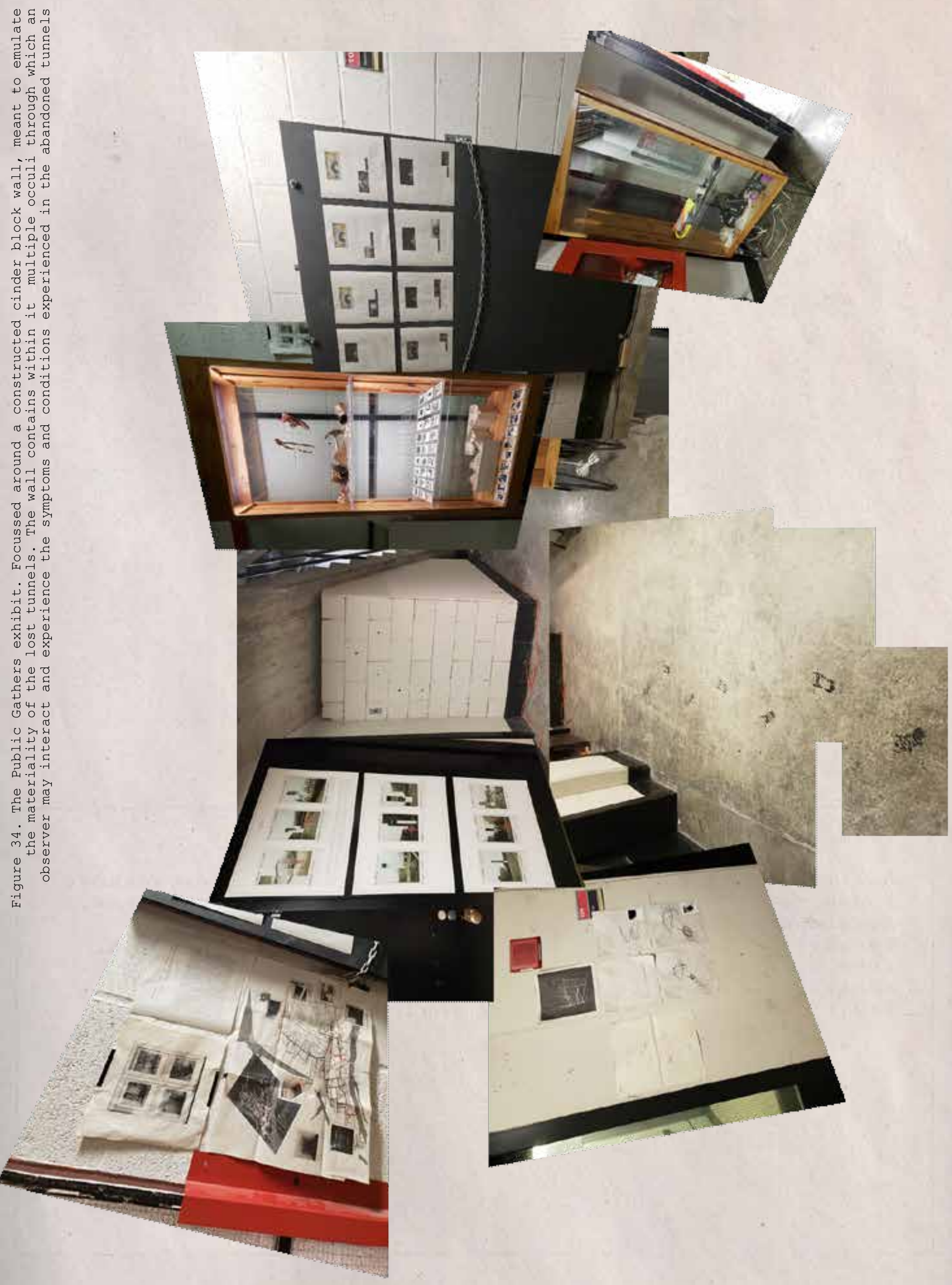




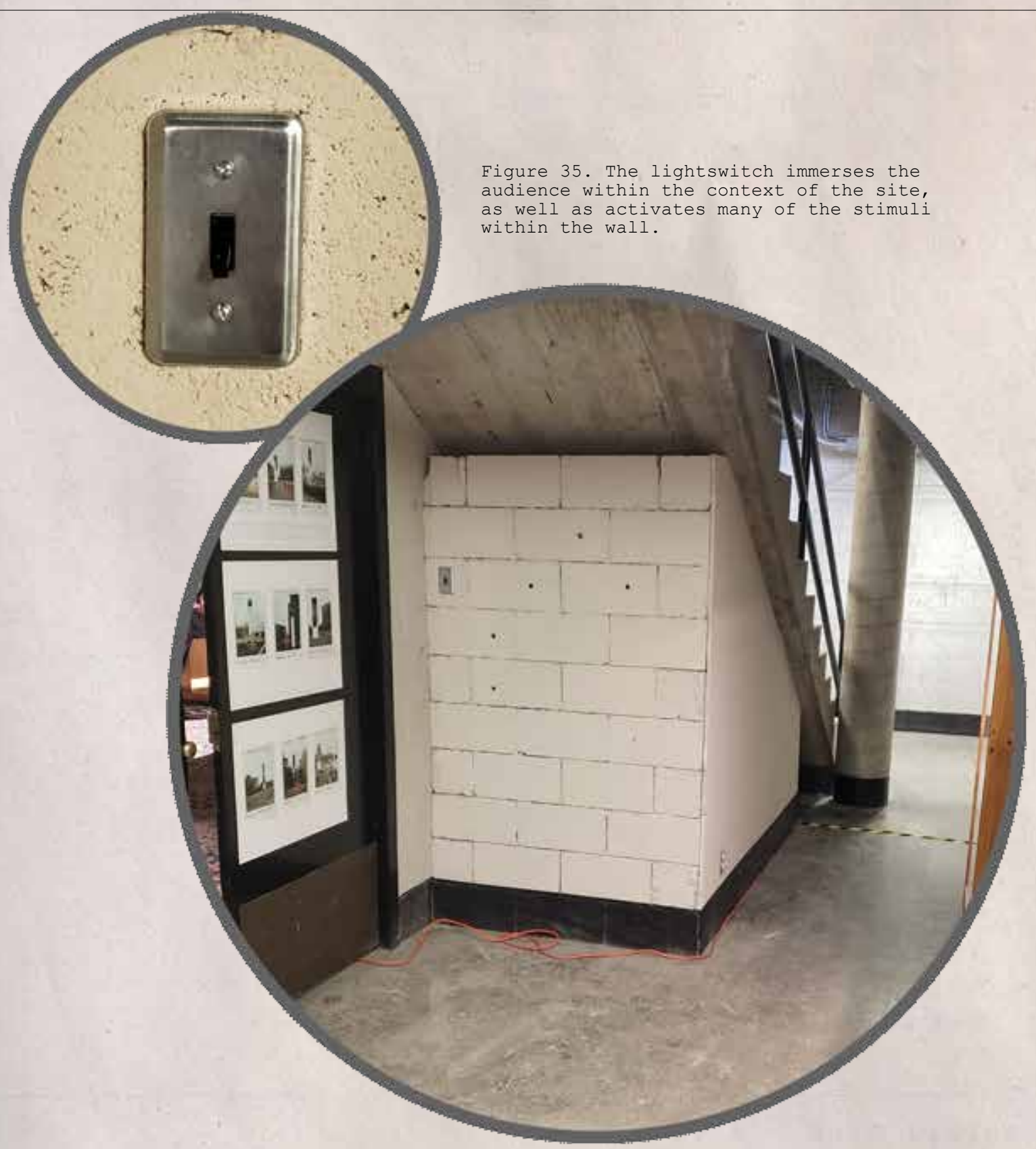

Figure 36. The wall, constructed from CMUs, designed to disorient the viewer by turning the familiar layout of the school of architecture into something foreign and (un) familiar.

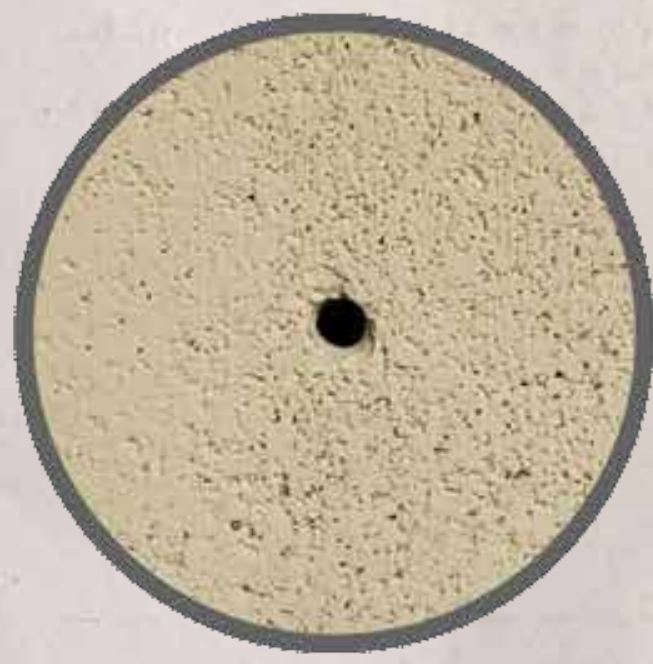

Figure 37. Sonic occuli, through which sound from the abandoned tunnels is transferred.

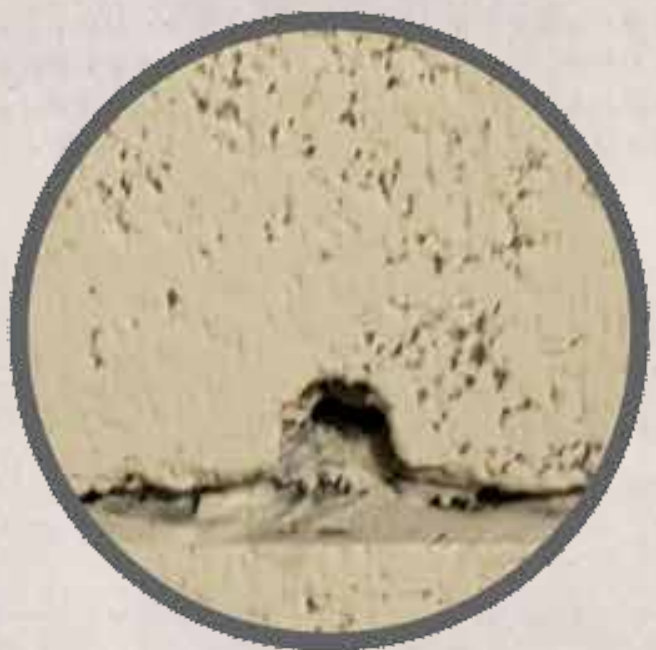

Figure 38. An opening in the wall through the which the movement of cool air from beyond can be felt. 


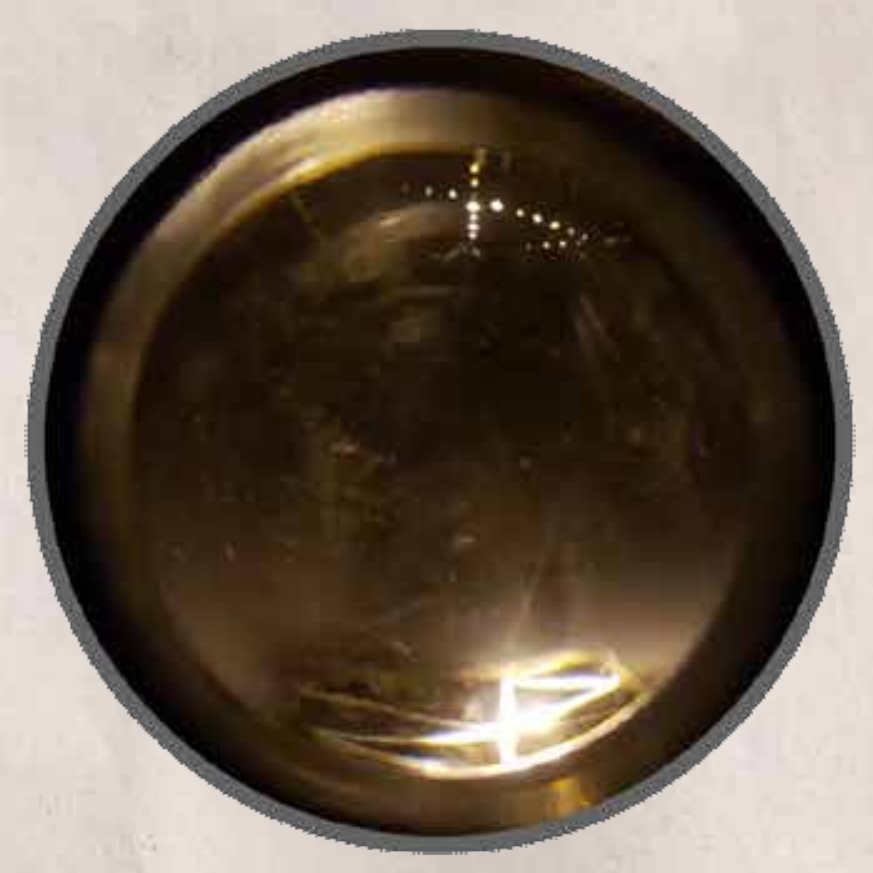

Figure 39. An image of the visualization of sonic and tactile data collected from the sensory probe is depicted through a peep hole in the wall.

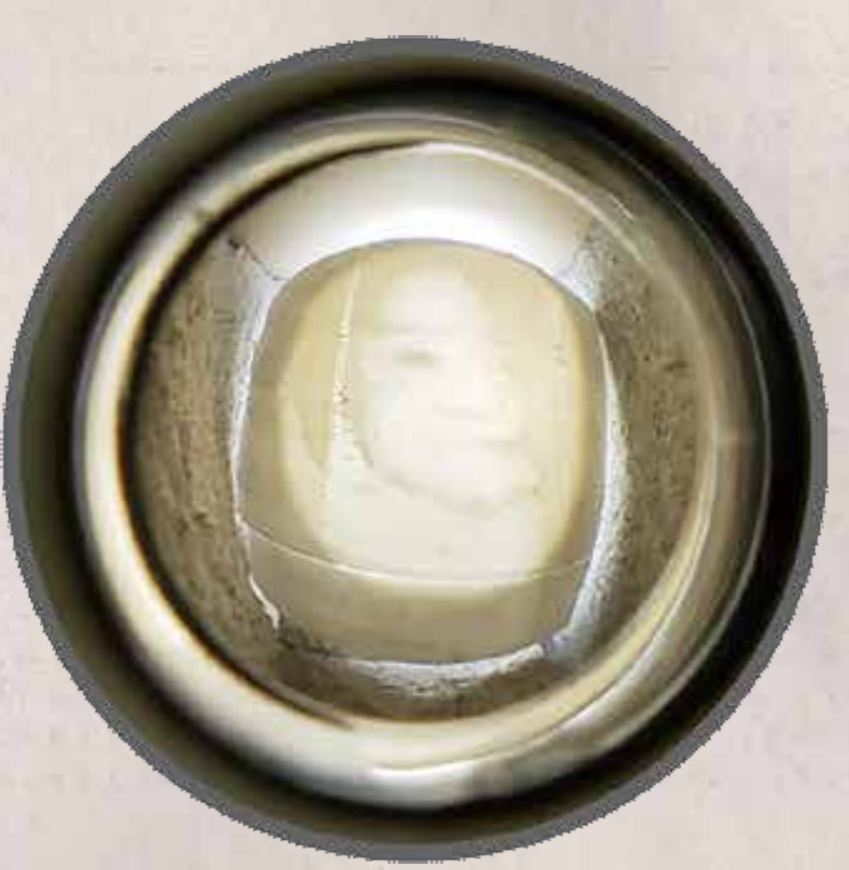

Figure 40. The face of a missing child is $3 d$ printed printed from data recovered via a photograph. 


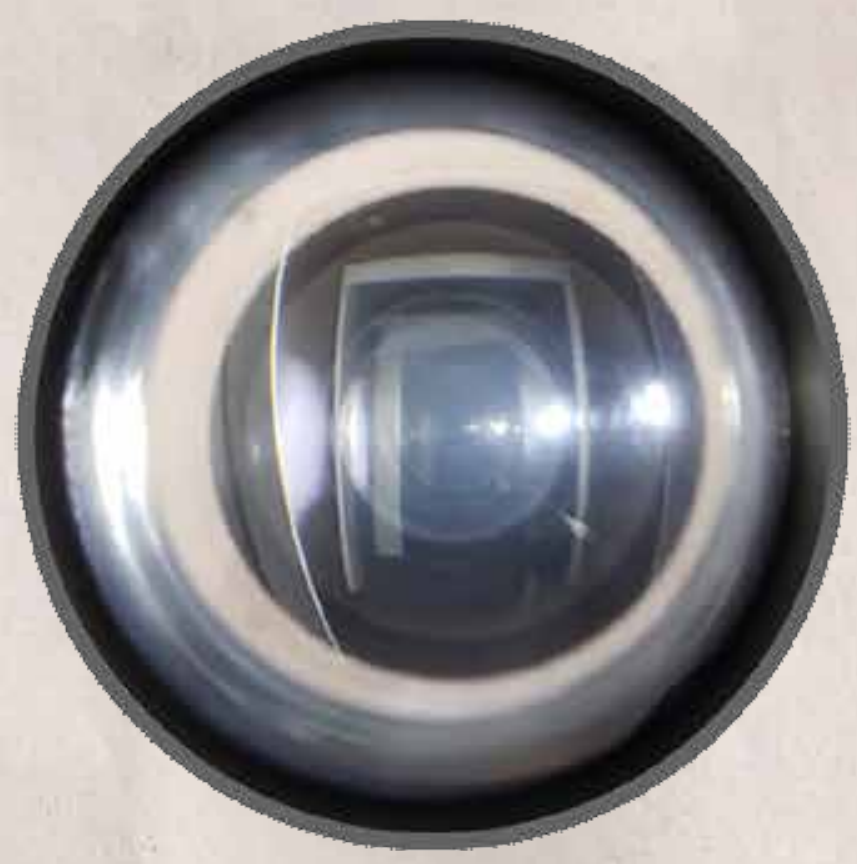

Figure 41. An endless corridor seen beyond the wall suggest the unknown nature of the sprawling expanse of tunnels beneath the campus.

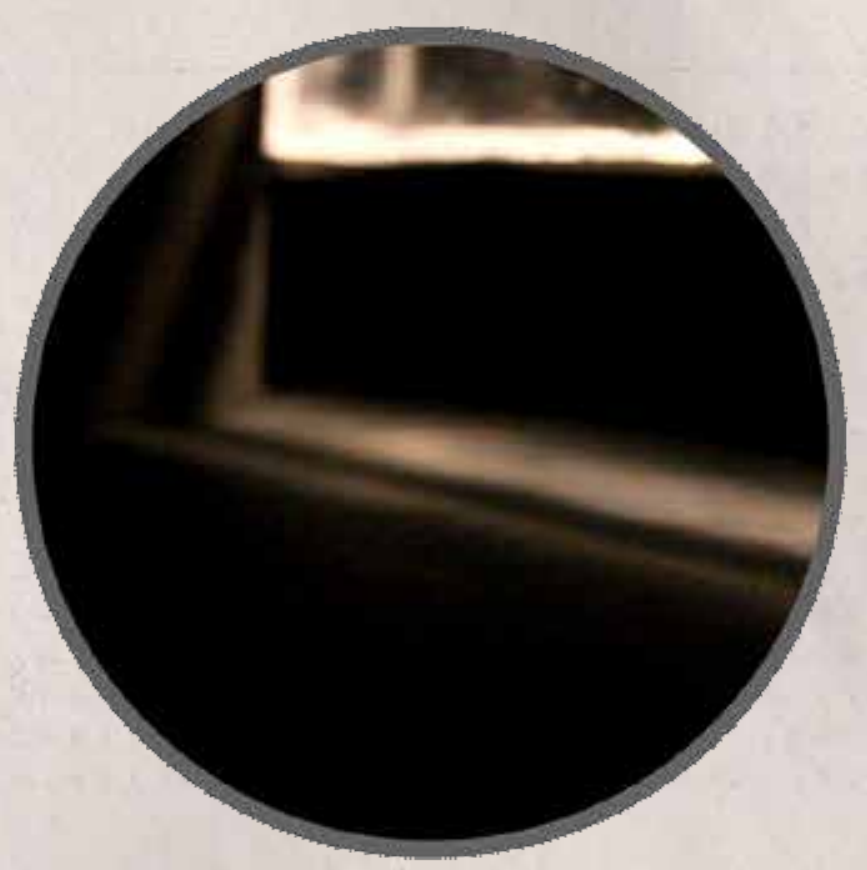

Figure 42. Brief moments of sunlight cast shadows through grates and pipes as this still from a video that played within the wall suggests. 


\section{Benind a Door that Doesn't Exist:}

A Journery fnto the Harrific spaces Beneatin Us

- appendices - 
Beinind a Door that Doesn't Exist:

A Jaurnery Into the Horrific spaces Beneatin Us

- Catalogne of Taols - 


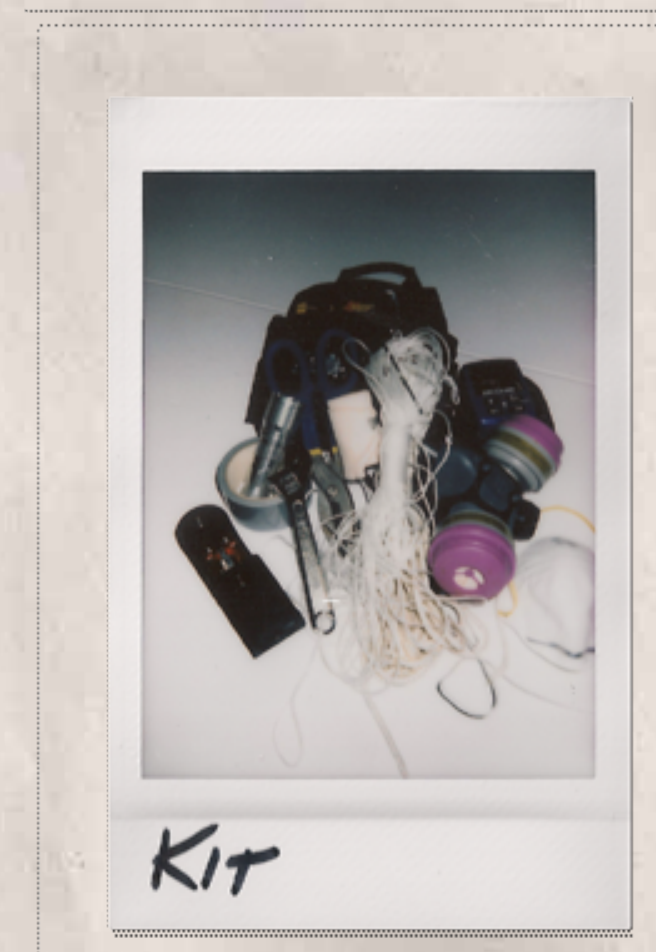

\footnotetext{
ToO王：Kit

Dimensions: Various 5 i $z$ en

Model \#: Varions nubers

Bateries: various
}

Item 万u $\pi$ का

Description: Phis kit includes essential and recommentd

items for the tield explorer in order to obfairackess, record data, and avojedetection. Kit includes: tensox-wrap, nulti-tooj, adjustable hrench, duct tape, Iope 3, Iope 2 , Iespjeator, dust mask, book, srake

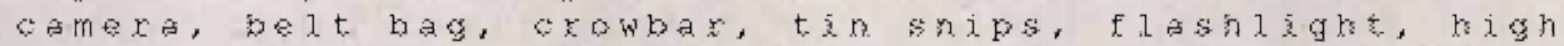
vis ìbility vest, roomba, and sonar device. 


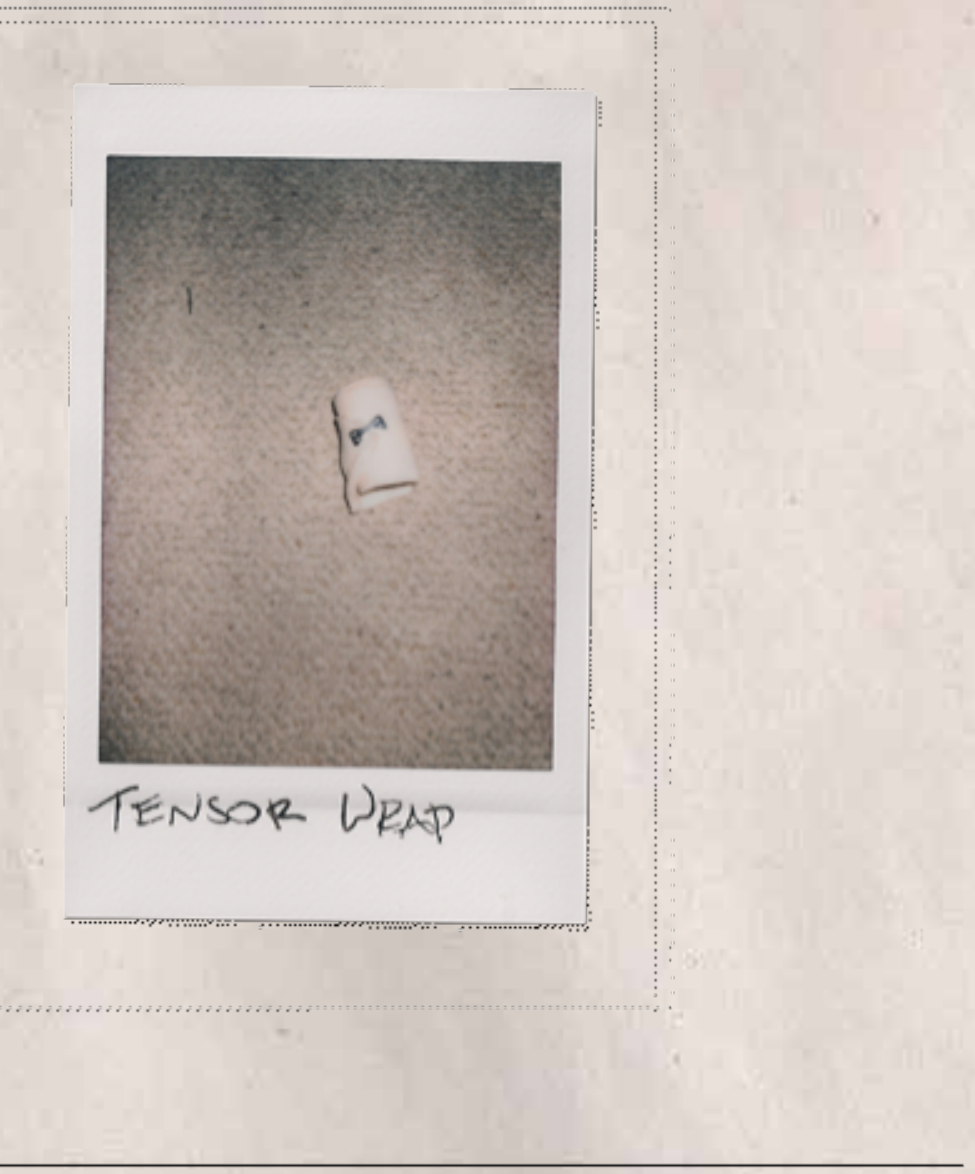

Tool: Tensor Wrap

Dimensions: $3^{\prime} \times 3^{\prime \prime}$

Model \#: n/a

$\mathrm{Bat}$ aties: $\mathrm{n} / \mathrm{a}$

Item 万uther: BDEE - 00 B

Description: Standard elastic tensor bandage. pypically For medical uses. hith splints can be bsed to 5 batilizes sproins and minox distocetions in ankles, knees, wrists, and fìngers. Also used for temporary connections and grip on otherwise slippery surfaces. 


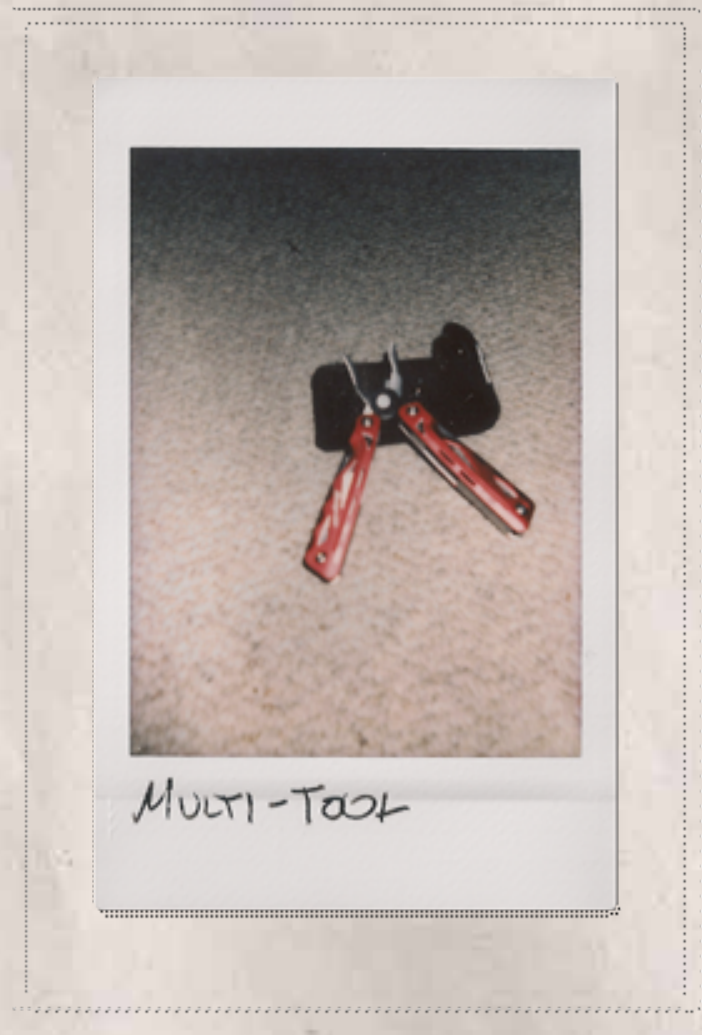

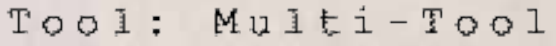

Dimensions: $2.5 " \times 4.5 " \times 1 "$

Model \#: Snap-on $0 \div 63$

Bateries: $n / a$

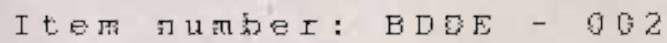

Description: Stainless steel red multi-tooj with carrying case. Tools irclude: pjiers, saw, knjete, bottle operer,

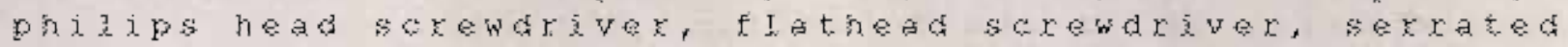
knife, file, roper cuttex. Compact design and aultiple uses Ieduces overall weight Exom tooj bej. Hardy for

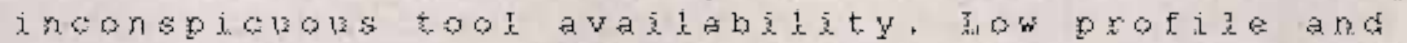
commonality reduce suspicion. 


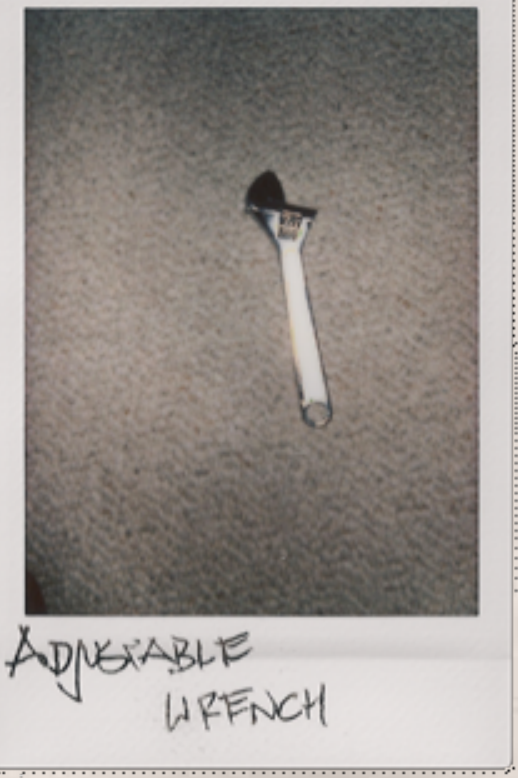

Tool: Adjustable wrench

Dimensions: " " $^{\circ} 2$ "

Model \#: BM B-200

Bateries: n/a

Item 万uther: BDEE - 003

Description: Stainless steel benchmaxk adjustable $200 \mathrm{~mm}$

wrench. omm-25mm molth size. Verts and grates ofter

secuxed by hexagonat-keaded bojts making this topl

perfect for accessirg smali recessed spaces. 


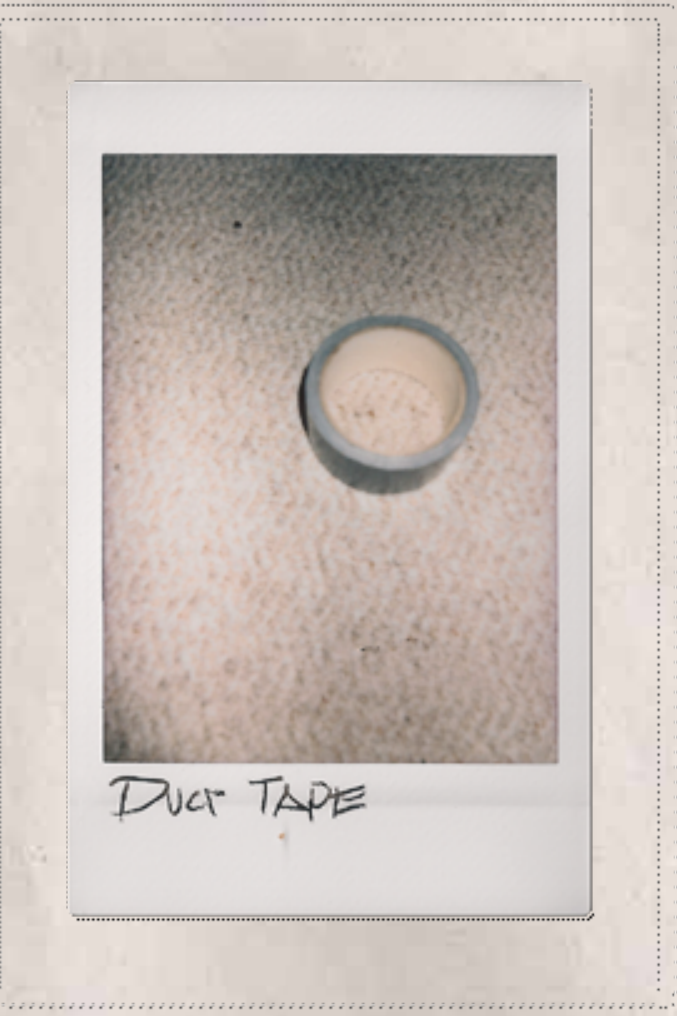

Tool: Duct Tape

Dimensions: $4^{n}$ diameter

Model \#: n/a

$\mathrm{Bat}$ ateries: $\mathrm{n} / \mathrm{a}$

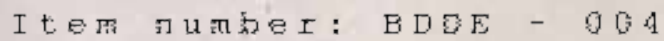

Description: Duct tape. Sojves an unbejievabje spectín

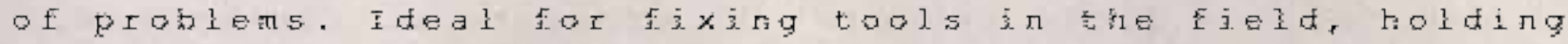
open doox and tocks, gffixing scxeens ovex camexas and windows and silercing the sound of thoes on concrete. 


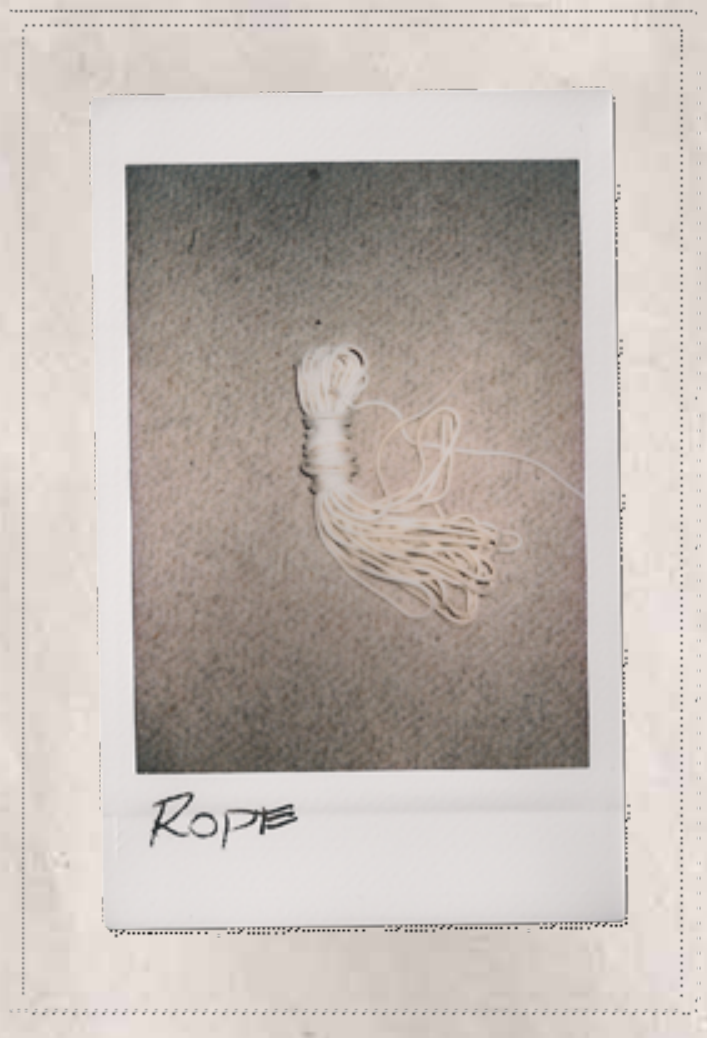

\section{TOOI: ROPE \\ Dimensions: $3 /{ }^{\prime \prime}$ diameter $15 \mathrm{~m}$ length \\ Model \#: n/a \\ $\mathrm{Bat}$ ateries: $\mathrm{n} / \mathrm{a}$}

Item 万u $\pi$ the I: BDEE - 005

Description: Fope for lashing, chimbing, tieing of holding shut. Handy to have arinexpensive rope at your disposal that can be left benind if needed, sturdy exolgh to climb up or down is needing to access a difficult location in the Eield. Can ajso be used hojd doors ard entaywas oper, to ensure exit, or dzosed, to ensuxe Dxivacy 


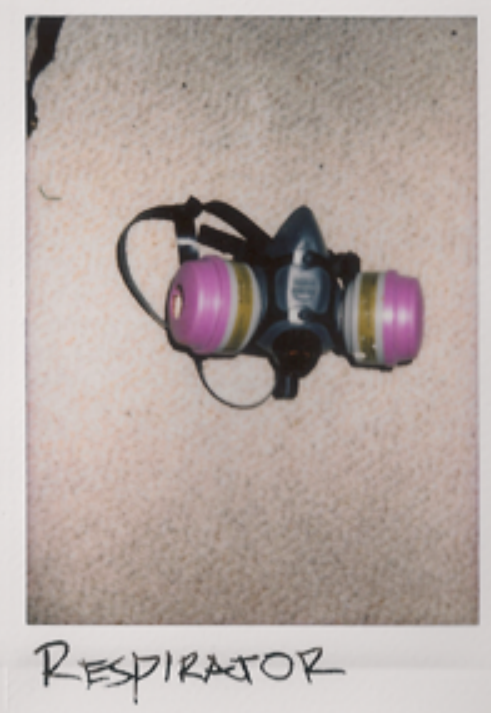

Tool: Respirator

Dimensions: Lower face, adjustable

straps

Model \#: $5500-30 \mathrm{~m}$

Bateries: $n / a$

Item กuther: BDEE - 006

Description: North bxand painters respirator to renove particles ard fumes from breathing aji when exposed to

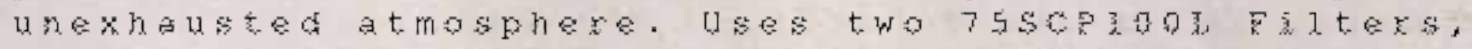
affixed to the front. Rated:

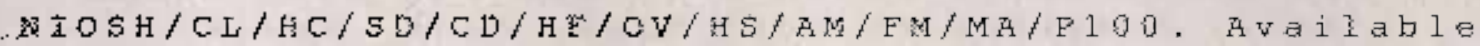
access roptes often jrexube sexvoe zines and abandored pathnays. Toxins and dust often present. Recomend to

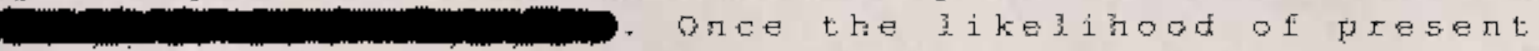
toxins is detexmined, the wsex con moke a judgement on whether the usage of the mask is required. 


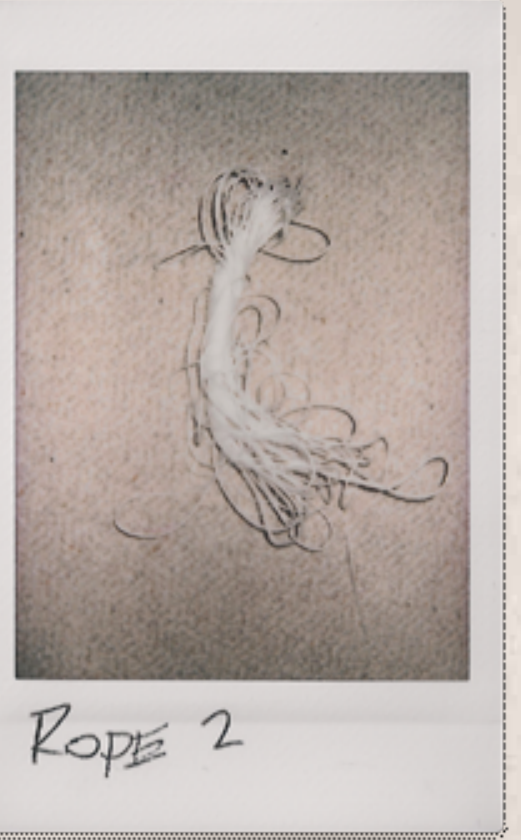

ToOI: ROpE 2

Dimensions: $1.8^{\prime \prime}$ dimeter, $30 \mathrm{~m}$

length

Model \#: त/ a

Bateries: $\mathrm{n} / \mathrm{a}$

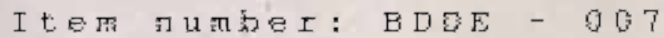

Description: Small piatsic cord for affixing to the sensory probe. Used to gide the probe hadk to the depzoyment site via a "yenking motion. Qujokly gujang the probe back through the labyrinth being mapped to the depjoyment site can be essertial in avoiding defection and an ensine retention of probing device sholid is become stuck while napping. 


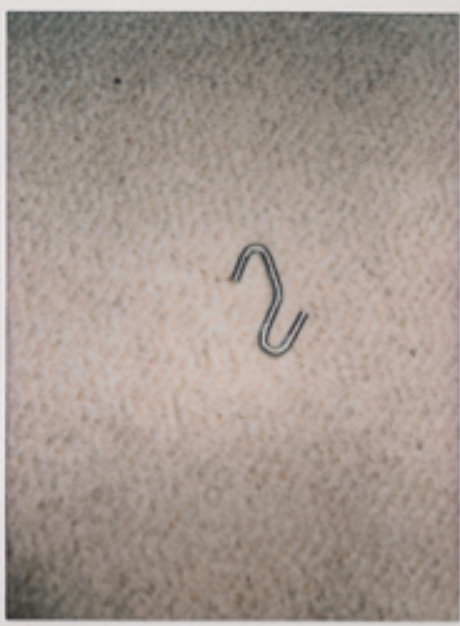

Hook

008

Tooli: Hook
Dimensions: $2^{\prime \prime} \times 3^{\prime \prime}$
Model \#: n/a
Batteries: $\mathrm{n} / \mathrm{a}$

Item пuther: BDEE - 00 B

Description: Small metal hook. Can be used in addition to rope in order to act in plade of crowtar. Frovidingless levexage when pliting blt is moxe conceazable on oners persor. Can also be used to attach a rope to arout of reach location by afixing to ore end of the rope and lourchig it to tre desined jocation. 


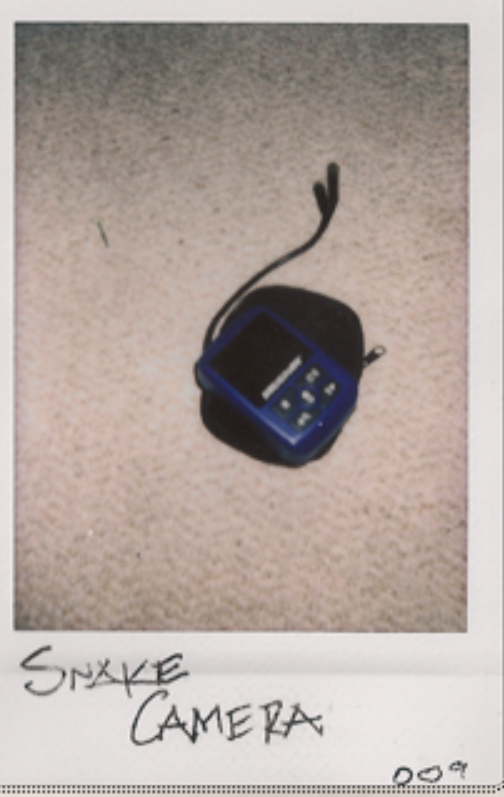
Tool: Snake Camera
Dimensions: 5 " $\times 4$ " $\times 1$ "
Model \#: 050080C
Bateries: $3 \times A A A$

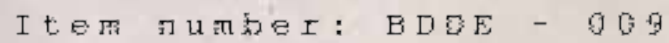

Description: Vaughan Digital Video Inspection Canera.

Intended tor inspectirg the jriside of venzs and wall to

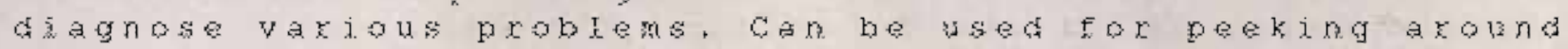
corners and investigation potential access sìtes in the Fiela. Cońairs Flashijgt furetion for added visjbility दी snake arm leлgth: $45 \mathrm{~cm}$. 


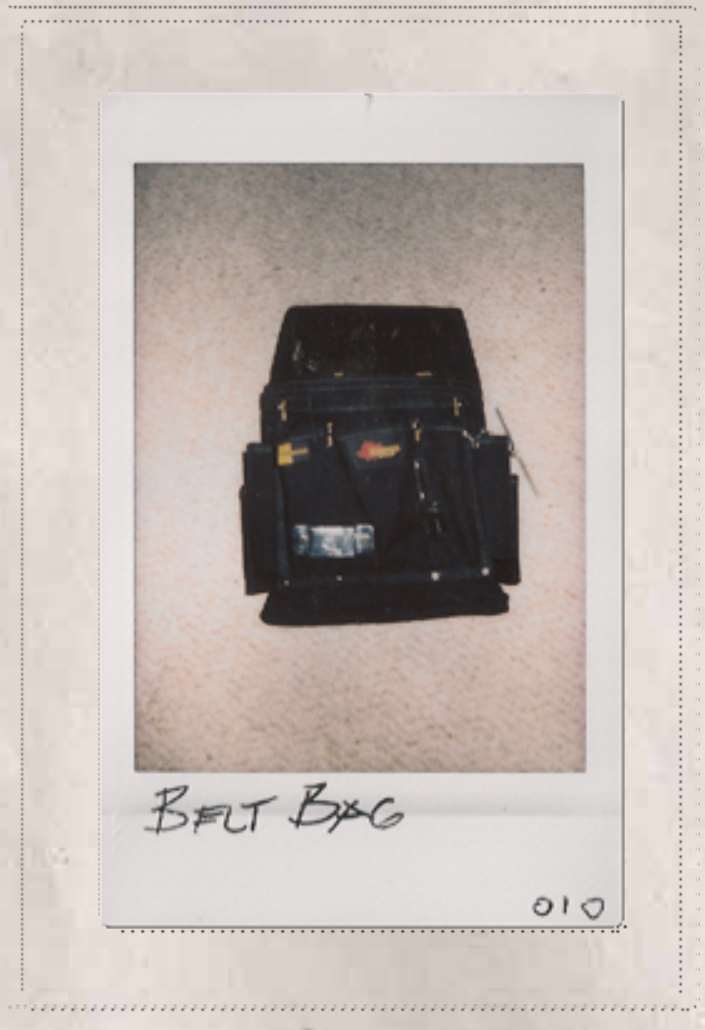

Tool: Beit Bag
Dimensions: $12^{\prime \prime} \times 9^{\prime \prime} \times 6^{\prime \prime}$
Model \#: 04T-027B603
Batteries: n/a

Item пU

Description: Belt bag for easy access of a kit. While it sits heavy on the bejt and reduces motilisy

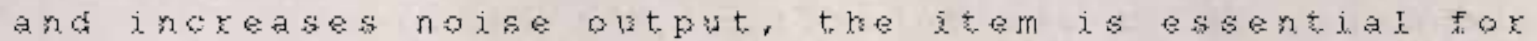
b3ending in during dayight hours and in

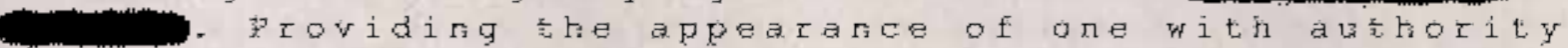

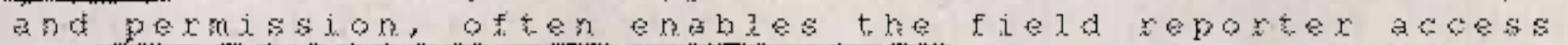
to

$-03.5$ Thm Best paired with BDDE a i $d$ apathy. 


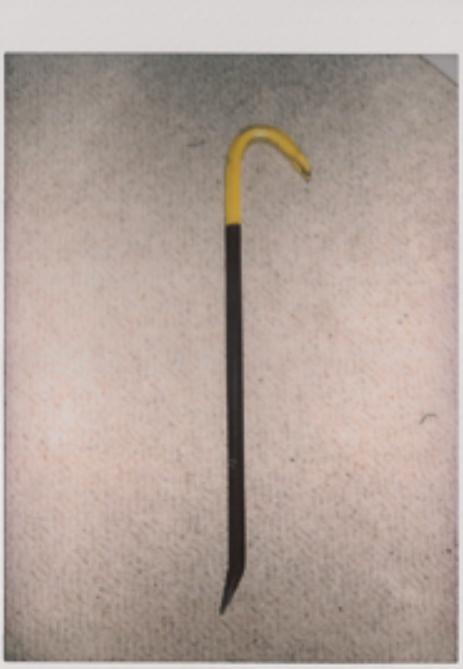

Crow BAR

$0 \ell l$

Tool: Crowbar

Dimensions: 2.5'

Model \#: n/a

Bateries: $\mathrm{n} / \mathrm{a}$

Item пu此 I : BDEE - 13

Description: Dewalt crowbar. Standard uses include

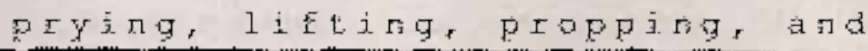




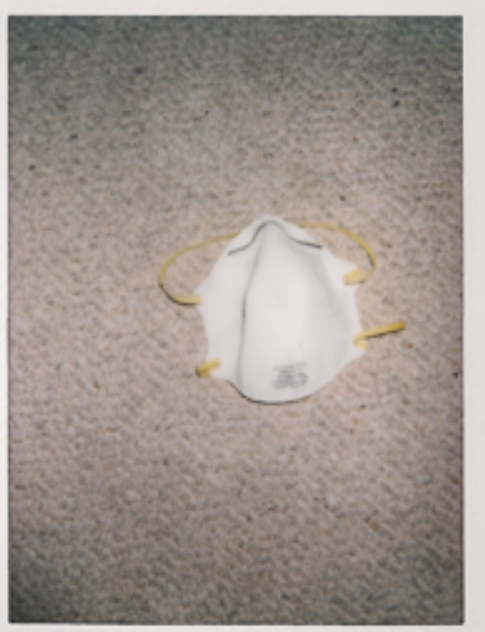

\section{FACE MASK}

012

\footnotetext{
Tool: Dust Mask

Dimensions: Lower Face

Model \#: MCD-66-9

Bateries: $n / a$
}

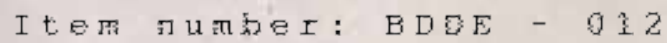

Description: Standard lower face dust rask, ratedi kísh,

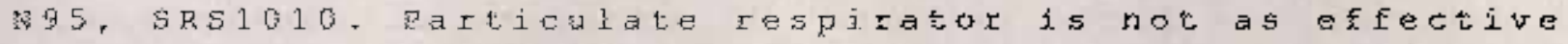

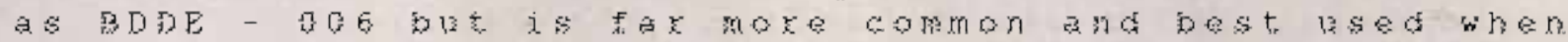
operating and performing tield work in higher traffic areas. Draws less attention wher sasceptis eye site. 


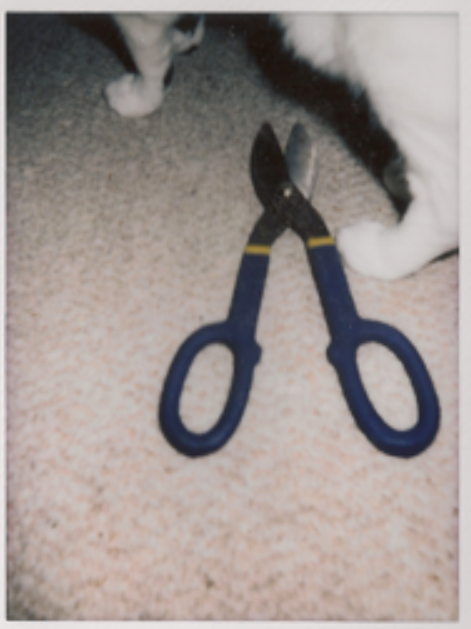

\section{SNIPS}

(AND KITY)

$$
013
$$

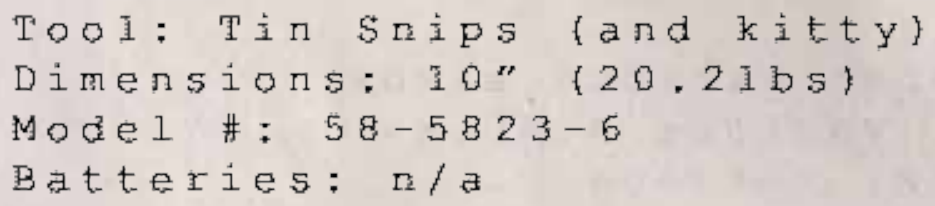

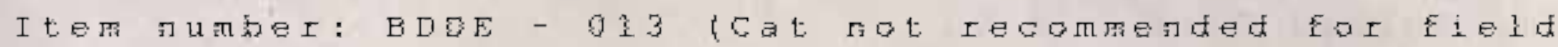
work

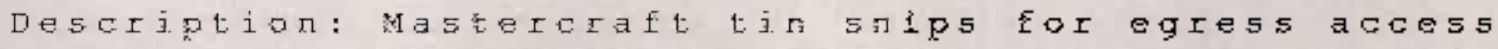
through chajn link and sajkg gouge security fences. company is not recondended during field work but can prove fo be ar exoelsent companion when assessing the dita necovexed fxom the site visists 


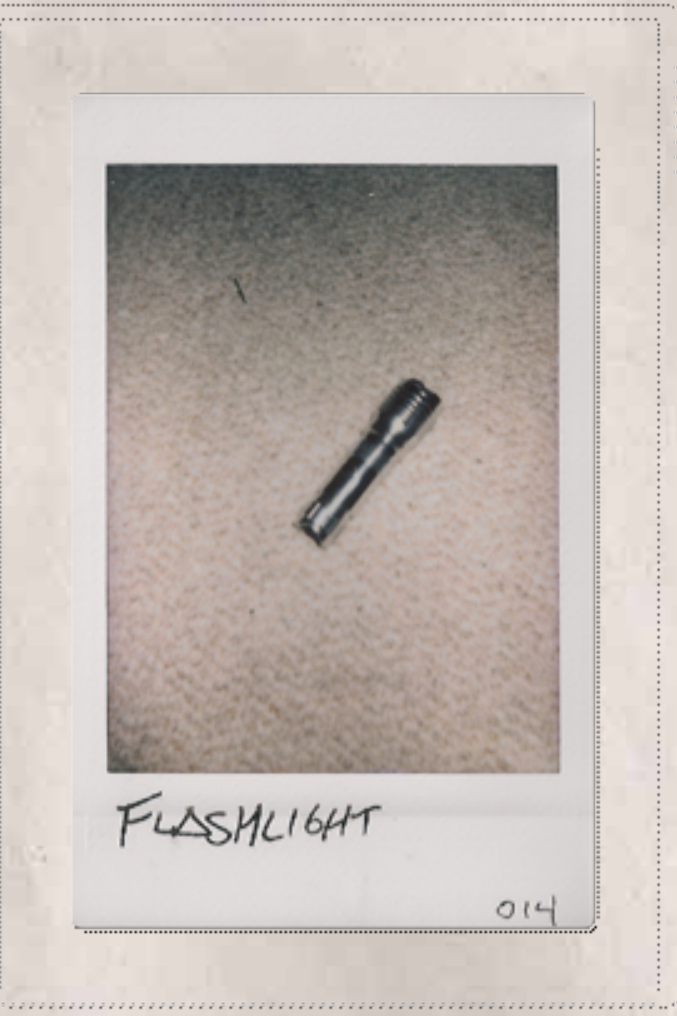

Tool: Fiashlight

Dimensions: $6^{\prime \prime}$

Model \#: 350

Bateries: $4 \times \mathrm{AAA}$

Item 万uther: BDEE - 014

Description: Compact duracelj EED flashlight. Can tocus or broader lightway for di

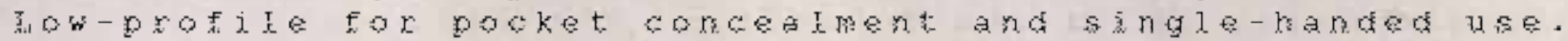
single operation button for ease of dousing.

Instantaneous removaj of light source without havirg to

fumble thxolgh mutiple zight-jntensisy zevezs is

recomerded in order to 

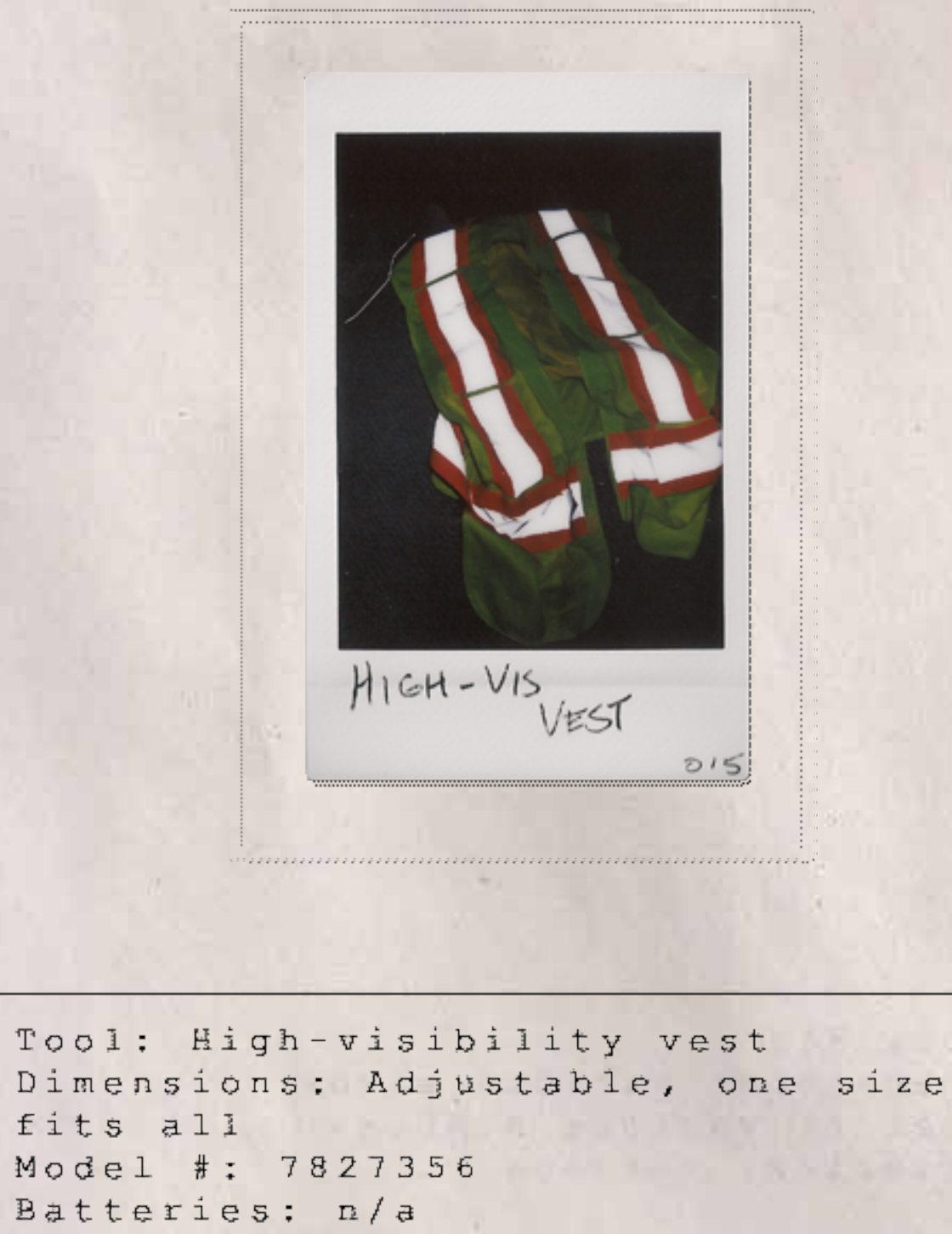

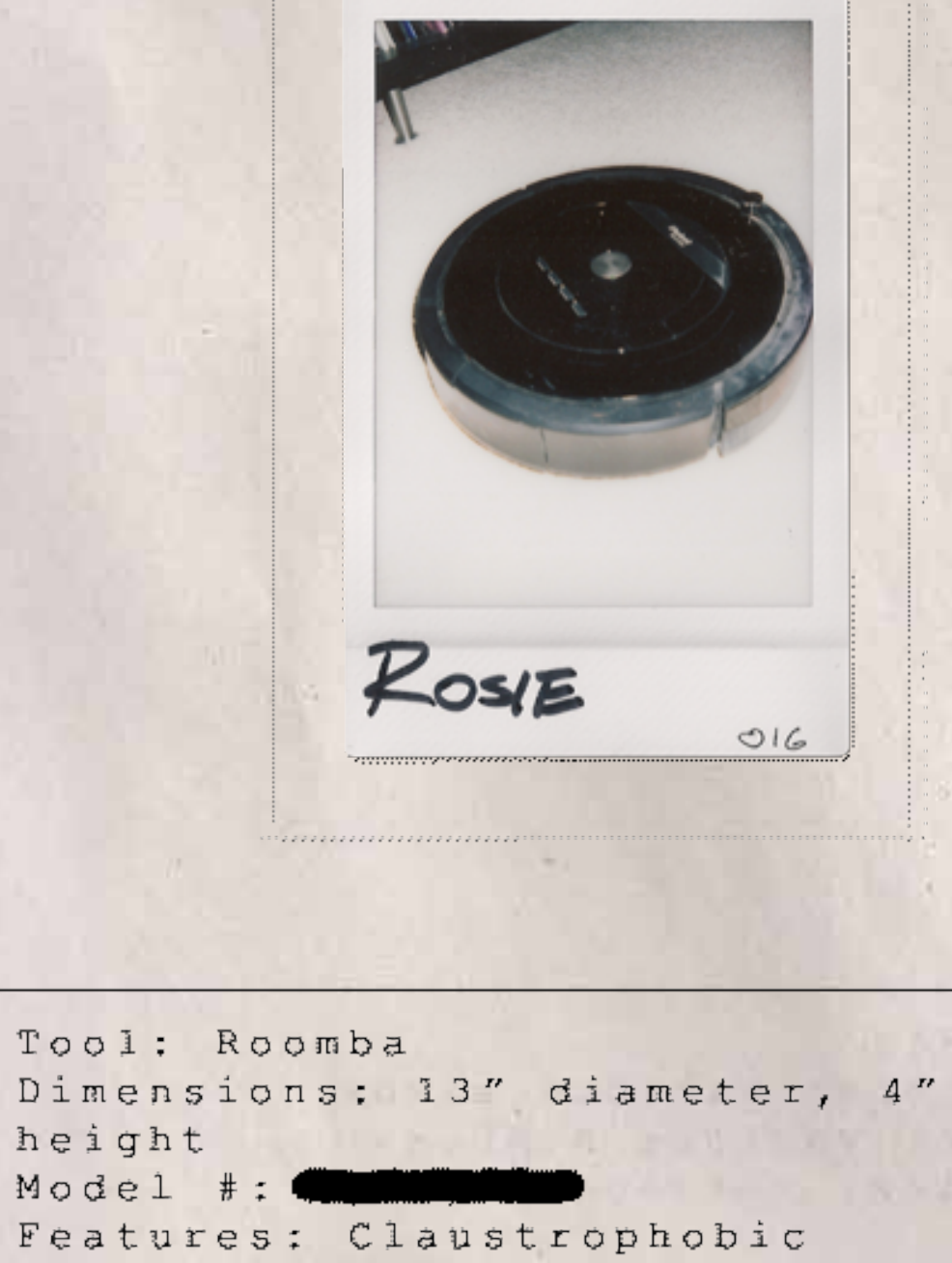

ToO1: Roomba

Dimensions: $3^{\prime \prime}$ dimeter, 4 "

he is $\mathrm{g}$ t.

Model \# :

Features: Clatstrophobic

Item 万uther: BDEE - 016

Description: Foomba used for accessing areas where opening is too small for explorex. Collects samIes of

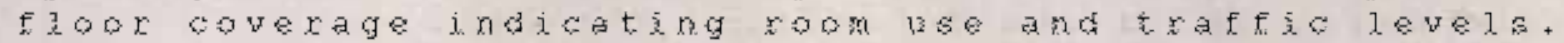
Data received after connecting to base can be used to

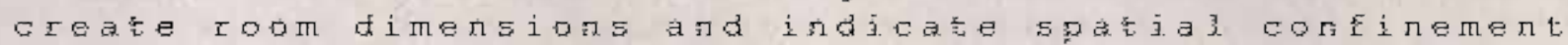
and obstrutions. When connecting to the dock, 


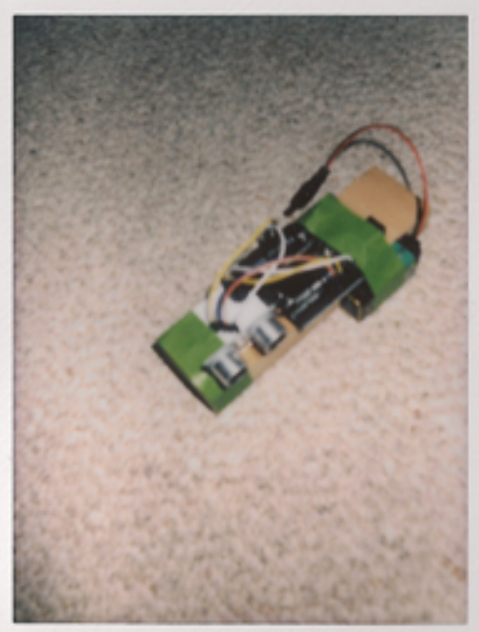

\section{SONAR}

017

Tool: Sonar device

Dimensions: $6^{\prime \prime} \times 3^{\prime \prime} \times 2$ "

Model \#:

Bateries: $9 \mathrm{~V}$

Item 万uther: BDEE - 017

Description: Sonar device using Arduino coding, u立rasoric sersor, and beeper. Fhe $50 \pi$ ar devide, wher

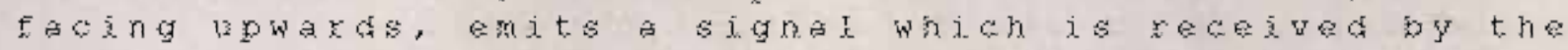
sensor after bumping off of the ceiling. The data is coljected and can later be processed to determine appoximate ceiting hejghts of obstructed frea when instailed on the bagk of the roofba, creating the sensory probe. Code arid face car be accessed via 
Beinind a Door that Doesn't Exist:

A Jaurnery Into the Horrific spaces Beneatin Us

- Index of Folaroids - 

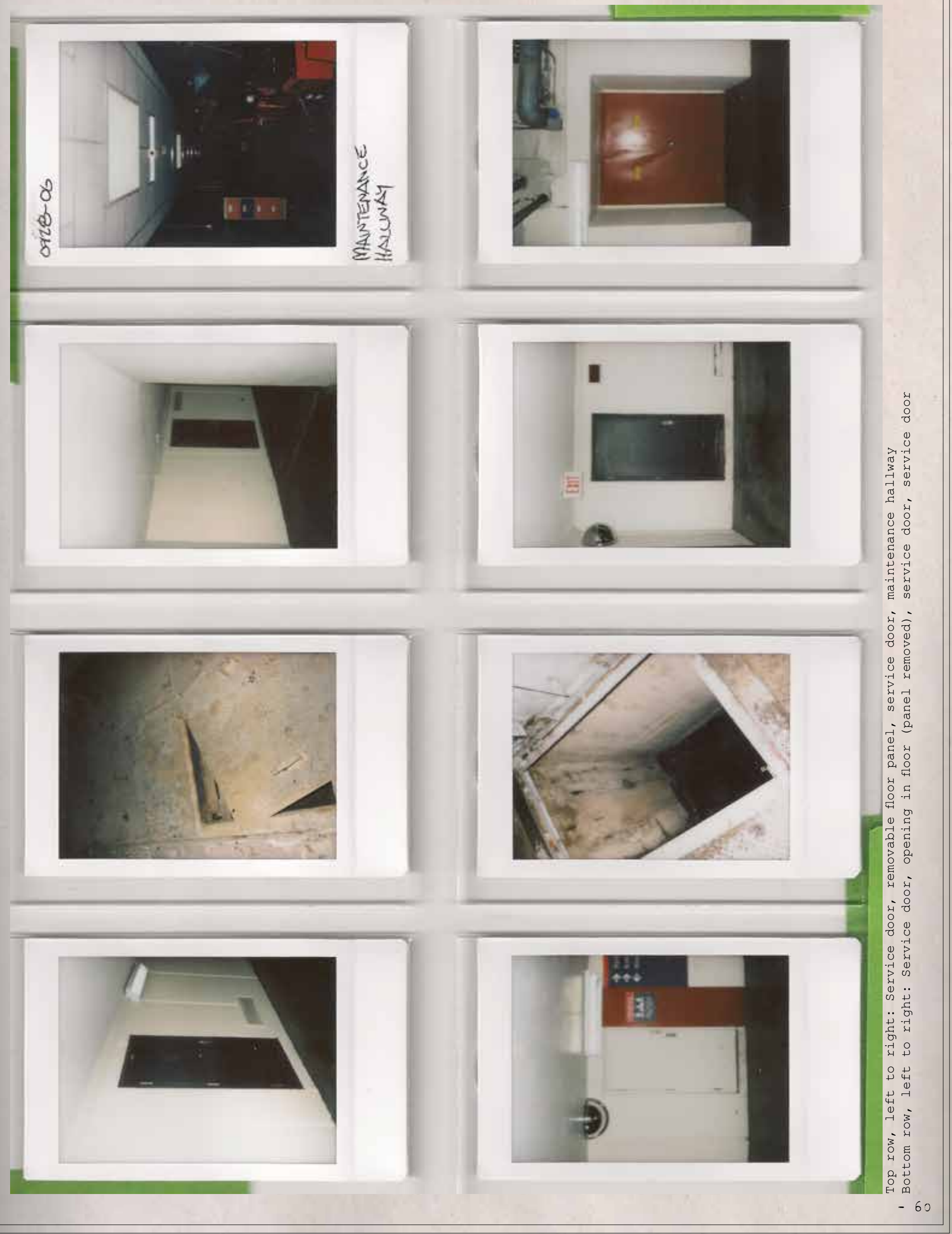


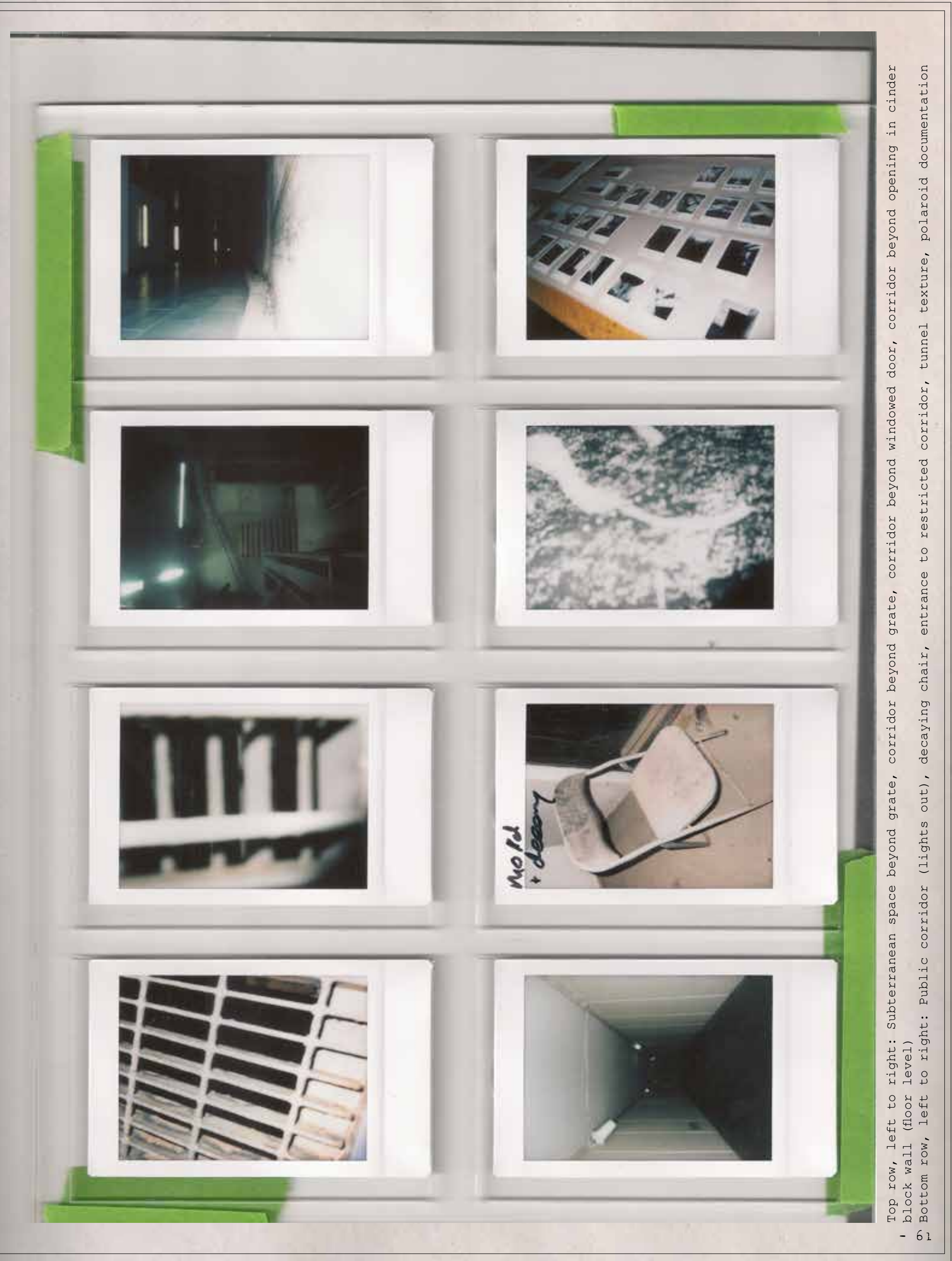




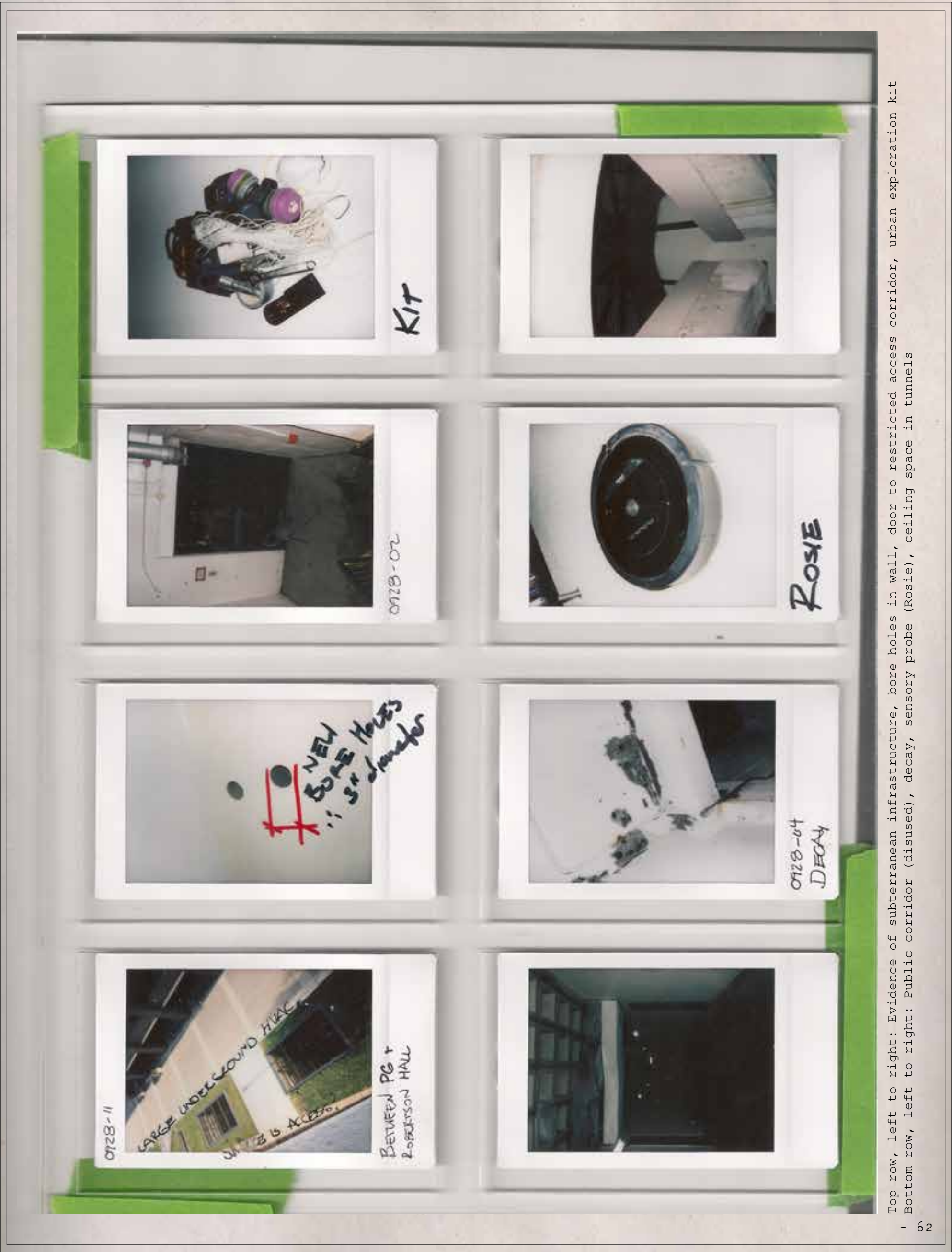




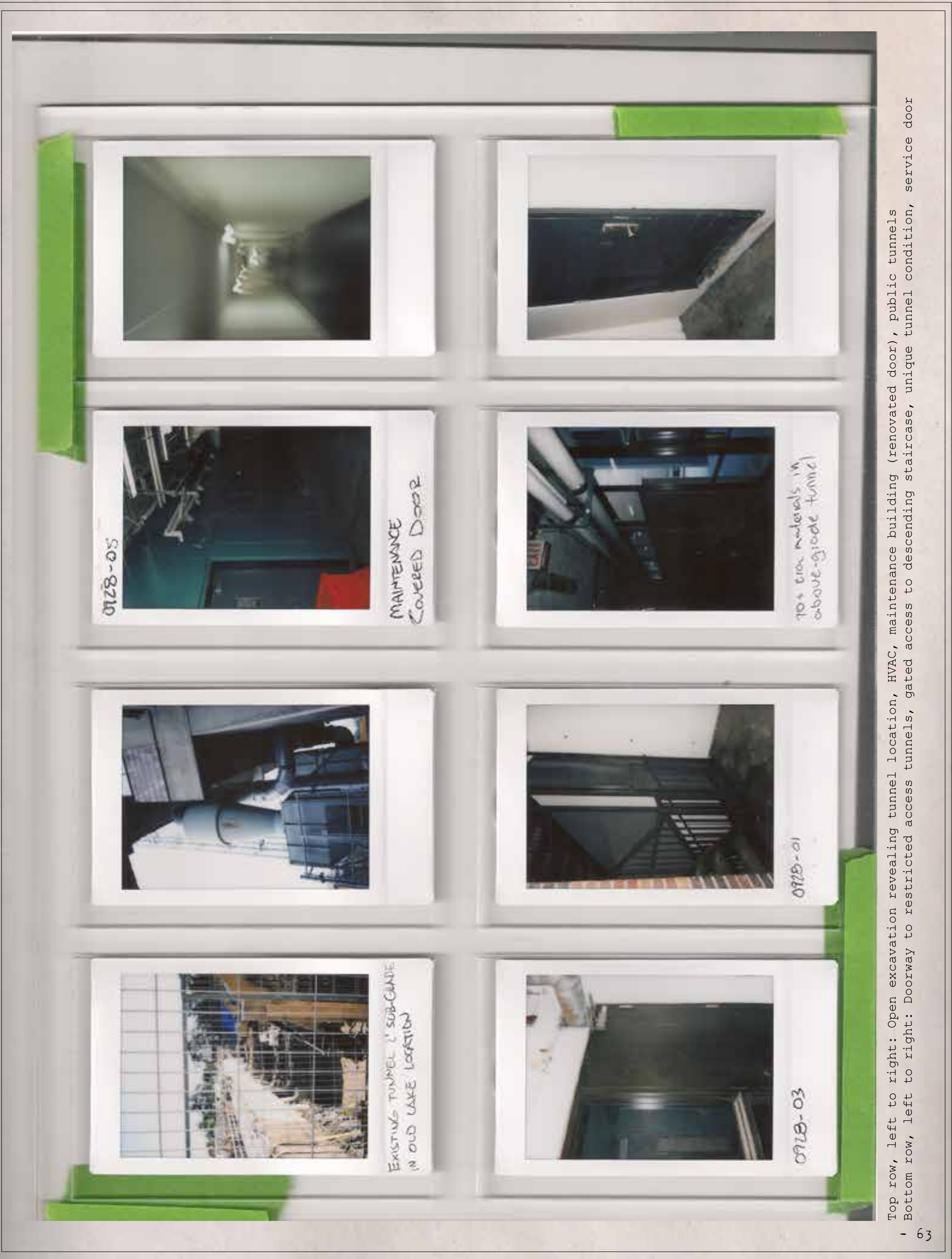



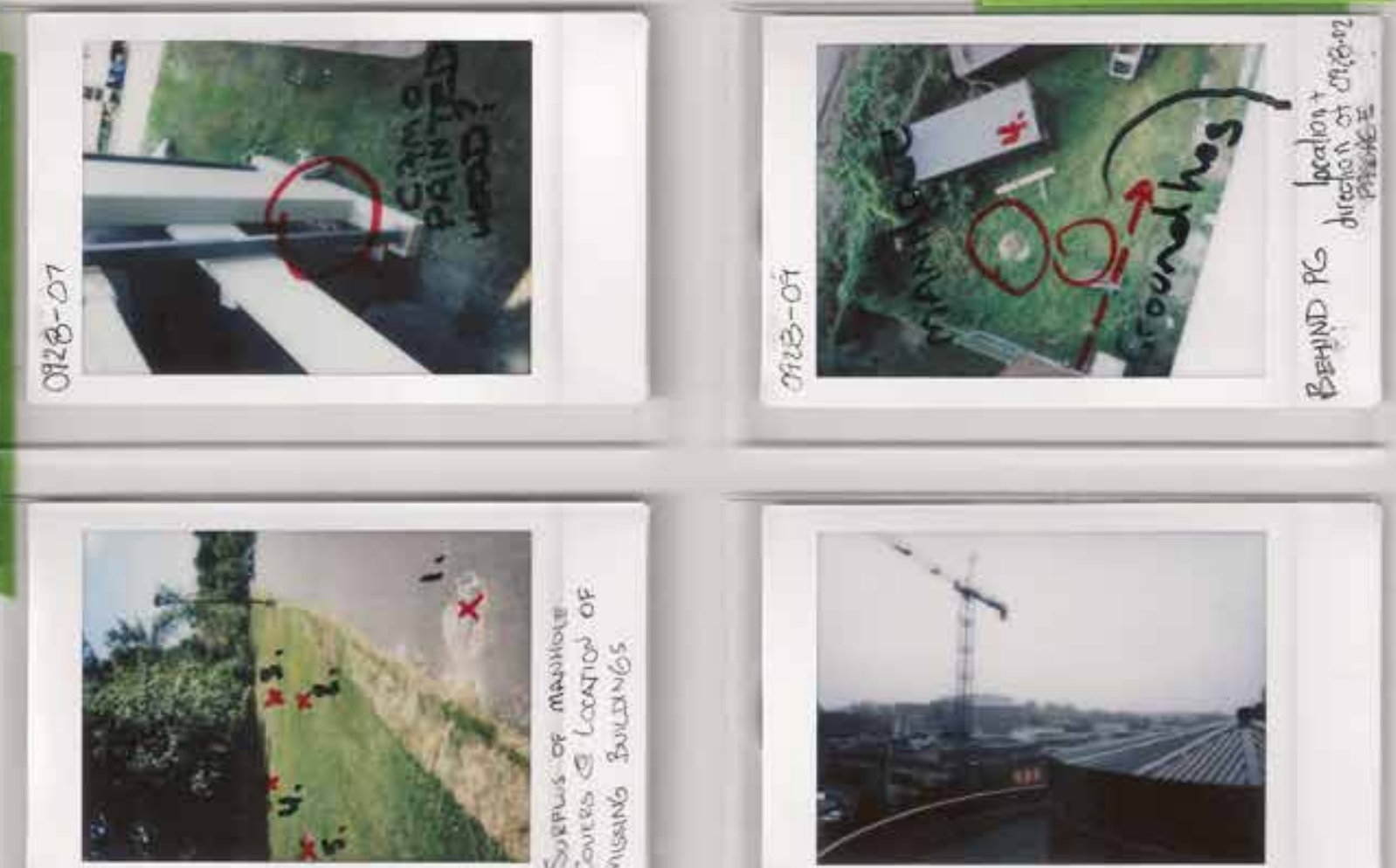

30

争

है 32

8 of

तै

$\frac{3}{2} 8 \frac{2}{3}$
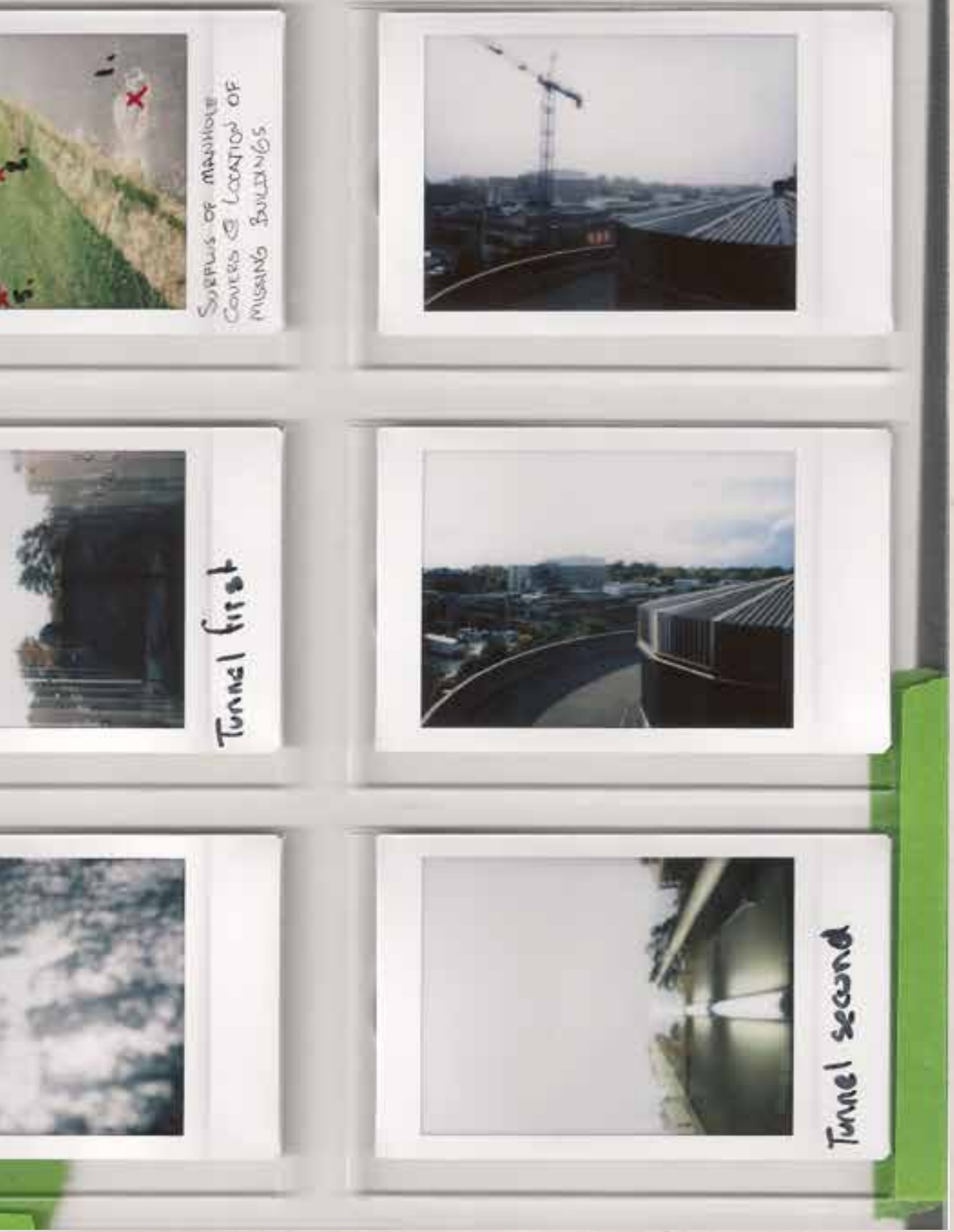

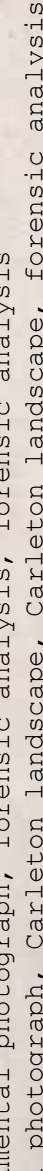

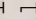

4.

ब

is

दै से

๑ ..

.. हू

त्

군우

$+\underset{4}{4}$



$\stackrel{-1}{\circ}$ 


\section{踏

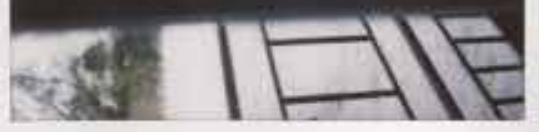
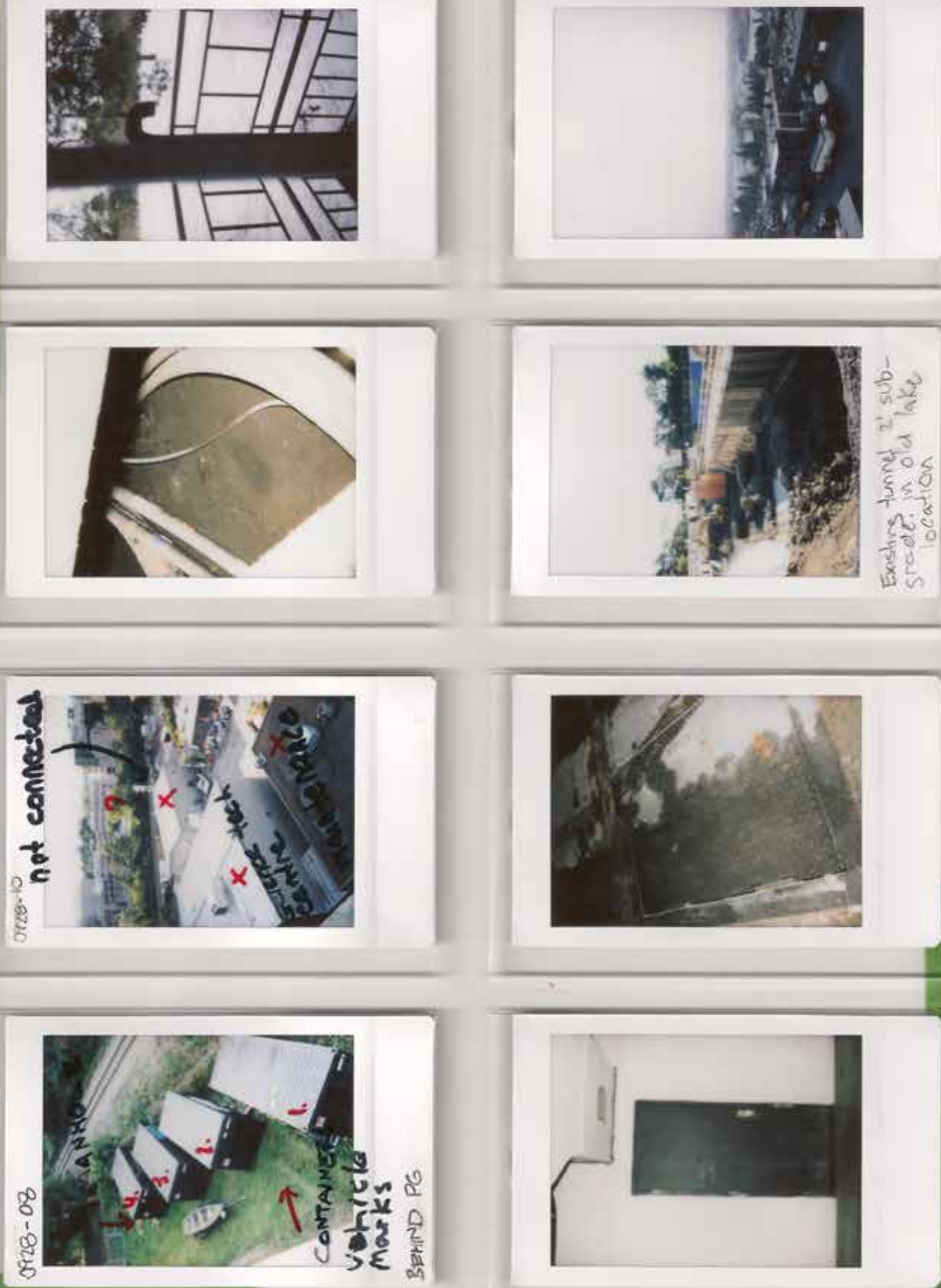


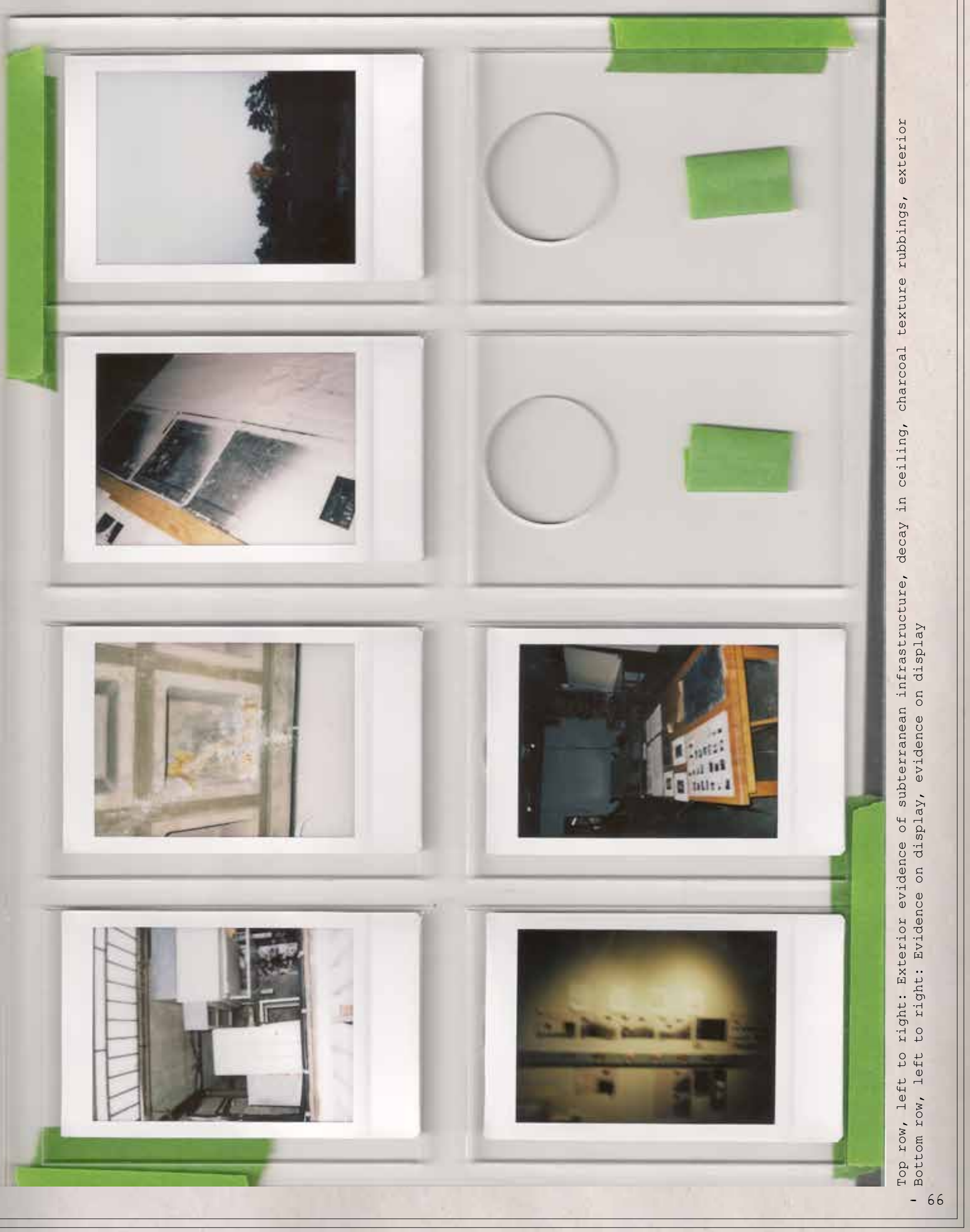



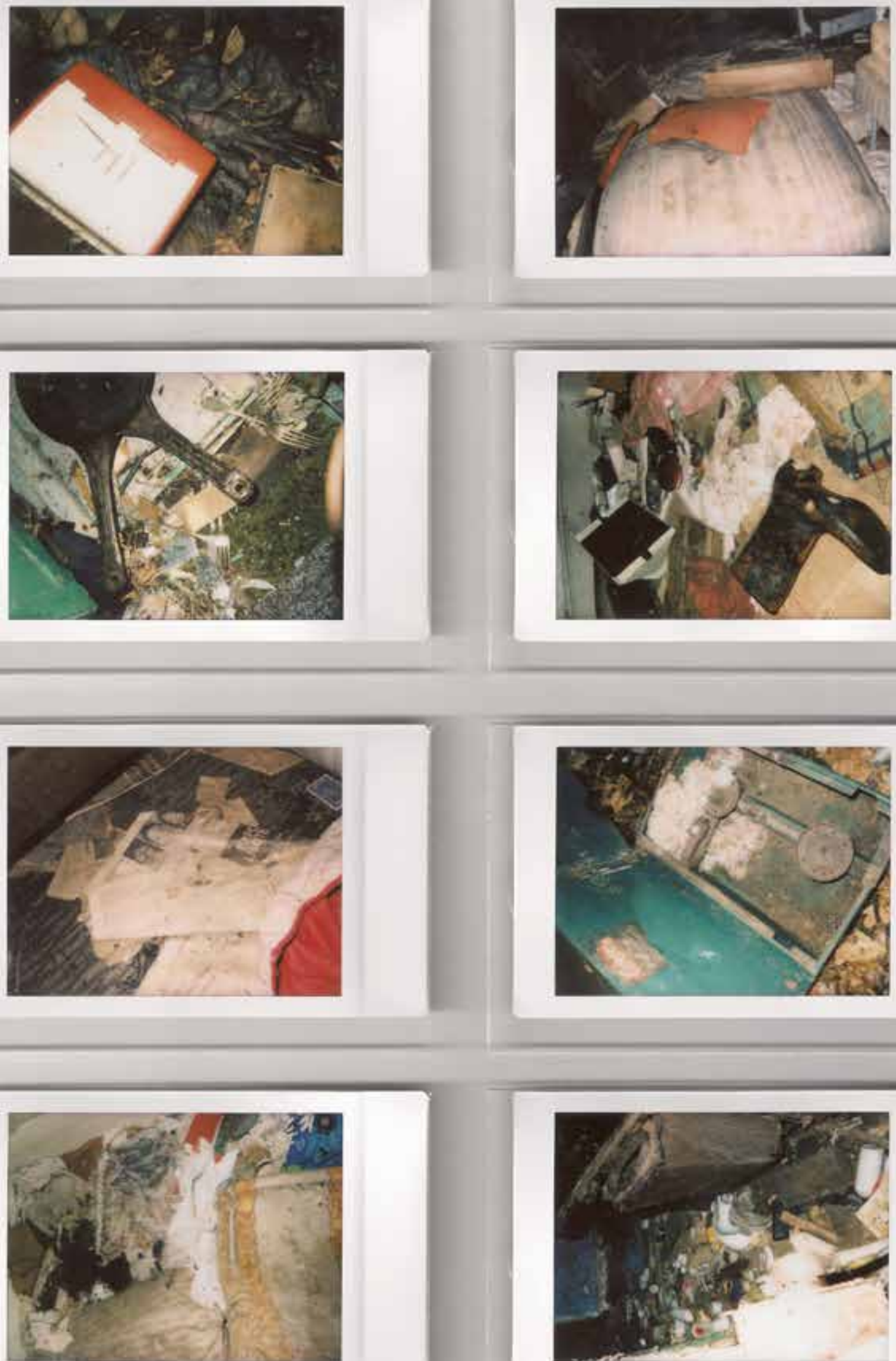

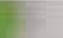



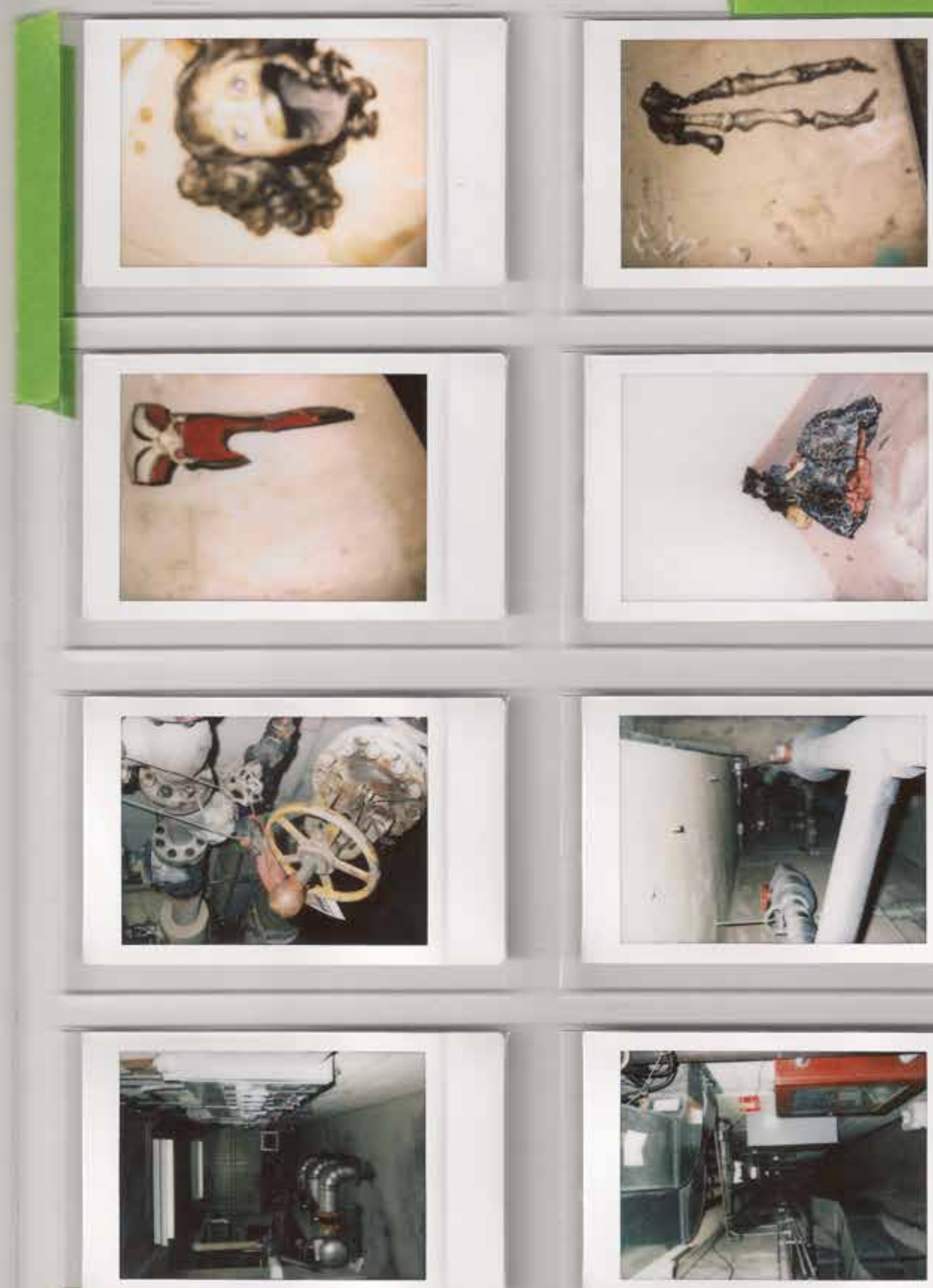


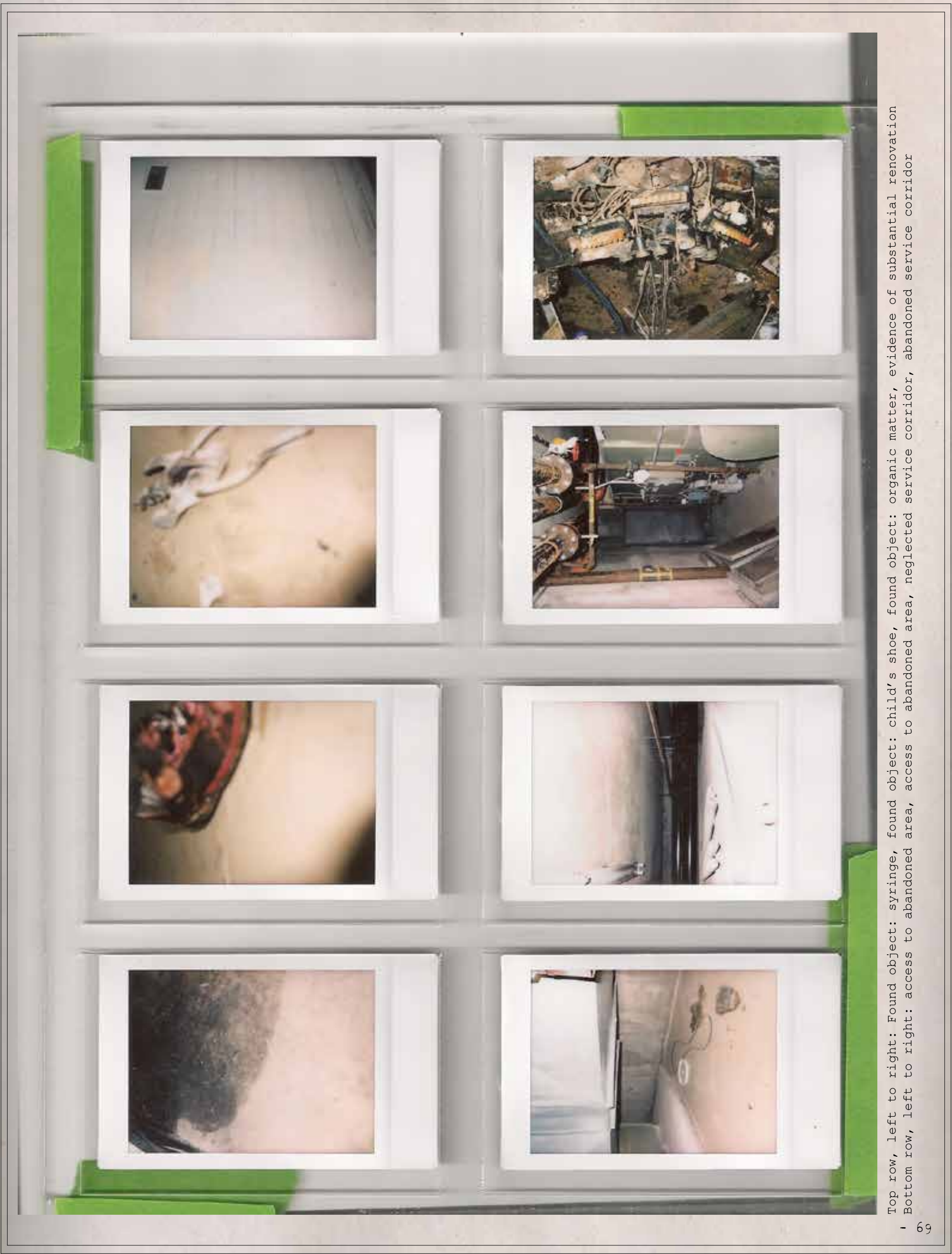



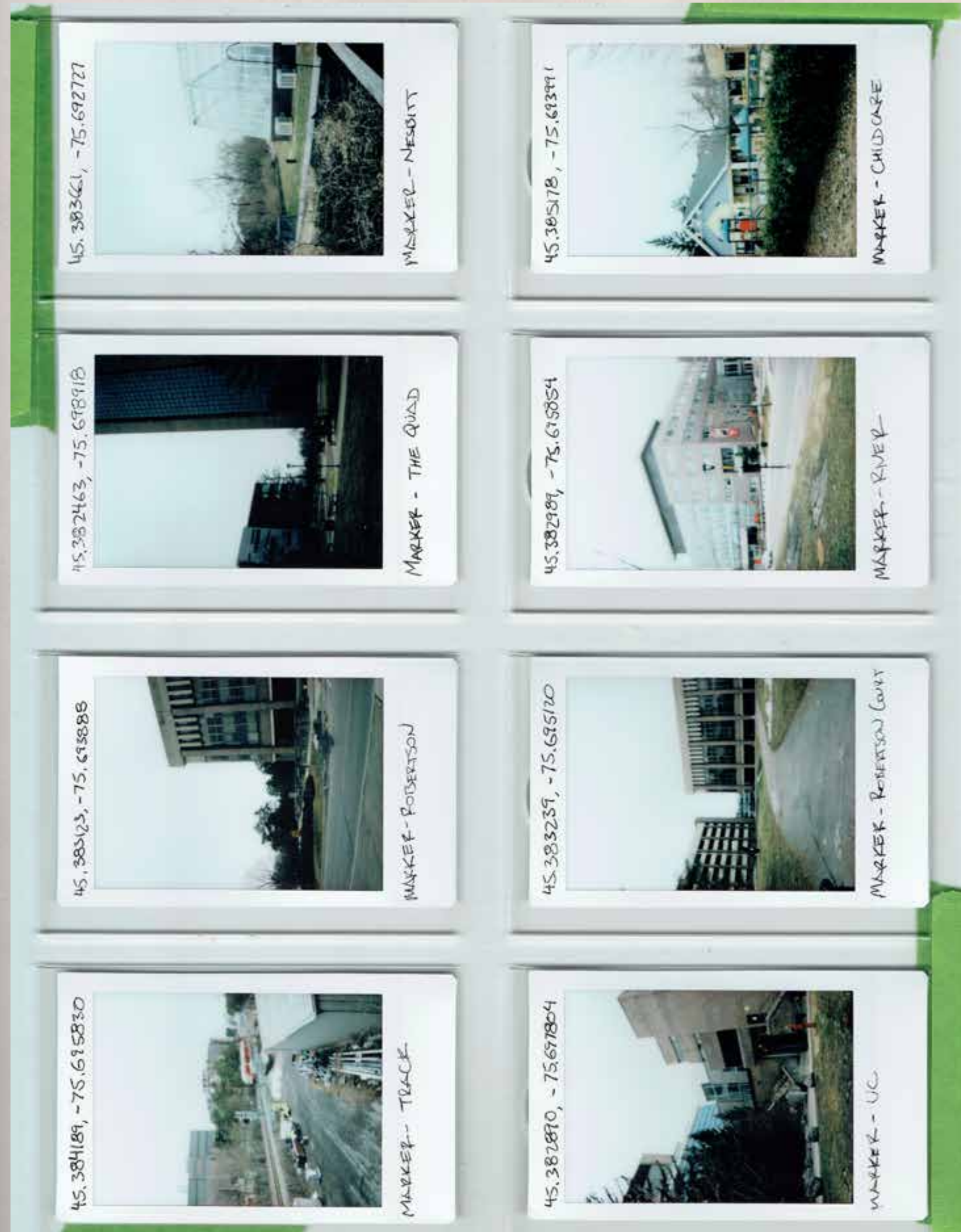

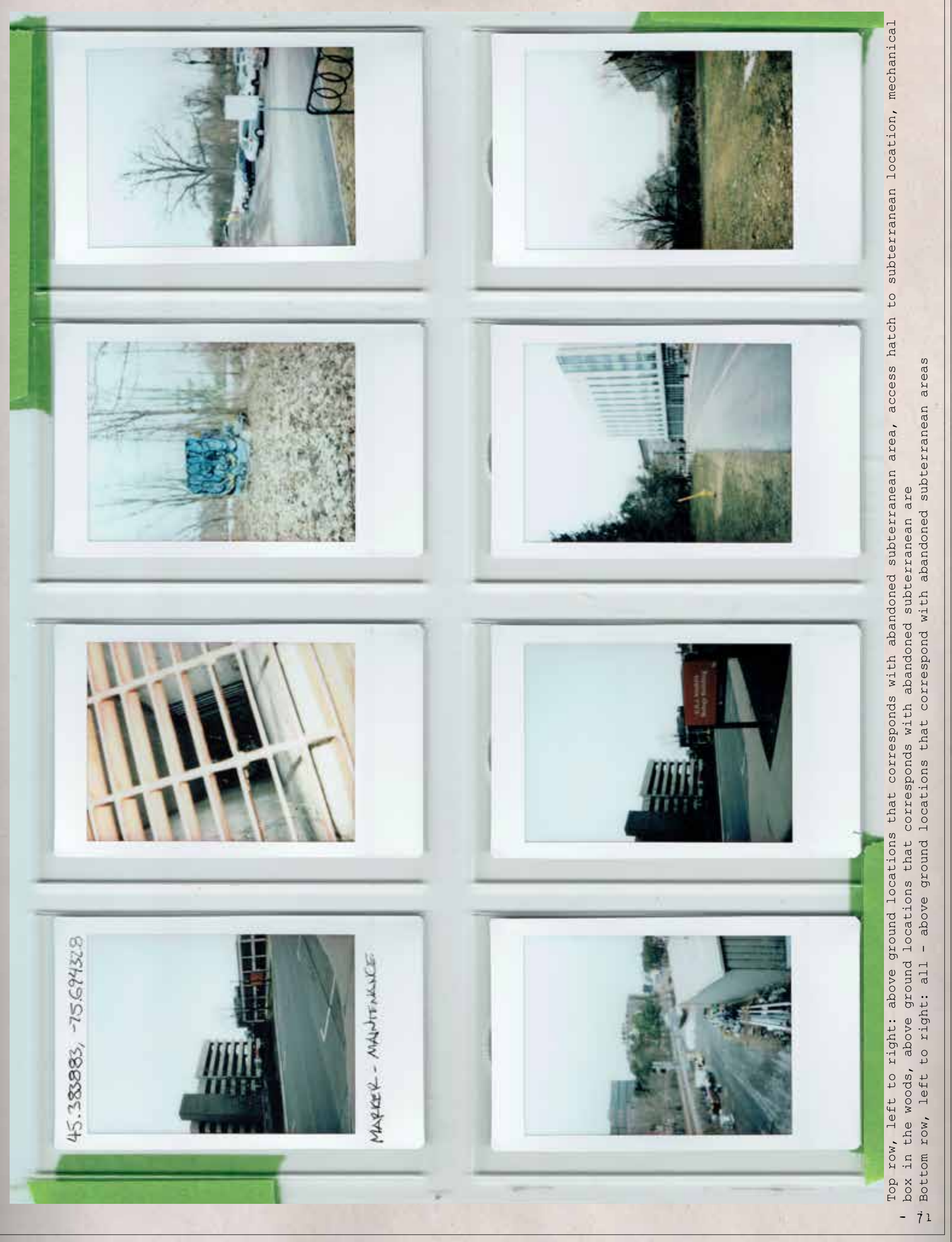
Beinind a Door that Doesn't Exist:

A Jaurnery Into the Horrific spaces Beneatin Us

- Sensary Frabe Data - 


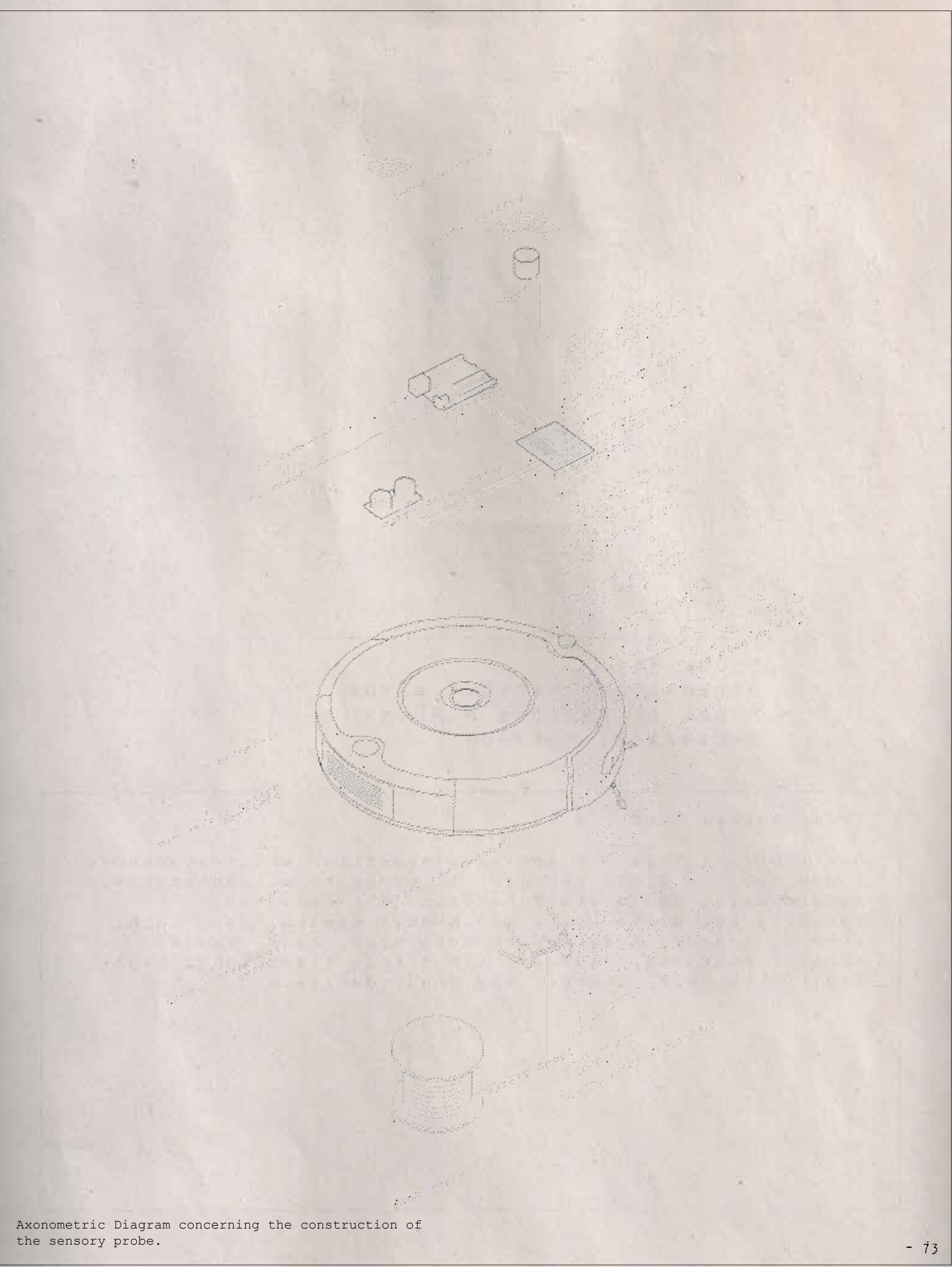




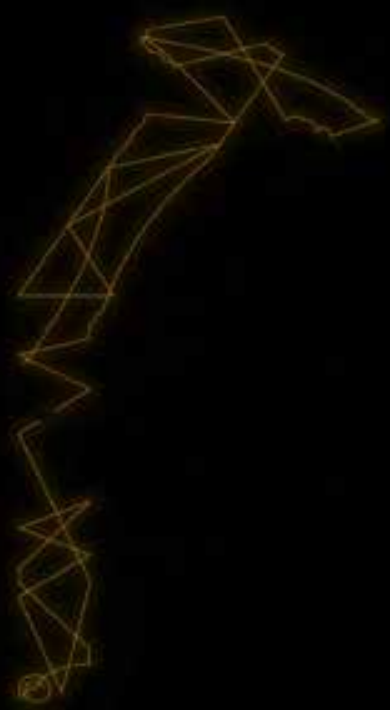

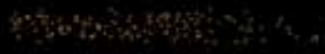

Site 1 , elevation data

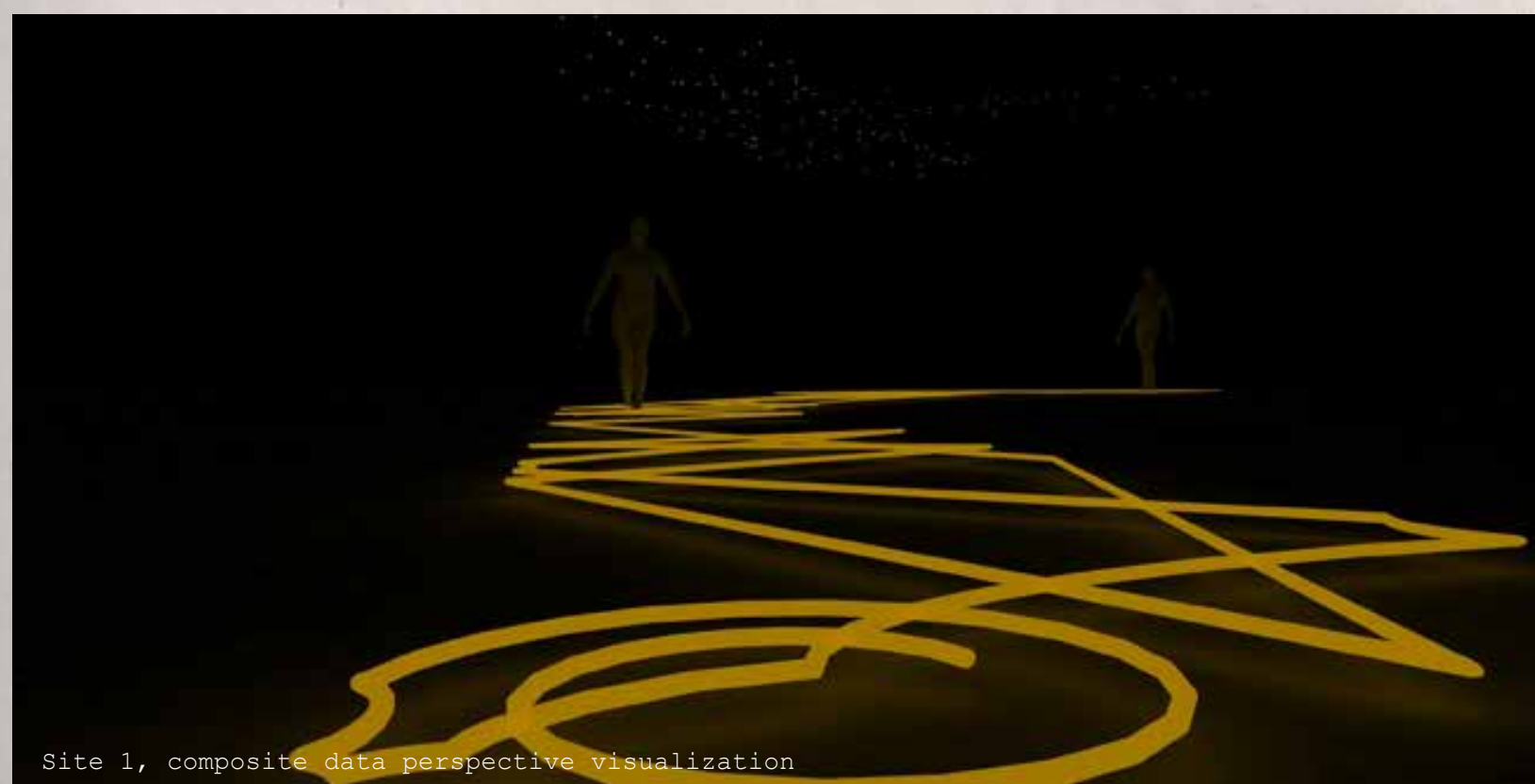




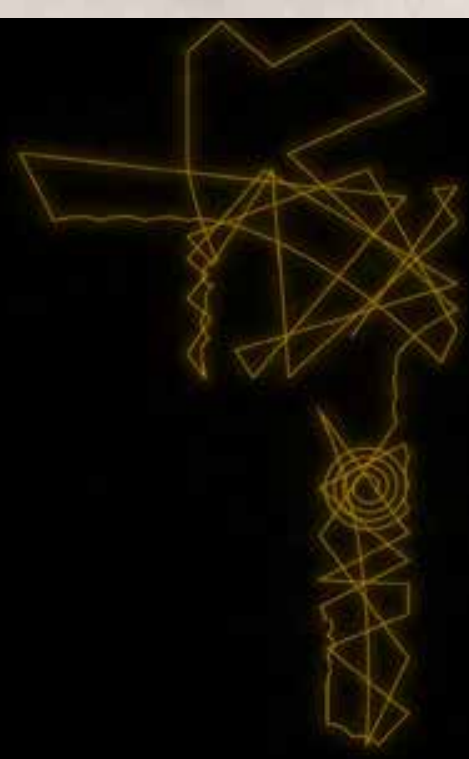

Site 2, elevation data

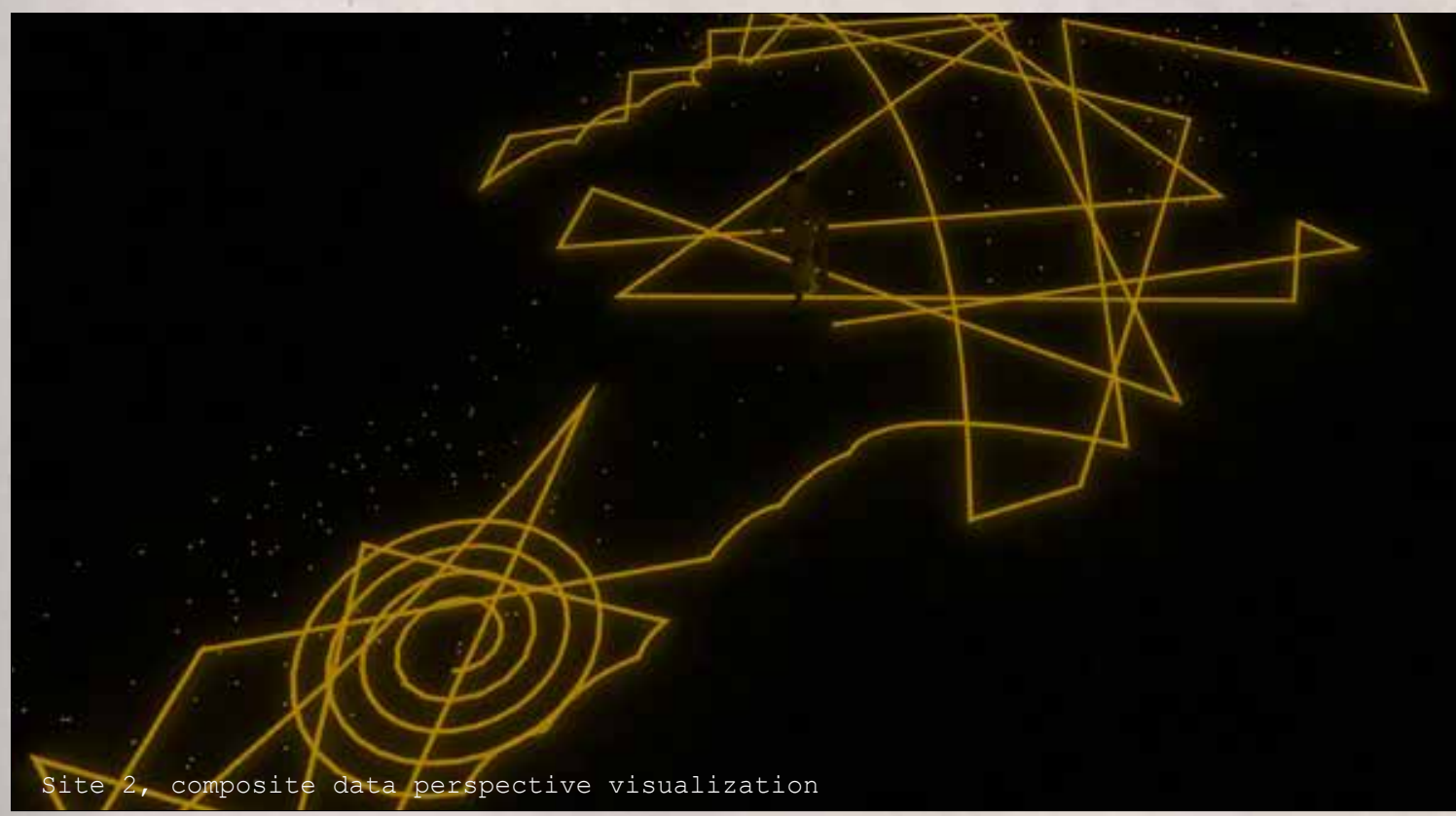




\section{Beinind a Door that Doesn't Exist:}

A Journery fnto the Harrific spaces Beneatin Us

\section{- Jaurnal of Nisntmares -}




\section{Journal of $N$ is ntinares}

Since beginning my research on the topic of horror at the onset of the semester, I have noticed a startling rise in the unsettling nature of my dreams. The research I have been engaging with seems to have had a larger effect on me than I thought. I have decided to record these dreams for potential analysis or use during my thesis.

\section{Morning October 7 th}

In a city similar to Ottawa, I work. My friends and I are young and struggling financially, but happy with each others company. I am considering moving into a friend's apartment building; it is downtown and has many amenities. There is attraction between us. I leave from my friend's place to go to work. I pass some men on the street. One of them, who was driving a nondescript van, has stepped out and began engaging with the man walking on the sidewalk. The man from the van is aggressive and physically violent and beats the man from the sidewalk. Through the open door of the van we see other men and weapons. I cross the street and alter my course to work. A blind homeless man is walking in the shade beside me and asks why I'm frightened. He says seeing is a gift and a curse. Not all things should be looked at.

On my way home from work I visit my friend's apartment again. While en route, men burst from a building behind me, the same men from this morning, and begin firing into the street with automatic weapons. They behead a person who has tripped while fleeing .

I run into the apartment building and race up some stairs to a mezzanine level for visibility. The men enter the building and begin shouting demands and attacking. I try and navigate the apartment to locate my friends and warn them. I am unable to reach them and am forced to leave, or be discovered.

While fleeing the building, I make my way into a ruined section of the city, old ruins from a long past conflict, that have been incorporated into the urban fabric as a sort of nature walk. As I enter the area, a great flash of light behind and an explosion. Traversing the rubble beside me is the blind man from this morning. He says to me "I remember that sound, and what I saw leading up to it. But after I looked, I don't remember seeing anything ever again." He is much faster than me and quickly moves beyond my pace through the rubble. I continue running. Then I wake up. 
Morning October 8th

The details of this dream are cloudy, but I was witness to the terrible reality of an escape room where the consequences of failure were torture and actual death. I watched omnisciently as a group attempted, failed and were subsequently killed. I awoke in the dream while en route to attempt it myself.

Morning October 16 th

I've gone on a kayaking trip with Ben. We stopped at the water's edge to meet with the rest of the group. We then travel through a mangrove to collect the rest of our supplies at various other points. I've had this dream before. This time, however, there's a body in the water.

Evening October 22nd

In a strange mix between real-life and virtual reality, a "game" operates. The game, similar to V2 in its mechanics, does however have real consequences for failure. As the game progresses, teammates start to die off, and the game seems to "lag". Things that shouldn't normally be occurring are happening despite our best efforts - the game's AI has developed consciousness. It mocks our efforts to disable and destroy it, and even assists as we try to record it in our last ditch effort for evidence of this encounter. It laughs as it turns us off.

\section{Afternoon November 8th}

I am leaving my friend's condo building downtown with my bag over my shoulder. A large man on the bus is behind me, attempting to get into the bag. I push him away and disembark. Making my way on foot westward across downtown, I notice the man following me. I make my way into and through a number of various office and condo buildings in an attempt to lose him, yet he only seems to gain ground. Pursuing me at a consistent pace. Eventually he catches up to me and a chase begins through a public pool. I throw things in his path and plead with pool goers for assistance. None seem to react to the man. I find a way to hide in ambush, waiting for him to round a corner near the hot tubs. I strike him over the head with a golf club from my bag before pushing him into the pool. The man does not struggle, and eventually surfaces, face-down. He is dead, and I am exhausted. 
Morning November 12 th

There is a party for a friend this evening. I go about making all of the necessary preparations for the evening. One such task includes getting a haircut. After this $i$ continue with my day. Just before $i$ prepare to leave for the party, I notice that my hair has grown quite significantly since the hair cut; a uniform length across all areas of my head. It's a shocking look to say the least, resembling a mullet of sorts. I decide to take scissors to the mess and will cover it with a hat, but as I cut my hair, it re-grows instantly at twice its length. I frantically try to remove the mass but eventually succumb to the weight and collapse to the floor, unable to move.

Morning November 13 th

I was lounging in my living room, enjoying the onset of winter, being cozy in a sweater, surrounded by blankets. My cat, Shakespeare, was purring quietly in my lap. Outside, a bird lands on the snow-dusted railing. A siren blairs in the distance, and my cat turns to liquid, melting through my fingers. The room around me melts into blackness and I begin an endless fall.

Morning November 16 th

A secretive and malicious conglomerate of landlords, called "the Zion", plots to overthrow and evict (or worse) my friends and I. their agents are everywhere and they attempt to interfere with our daily lives. They operate with no regard for the law, but act with impunity thanks to the clandestine nature of their actions. After plotting to expose this group, and how we might gather evidence, an operative whom we believe to be low ranking but ambitiously trying to climb the ladder arrives at our door and starts spouting various by-laws as to why he is allowed to come inside and keep an eye on us. He forces his way into our apartment and closes the door behind him. The door is locked from the outside. He monitors us and listens to our planning. When we're not looking, he is taking extensive measurements of our apartment. We scheme about how to escape and how to resolve this situation, but know that involving the police would only affect this one member - The Zion seems happy to be rid of him, as if we were doing them a favour. No. we have to wait to take down more of the organization. But for now, we our trapped in our lives. 
Morning November 18 th

With no place to live, I couch surf from one friend's apartment to another. Eventually, I find a more permanent apartment in a 20 th floor resort-style condo. A lovely balcony that overlooks a central courtyard. The 4 bedroom apartment has 3 roomates. One of them is my friend, another is her friend. The fourth was there before the others. They don't know him and he never leaves his room. After I join the apartment, he decides to come out of his shell. Discovering new tendencies of his was not a treat. Kleptomania and horrible messiness was a terrible combination. His room was almost the size of another apartment, but it contained within it a decade of garbage, making it impossible to retrieve any of our possessions that had gone missing. One day, after he had stolen the fridge, we had had enough. We stormed into his room to confront him, but came across him while organizing a stache of weaponry. He flew into a rage a chased us about the apartment with an axe. In a desperate bid to escape, I leapt from the 20 th storey balcony, hoping to land in the pool below.

Morning November 26 th

I awake to my alarm clock blaring. I hit snooze and drift back to sleep. This process continues, each time the alarm clock wakes me up, I hit snooze and go back to sleep. But each time, the number on the clock has gone back 5 minutes. I am unable to stop myself from hitting snooze, I become more and more exhausted as I travel backwards through my sleep. I try to scream, but no air escapes my mouth.

Morning November 27 th

I was back in a relationship with my ex.

Morning December 6th

In a 3-dimensional maze I am trapped. Shifting rooms and their connecting staircases grind against each other as they endlessly shift into new positions. I thought this way was the way out... 
Morning December 20,

While attending the venice biennale, I noticed a very pungent smell, the distinct odour of wet clothes that have been left to sit too long in a washing machine. There was a pool of water on the ground nearby that I assumed was the source, but attempts to leave did nothing to remedy the smell. After more searching, I was still unable to locate the source, I decided to leave the area, but the smell continued. After searching for some time, I finally spotted a figure lurking around a corner. Its hulking form was obscured by the silhouette of dozens of layers of all manner of worn fabric and clothing, all drenched and dripping. Noticing my gaze, the figure motioned towards me. I turned and calmly walked away, back through the biennale. The figure was gaining ground and was upon me before I could come up with a plan. I was forced to act! I turned and swung my fist square for the figure's slightly covered jaw. My punch landed with a wet squelch and my hand sunk into what should have been solid bone. Water seeped in around the indent I left, filling the void around my hand like a boot in a bog. Wasting no time in retaliation, the figure opened up its layers of fabric, revealing a shriveled festering corpse beneath. I tried to run but my hand was trapped in the quagmire that was its face. It closed its heavy, tattered garments around me, restricting my movement. I tried to scream as the last sliver of light closed behind me, but water began to fill my lungs.

Morning January 21,

Standing in the empty basement of my childhood home, I watch my brothers climb a ladder into a hole in the ceiling before disappearing out of sight.. Their footsteps echo as they move towards the edge of the room. They drop behind the wall and I can no longer hear them. A heavy silence lingers before I notice a shift in the wall. A hand presses against the wallpaper from the other side. Stretching and contorting the surface. I run over to the wall and rip the paper off. Behind is a solid cinder block wall.

Morning January 22,

I awake on a dirt floor. The ground is damp and cold. The room is dark save for a pinpoint of light coming from high above me. Glancing around, I touch the walls to find they are made of stone and covered in moss. The room is small and circular - I'm at the bottom of a long empty well. As my eyes adjust to the darkness around me, I notice I am not alone. Perched against the far side of the bottom of the well is a small porcelain doll. Her eyes, glassy and emotionless, stare right through me. She is crying. 
Morning January 25,

When I went through my father's things to sort out his will, I came across a box meant for children's lost teeth. A keepsake full of memories, and a sign of how much I had grown. As a child, like many others, I delighted at the thought of the tooth fairy coming to trade my lost teeth for a shiny loonie while I slept. Excited to reflect on how small I once was, I opened the small molar shaped box. This was a mistake. Inside, I saw a deep, swollen blackness, writhing in the shadows of the impossible depth contained within. Silhouettes on the walls of the chamber gnashed and tore - thousands of lost teeth lined these walls, waiting for the unsuspecting.

Afternoon February 1,

Lately I've been waking up from my sleep with an insatiable itch all over my body. I endeavored to get to the bottom of what is causing this by setting up a camera to observe my sleeping habits and patterns. I watched the footage and was only slightly disgusted by what I saw: a bug, large and red, crawling up from under my bed, across my bedsheets and over my face. I swatted it away before rolling over. I decided to set a trap for the creature the following night. In the morning I awoke without an itch, but I immediately ran to the bathroom and began to vomit. I checked the trap and it was empty - checking the footage however, revealed a different story. As I slept, a darkness loomed over the room, only broken by the tiniest movement. A bug, similar to the one from the night before, emerged from my open mouth. Slowly it crawled across my face. Followed by another one. And another. And more. Until a column of these red nightmares marched across my bed towards the window sill and out into the night.

Morning February 5,

Today is my birthday, but I was most relieved to wake up and realize that I hadn't lost both of my hands.

Morning February 9,

Laying on a cold, hard laminate floor in a well lit, featureless and square room, I am unable to move. Staring up at the ceiling, I can faintly hear something. I ticking sound. Like that of a clock. The ticking is getting louder, or closer. Louder and louder, closer and closer, until it is unbearable. Just before It becomes so much that I have to scream, the ticking stops and the room goes dark. A deep but quiet laughter echoes next to my ear.

I wake up in a sweat, but I am safe. Until, faintly, the ticking started again. 
In my childhood home, the stairs to our basement travelled upward before taking a sharp right turn just before you reached the ground floor. The basement was always dark and scary to my younger self, so whenever I was the last to leave the basement, I would quickly turn off the lights before sprinting up the stairs and around the corner to the brightness of the ground floor. This time however, when I turned the corner, expecting to arrive in our kitchen, I instead found myself looking upwards from the bottom of the basement stairs. I only just caught a glimpse of a boy running up the stairs and quickly turning the corner out of sight.

Morning February 17,

I had the same dream from two nights ago, only this time, when I found myself looking upwards towards the stairs, the boy stopped at the landing. He slowly and hesitantly turned around to peer towards me in the darkness. I recognized his face as my own. We made eye contact before he ran off around the corner, but I know that he saw nothing. I always saw nothing in the darkness when I looked back.

Morning February 22,

I was on vacation with my family at a quiet cottage in the woods by a lake. It was nice to get away from the city and spend some time with them; I don't see them too much anymore. We were all enjoying the day - it was overcast, but quite warm, so we spent most of it down by the water.

I leapt from the dock and dove into the lake. My eyes were closed for the initial dive, but I opened them under the water to catch my bearings. I was deep amongst the lakeweed. It shimmered and swayed in the light from above, but that light began to dim until I was left in darkness. I quickly swam to the surface. When my head broke the water, I looked around but found that I was in a dense fog, I couldn't see beyond a few feet away. The water was very choppy and I was struck with a wave. I spat out the water and cleared my eyes. It was salty. I dove beneath the surface again and saw only a deep blackness. The shallow lakebed, and fish, and plant life were gone, only the dark abyss of the ocean remained. 
Morning February 27,

A man, who I responded to as my father but I did recognize as such, beckoned me from the basement to come and help him with a task. I made my way downstairs and turned on the lights. He called out again, "I'm in the mechanical room". The voice came from under the stairs. I went to the crawl space entrance that lead to that space and made my way inside, using the light from my phone to guide my path. There was my father. He gestured towards a hole in the concrete floor from which the top of a ladder protruded. "My back is bothering me, can you go down there and tell me what's wrong with the breaker?" I did not recognize this space, but I made my way down the ladder, descending into the pit. At the bottom of the ladder I looked up and asked him to send me the light. He tossed down an old flashlight, the lens of which cracked upon impact with the cold earth. I picked it up and gave it a smack. The old bulb sputtered with a faint glimmer of life, revealing that the ladder was no longer there. I looked up and motioned to speak to my father, but I was met with a mouthful of earth. I was knocked to the floor and the sound of a shovel moving dirt was heard as more earth was piled into the hole. I lay still as the earth rose around me, covering the dim light of the old torch, then preventing all movement. Finally, the cold damp earth encased my head. A worm crawled by my ear as I heard the muffled grinding of something heavy being slid over top of the opening to the pit.

Morning April 2,

I am having breakfast on a sunday morning at home with my family. The sun is shining and birds are chirping and flitting about cheerfully in the spring warmth. A record plays from the other room - this is our weekend routine. I'm taking a sip of warm coffee when I'm interrupted by a large thump from below us. I look around at my family but none of them seem to have felt it. I look over to the door to the basement. The door is closed, and the deadbolt is in place. I stare intently at the door, unable to move from my seat. The doorknob begins to rotate back and forth. Slowly at first, then with a panicked quickness. There is a pounding on the other side of the door, my mother's voice calls out from behind the locked barrier, "don't look us in the eye, ryan". My family stops eating breakfast and turns to face me. 
I am in a narrow corridor. The quiet hum of fluorescent lights echoes around me as their aggressive glow illuminates the hallway. Two concrete walls extend in both directions beyond what I am able to see. I take a few hesitant paces and my footsteps echo off down both directions. I begin to walk, choosing a direction at random, running my hand along the cold, coarse concrete. I walk for some time, the skin on my fingertips is starting to get raw from the rough concrete. The lights flicker briefly, but when they turn back on, I'm in my bed at home.

Morning April 16,

I haven't dreamt in almost two weeks.

In my dream, I awake in the same narrow corridor from the previous nightmare. The sting from my raw fingertips is back. I start to run down the hallway in the direction I thought I had been heading before. I ran and ran, passing light after light. The hum of the fluorescents became louder and louder until it turned into a roar. I covered my ears with my bleeding hands and kept running. Now I could see it, a door at the end of the hallway. I raced faster towards the door, extending my arms to brace myself as I came into contact with it, but when I expected to touch the surface of the door, my hands fell through cold steel and my momentum carried me as well. I began to tumble in the air, turning end over end as I fell into darkness, the door above me moved further and further away, I could barely see it, until finally it disappeared from sight and I was left in blackness, unable to orient myself or even discern if I was right-side up. I drifted like this for what seemed like an age. When I woke, the sun was shining. 
Beinind a Door that Doesn't Exist:

A Jaurnery Into the Horrific spaces Beneatin Us

- Fieldbaar af Badily respanses - 


\section{Fieldboak of Bodily responses: Fsychological and Fhysiolosical}

Post-Traumatic Stress Disorder

Post-traumatic stress disorder (PTSD) is a mental health condition that's triggered by a terrifying event - either experiencing it or witnessing it. Symptoms may include flashbacks, nightmares and severe anxiety, as well as uncontrollable thoughts about the event.

(https://www.mayoclinic.org/diseases-conditions/post-traumatic-stress-disorder/ symptoms-causes/syc-20355967)

\section{Sweaty Palms}

Excessive sweating is when you sweat more than you might expect based on the surrounding temperature or your activity level or stress. Excessive sweating can disrupt daily activities and cause social anxiety or embarrassment. Common causes for excessive sweating include anxiety and stress.

(https://www.mayoclinic.org/symptoms/excessive-sweating/basics/definition/sym-20050780)

Increased heart rate

Most people have experienced an increased heartbeat as a result of nervousness. But there are times when you're convinced that something is wrong and you believe that this pounding heartbeat represents something more ominous. You may also experience other symptoms, such as chest pain or lightheadedness, and these further reinforce your belief that you're having a heart attack. Anxiety - especially panic attacks are a frequent cause of a rapid heartbeat. Unfortunately, they are also accompanied by a "feeling of doom." Your body erroneously tells you that something is seriously wrong, and so you experience profound fear and dread that you' re about to die.

(https://www.calmclinic.com/anxiety/signs/heart-pounding)

\section{Muscle Weakness}

During the fight or flight response, anxiety causes several changes in the body. These include an increased heart rate, higher blood pressure, faster breathing, and changes in blood flow. One of the effects of these changes is the sensation that the muscles are weakened. They may not actually be weaker, but the complex bodily and hormonal changes may cause your muscles to feel that way. This experience can be really distressing, leading to severe tension and worry, which only serve to make the anxiety worse. Ultimately, feeling that you don't have the physical strength to live a act safely can really make things difficult. 
Fear-Induced Incontinence

Anxiety symptoms can cause you to feel shame, embarrassment, or fear.. There are a lot of anxiety symptoms that create significant distress, and unfortunately, anxiety is the type of condition that makes it difficult to ignore or forget that distress. Loss of bladder control is one of the best examples of a distress condition that can be caused by anxiety and fear.

(https://www.calmclinic.com/anxiety/symptoms/loss-bladder-control)

Shaking

Shaking is a result of an activated fight or flight system - an evolutionary tool that's meant to keep you safe in times of danger. During intense anxiety, your body is flooded with a hormone called epinephrine (adrenaline). That hormone activates your nerves and muscles, giving them the energy they need to fight, flee, or react.

(https://www.calmclinic.com/anxiety/symptoms/shaking)

Anxiety

Examples of anxiety disorders include generalized anxiety disorder, social anxiety disorder (social phobia), specific phobias and separation anxiety disorder. You can have more than one anxiety disorder. Sometimes anxiety results from a medical condition that needs treatment or from specific environmental stimuli. These feelings of anxiety and panic interfere with daily activities, are difficult to control, are out of proportion to the actual danger and can last a long time. You may avoid places or situations to prevent these feelings.

(https://www.mayoclinic.org/diseases-conditions/anxiety/symptoms-causes/syc-20350961)

Hyperventilation

While anxiety is to blame for hyperventilation, hyperventilation is to blame for many of the other distressing symptoms associated with anxiety. Hyperventilation can cause so many problems that some doctors label it its own disorder, known as "hyperventilation syndrome." Hyperventilation literally translates to "over-breathing." Contrary to popular belief - and contrary to the way it makes you feel - it is not the act of getting too little air. Instead, hyperventilation is the act of exhaling carbon dioxide too quickly, causing too much oxygen to enter the lungs and an imbalance of the two within the bloodstream.

(https://www.calmclinic.com/anxiety/symptoms/hyperventilation)

Chest Tightness

Chest tightness is an anxiety symptom that often causes a severe amount of distress. This is often because chest tightness has a negative connotation for being linked to severe health conditions. This can be very daunting for individuals that do not know much about the physical effects of stress and anxiety in their life. Chest tightness occurs most often right before or during an anxiety attack. It may also present spontaneously with no anxiety at all, in what is known as a limited symptom panic attack.

(https://www.calmclinic.com/anxiety/symptoms/chest-tightness) 
Beinind a Door that Doesn't Exist:

A Jaurnery Into the Horrific spaces Beneatin Us

- Glossary of Fear - 


\section{Glossary of Fear}

(Un)Familiar - (Condition) As Familiar, but with elements unknown previously to you. An environment or object often seen, heard, or felt thereby being easy to recognize, yet with an unknown unsettling feeling.

Agoraphobia - The fear of public spaces, related the vulnerability from others and restriction of movement.

Ambiguity - (Symptom) That which can be understood in more than one way having multiple meanings, or what may not be understood at all, thereby relying on speculation to make conclusions.

Arduino - An electronics platform which relies on open-source hardware and software that is able to receive inputs and turn it into various outputs when coded correctly. Uses the Arduino coding language.

Autophobia - the morbid fear or dread of being physically or mentally isolated or alone.

Atmosphere - (Symptom) In a particular space, the air of a feeling or mood, as influenced by a variety of tangible and intangible factors.

Bunker - A robust subterranean shelter constructed for protection, typically for military or political personnel.

Claustrophobia - (Symptom) An extreme fear where, when restricted, creates a strong feeling of unpleasantness, especially from small confined spaces

Condition - The found or existing physical state or circumstances that a space exhibits. Often a situation which causes other phenomena to occur. Also, a severe or crippling illness, incurable and present for an extended period of time.

Echolocation - The use of sound waves for the purposes of orientation, object avoidance, and identification.

Horror - an overwhelming feeling of intense shock, fear, and disgust. 


\section{Glossary of Fear}

- Lighting - (Condition) The arrangement, implementation, and effect of natural or electrical light in location.

Perspective - (Condition) one's attitude and method of thinking towards/on a given situation or experience. Often influenced by their own unique past

Phobia - A strong and unreasonable fear of an object, space, or experience.

Roomba - A brand of battery-powered robotic vacuum cleaners, commonly found in domestic environments for small to medium sized areas.

Rosie - The trusty vacuum employed for multiple expeditions and delves into lost spaces beneath Carleton University. Also a robotic maid from The Jetsons.

Sensory Probe - An unmanned device used to gather data and record hidden information regarding the physical senses, specifically sound and touch.

Sonar - The process and equipment used in locating objects and boundaries using sound waves, typically under water.

Subterranean - A natural or man-made structure or space constructed or found underground.

Suspense - A feeling of worry or dread when you anticipate that something is going to occur.

Symptom - A sign or change in a body or space, indicating the existence of illness, a condition, or generally something negative.

Tension - (Symptom) The state of intense anxiety and stress induced by one's situation or environment which makes it impossible to relax. Also the state in which an object or person is physically or figuratively stretched. 


\section{Glossary of Fear}

- Terror - The overwhelming and intense feeling of immense fear. A person, place, or thing which induces such a feeling.

Tunnel - A natural or man-made passage or area found or constructed underground.

Uncanny - a phenomena which is strange or difficult to explain. Often related to

the feeling of being watched or concerning subconscious similarities/resemblances.

Unsettling - a situation or spaces which causes you to feel afraid, upset, anxious or worried. 
Beinind a Door that Doesn't Exist:

A Journery Into the Horrific spaces Beneati Us

- reflections - 
Reflections: A Postscript

This thesis may be seen by some as a little controversial. While the methodology is clear, and documentation is thorough, It may be less academically focussed than other works. I found that while adventuring into this topic, the work was going to take less of a research focussed journey, and become more of an exploration. To try and explain where one might find value in such an experience, it is best to ask oneself "What have I learned?". After being prompted by a member of the faculty, I did that. I reflected on the journey that I had been on, thinking back on what work I had done that was the most fruitful. Was it the thorough documentation of a site via photography? Or the creation of a sensory probe with on-hand materials? Or was it the ability to dissect key elements from fictional sources and apply them to real life scenarios? Truthfully, all of the work and research is no more important than any other. I would follow a path and continue along that path with a given medium until I encountered a "dead end". Encountering such didn't mean I stopped, it only encouraged me to ask question, to swap to a new medium to find a new way around, or under, that wall. Finding nothing in the archives encouraged site visits. Boundaries on the site encouraged unmanned probes. Limited data turned direction to digital visualization strategies. Behind all of these methods and mediums is a drive and curiosity. What was most fruitful was trying to find an answer where I thought there was none. The dead ends encouraged questions - digging one step deeper. You never know what you might find. 
Beinind a Door that Doesn't Exist:

A Jaurnery Into the Horrific spaces Beneatin Us

- Bibliograpin - 


\section{Bibliognaphy}

2014.

Comaroff, Joshua, and Ker-Shing Ong. Horror in Architecture. San Raphael: ORO Editions,

Identifies various typologies of horror and directly compares them to examples in art, film and the real world. Of particular interest to this thesis is the chapter on the "incontinent object", which discusses the importance of entries and orifices in a body or building with specific attention to their predictability. When this predictability is shattered either by location or function, the object creates discomfort.

Triggs, and Riley Grant. "Reel Houses of Horror: Film, Body and Architecture." Rice Scholarship Home. January 01, 1970. Accessed September 1, 2018. https://scholarship.rice.edu/handle/1911/17925.

Thesis discusses the cinematic setting of Stanley Kubrick's "The Shining" and Ridley Scott's "Aliens" from an architectural lens. This document is helpful as a precedent for the analysis of fictional architecture used in horror and how it works to achieve its goal of fulfilling the needs of the genre.

Ferro, Shaunacy. "The Architecture of Fear: How To Design A Truly Terrifying Haunted House." Fast Company. October 29, 2014. Accessed September 1, 2018. http://www.fastcompany.com/3037618/thearchitecture-of-fear-how-to-design-a-truly-terrifying-haunted-house.

Article that covers the practical steps of creating a successful haunted house. What's interesting about the article is how it avoids typical ideas such as gore or actors and focuses primarily on the transformation of mundane space.

Tanizaki, Junichiro, Thomas Harper J., and Edward G. Seidensticker. In Praise of Shadows. London: Vintage Books, 2001.

A classic for architects, I intend to use this book to temper my explorations into the importance of lighting. A shadow is not inherently horrific, therefore making an understanding of contemplative shadows necessary to the success of this thesis.

Calvino, Italo. Invisible Cities. Vintage, 1997.

Inspiring written sketchbook useful for visualising the potential operation of non-existent spaces. Of particular importance are the "Cities \& the dead" and "Hidden Cities" chapters purely as imagination exercises in fictional spaces.

How Media Scares Us: The Work of Junji Ito. October 1, 2016. Accessed September 4, 2018. http://www. youtube.com/watch?v=lIIA6QD.

A video essay that discusses the variety of ways in which media scares us, with specific attention to the graphic novels by Junji Ito. The medium of a graphic novel is especially relevant to the context of a thesis as it appears as printed media and can not rely on strategies used by mediums such as film.

Juhani, Pallasmaa. The Eyes of the Skin: Architecture and the Senses. Chichester: Wiley, 2014.

Addresses the impact of the action of touch and other sense aside from the visual. Horror is not strictly founded in the visual realm, especially in darkness. It is then important to consider the implications of spatial interaction from other senses.

Pallasmaa, Juhani. The Thinking Hand Existential and Embodied Wisdom in Architecture. Chichester: Wiley, 2015.

Covers the importance of the hand in the experience of space and architecture. Gestures and touches provide information to the body even when visual ambiguity is maintained. This is important for creating atmospheric experiences of personal interaction.

Corbeil, Jean-Claude, and Ariane Archambault. The Visual Dictionary: English. Montréal: Québec/Amérique, 1999.

A visual reference for representation techniques and strategies. Important for creating sense of realism in created documents.

Barr, Charles. Vertigo. London: BFI, 2010.

An analysis of the work and minds behind the realization of Alfred Hitchcock's "Vertigo". Techniques and strategies of suspense are discussed and analysed when contrasting process with product.

Monmonier, Mark S. Cartographies of Danger: Mapping Hazards in America. University of Chicago Press, 2008.

Interesting visual representation strategies. Emotionless and sterile depictions of horrific events and disasters offers a level of removal from secondary and tertiary sources.

Garkavenko, Alex. "A Brief History of Horror in Architecture - Architizer Journal." Architizer. November 07, 2017. Accessed September 1, 2018. https://architizer.com/blog/inspiration/collections/horrorin-architecture/. 
Brownlee, John. "8 Horror Films That Use Architecture And Cities To Terrify." Fast Company. July 09, 2018. Accessed September 1, 2018. http://www.fastcompany.com/3064889/8-horror-films-that-usearchitecture-and-cities-to-terrify.

" "Dreadful Architecture: Zones of Horror in Alien and Lee Bontecou's Wall Sculptures." Journal of Research in Crime and Delinquency. Accessed September 1, 2018. http://journals.sagepub.com/doi/ abs/10.1177/1470412915607926.

Dick-Agnew, David. "The Architecture of Horror." Azure Magazine. October 22, 2015. Accessed September 1, 2018. http://www.azuremagazine.com/article/the-architecture-of-horror-halloween-part-1/.

Pavka, Evan, Jaclyn Bruneau, Tatum Dooley, Ryan Rice, Rupert Nuttle, Mireille Eagan, Adrienne Huard, Erdem Taşdelen, and Zainub Verjee. "The Banality of Violence in Architecture." Canadian Art. Accessed September 1, 2018. https://canadianart.ca/reviews/architecture-and-horror/.

Ellin, Nan. Architecture of Fear. New York: Princeton Architectural Press, 1999.

Griffiths, Gareth, and Minna Chudoba. City Cinema: Essays on the Specificity of Location in Film. Tampere, Finland: Tampere University of Technology, Department of Architecture, 2007.

Boulet, Cedric. "Please Disturb!: Exploring the Virtues of Dysfunctional Architecture." M.Arch diss., Carleton University, 2010.

Johnston, Adam. "The Dark Side of Architecture." M.Arch diss., Carleton University, 2012.

Al-Rawi, Reem. "The Architecture of War: A Conflict Generated Architecture." M.Arch diss., Carleton University, 2010.

King, Stephen. Danse Macabre. Gallery, 2010.

McIlroy, Brook. "CARLETON UNIVERSITY 2016 CAMPUS MASTER PLAN UPDATE." Carleton.ca, carleton.ca/fmp/ wp-content/uploads/2010-Final-CMP1.pdf.

Chiarello, M C. "A Little History of Carleton University Part 1: Paterson Hall and Macodrum Library." Carleton.ca, 7 Feb. 2013, chiarellodesk.wordpress.com/2013/02/04/a-history-of-carleton-university-part-1paterson-hall-and-macodrum-library/.

"History." Carleton.ca, carleton.ca/about/history/.

"Archives \& Research Collections." Construction U | Archives \& Research Collections, arc.library. carleton.ca/exhibits/construction-u.

Huard, Chelsea. "REFLECTIONS OF THE PAST: STORIES BEHIND THE TUNNEL MURALS." Charlatan.ca, charlatan. $\mathrm{ca} / 2016 / 08 /$ reflections-of-the-past-stories-behind-the-tunnel-murals/.

Waters, Anthony Scott. "12 Tips for Creating Truly Terrifying Art." Creative Bloq, Creative Bloq ART AND DESIGN INSPIRATION, 4 Aug. 2015, www.creativebloq.com/fantasy/terrifying-art-tips-71515949.

Lee, Alex. "Abandoned Warehouse District." The Rookies, 14 May 2018, www.therookies.co/projects/ illustration/abandoned-warehouse-district/.

Tudalia. "Beginners Guide To Horror in Art." DeviantArt, www.deviantart.com/tudalia/journal/ Beginners-Guide-To-Horror-in-Art-511670538.

Kleege, Georgina. "Blind Imagination: Pictures into Words." Kennedy Center, www.kennedy-center.org/ education/vsa/resources/VSAKleegeBlindImagination.pdf.

Moonlit_Cove. "Blindness." Creepypasta, 14 Aug. 2016, www.creepypasta.com/blindness/.

Morris, Susan. "Drawing in the Dark: Involuntary Drawing - Tate Papers." Tate, Tate, www.tate.org.uk/ research/publications/tate-papers/18/drawing-in-the-dark.

nativlang.com. "How to Tell a Scary Story: the Language of Prose Horror." Logic \& Language: Using Logic to Understand Ordinary Language, www.nativlang.com/edutainme/scary-story-checklist.php.

Whelan, Richard. "Anatomy of a Horror Story." The Irish Times, The Irish Times, 23 Sept. 2006 , www. irishtimes.com/news/anatomy-of-a-horror-story-1.1006742. 
Gerwel, Chris. "The Grisly Anatomy of Horror: Methods in Horror Fiction." The King of Elfland's Second Cousin, 22 oct. 2010, elflands2ndcousin.com/2010/10/26/the-grisly-anatomy-of-horror-methods-in-horrorfiction/.

Weisberger, Mindy. "Scary Science: How Your Body Responds to Fear." LiveScience, Purch, 30 Oct. 2016, www. livescience.com/56691-the-science-of-fear.html.

Javanbakht, Arash, and Linda Saab. "What Happens in the Brain When We Feel Fear." Smithsonian.com, Smithsonian Institution, 27 Oct. 2017, www.smithsonianmag.com/science-nature/what-happens-brain-feelfear-180966992/.

Mohney, Gillian. "The Science of Fear: What Happens to Your Body After a Good Scare." ABC News, ABC News Network, 30 oct. 2015, abcnews.go.com/Health/science-fear-body-good-scare/story?id=34855202. 
Beinind a Door that Doesn't Exist:

A Jaurnery Into the Horrific spaces Beneatin Us

- Acknowledgements - 


\section{Acknowledsements}

Something written from the heart can sometimes come across as awkward - I'm finding that it can be quite difficult to communicate the endless gratitude I have for all of the people that have helped to make this thesis, and academic journey, possible. I had hoped leaving it to the very end would make it easier, but alas, here I am. Bear with me while I fumble.

Yvan and Roger, your knowledge, experience and guidance were invaluable in taking a task that seemed incomprehensibly large and turning it into something that I will be looking back on positively. Your enthusiasm for our wide variety of topics made us feel important, and most critically, your patience. For me, this year brought many changes in my life, as well as emotional and physical health issues (only some of which were caused by this thesis). Knowing I could always send something to either of you is one of the reasons this actually got finished. The only word to describe that patience is "saintly".

Friends, working alongside you while we struggled in the final lap has been such an experience (feel free to add your own adjective). Bouncing ideas off of each other and offering encouragement after a sudden changes in our research were very important aspects of this year, but more importantly, were the things that took our minds off of school for a while. Whether it was going to the gym (far more often than our schedules sometimes allowed), posting up in a café (Néro?) for hours on end while "working", or practicing group escapism en masse with dice. You all made it worthwhile.

Anastasia (and Shakespeare), your support and motivation (and purrs), even when I was at my lowest points, or when we moved in the middle of a semester, or when I had to do stuff that I really just didn't want to, was always able to bring me back up. I've always valued your feedback and design sensibilities, so sharing ideas and showing you my photos and drawings was something I always intended to do. It took only a little time to learn that "yuck" meant that I was on the right track. I know you don't like scary movies, so I'm sorry about all the research I had to do, but don't worry - that's over now; it's Disney from here on out.

Non, Dad, and Ky. Everything I have I owe to you. Supporting me and guiding me and growing with me, encouraging me to find my path and pursue a dream (and sometimes gently turning me away from other "dreams") has helped me become who I am now. Even though I'm done school, I'm still learning and still growing, and it's all thanks to you. None of this would be possible otherwise, so, thank you. 1, 2, 3. 